\title{
A COMMUNICATION MODEL OF EMPLOYEE CYNICISM TOWARD ORGANIZATIONAL CHANGE
}

\author{
A dissertation presented to \\ the faculty of \\ the Scripps College of Communication of Ohio University \\ In partial fulfillment \\ of the requirements for the degree \\ Doctor of Philosophy
}

Yuxia Qian

November 2007 
This dissertation titled

\title{
A COMMUNICATION MODEL OF EMPLOYEE CYNICISM TOWARD \\ ORGANIZATIONAL CHANGE
}

\author{
by \\ YUXIA QIAN
}

has been approved for

the School of Communication Studies

and the Scripps College of Communication by

Tom D. Daniels

Professor of Communication Studies

Gregory J. Shepherd

Dean, Scripps College of Communication 


\begin{abstract}
QIAN, YUXIA, Ph.D., November 2007. Communication Studies

$\underline{\text { A COMMUNICATION MODEL OF EMPLOYEE CYNICISM TOWARD }}$ ORGANIZATIONAL CHANGE (161 pp.)

Director of Dissertation: Tom D. Daniels
\end{abstract}

The purpose of this study is to develop a communication model of employee cynicism toward organizational change. The few studies on employee cynicism were mainly conducted in the fields of management and psychology. The role of communication in shaping employee cynicism was rarely highlighted. Using the theoretical framework of social information processing (SIP), this study explored the communication variables in the social context which contribute to employee cynicism toward organizational change in a higher education institution. In the model, the three variables reflecting the social context, specifically, perceived quality of information, cynicism of colleagues, trust in the administration, are hypothesized to predict change-specific cynicism, which in turn, leads to intention to resist change. Participation in decision making (PDM) is hypothesized to predict intention to resist change both directly and indirectly through the mediating role of change-specific cynicism.

The research was conducted in a Midwestern university which was undergoing a comprehensive strategic planning process. An online survey was administered to all full time tenure track faculty in this university. Path analysis was used to test the overall model fit. The findings of the study suggest that the proposed model explained 
a significant amount of variance in the outcome variables. However, contrary to the theoretical assumptions, PDM did not have significant causal effects on the outcome variables. Based on the empirical data, the proposed model was revised. The revised model fit the empirical data under study and all path coefficients were statistically significant at the .05 level. The revised model suggests that perceived quality of information had the largest causal effect on change-specific cynicism, followed by cynicism of colleagues, and finally trust in administration. Change-specific cynicism explained $79 \%$ of the variance in intention to resist change.

The results of the study support SIP theory by indicating that change-specific cynicism emerges from the work environment. Future studies are called for to explore cynicism from the communication perspective. Further, more research should be conducted to investigate employee cynicism in the changing higher education environment. This study has significant practical implications for administrators in higher education institutions.

Approved:

Tom D. Daniels

Professor of Communication Studies 


\section{Acknowledgments}

The completion of this dissertation is a landmark on my journey of academic pursuit. I would like to express my heartfelt gratitude to all the people who have helped me thus far on this journey. First and foremost, I want to give thanks to my dissertation committee members: Dr. Hale, Dr. Brooks, and Dr. James. Dr. Hale, Thank you for your enduring support and encouragement since I joined the program. Your detailed edits of my drafts enhanced the quality of the dissertation. Dr. Brooks, your classes provided me with the elementary and advanced statistics knowledge and skills, which made this work possible. Dr. James, thank you for agreeing to serve on my committee and for you valuable feedbacks on my dissertation.

I can never thank enough my dissertation advisor, Dr. Daniels, who always stood by me from the very beginning to the final completion of this work. I have been very fortunate to work under your guidance. Your critical analyses of my numerous proposal drafts helped me generate the research idea for this work, and more importantly, cultivated my critical thinking ability and prompted me to grow as a young scholar. Your warmly encouragement provided me with confidence and hope during rough times. The success of this work would have been impossible without your consistent support. Thank you, Dr. Daniels, for your wonderful mentorship and guidance.

I am also indebted to my other two advisors, Dr. Medved and Dr. Larson, who assisted me in successfully passing the comprehensive examination. I would like to extend my gratitude to Dr. Medved for talking through research ideas in bi-weekly 
meetings and for showing deep understanding of my professional and personal concerns. You offered me emotional support as well as academic assistance during my first two years of study. Thank you for your friendship and guidance. I also owe thanks to Dr. Larson and Dr. Dearing, for introducing me to the research site and providing me with the literature on higher education. Thank you, Dr. Larson, for creating the "Yuxia File" and keeping me progress.

Last but not the least, I would like to express my special thanks to my family members. I want to thank my husband for accompanying me through the ups and downs in the whole process; for troubleshooting the statistics software; for taking care of our newborn baby during my busy hours. I am profoundly grateful to my parents for cultivating in me the desire for learning and the quality of persistence. Their unconditional love is my reservoir of strengths and happiness. Thank you. 


\section{Table of Contents}

Abstract iii

Acknowledgments. ..V

List of Tables. .. $\mathrm{X}$

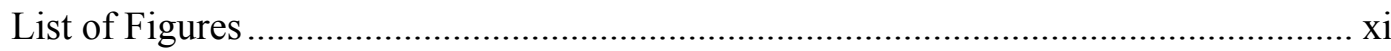

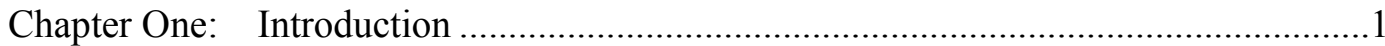

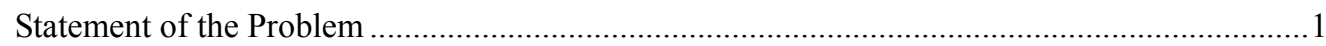

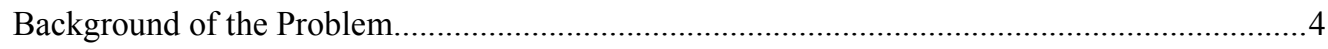

Definition of Employee Cynicism toward Organizational Change _............................................6

Theoretical Framework and the Proposed Model ....................................................................

Change-Specific Cynicism and Intention to Resist Change ...........................................10

Perceived Quality of Information and Change-Specific Cynicism ......................................13

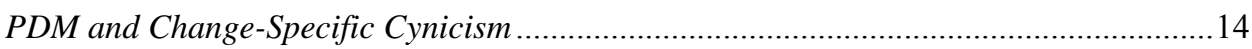

Cynicism of Colleagues and Change-Specific Cynicism ...................................................15

Trust in Management and Change-Specific Cynicism......................................................17

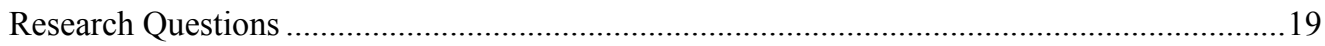

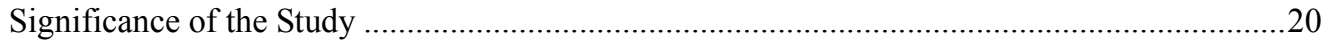

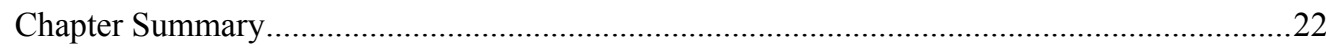

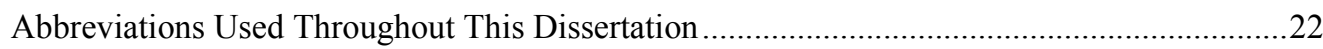

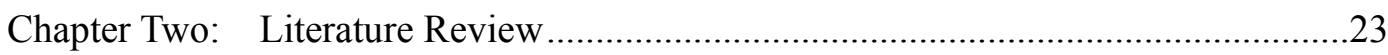

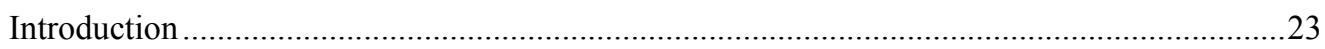

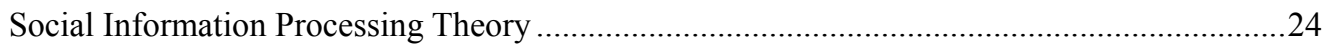

Perceived Quality of Information and Work Attitudes....................................................27

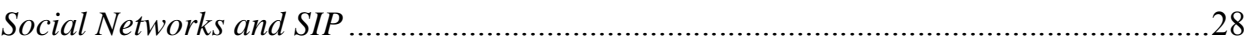

Characteristics of Higher Education Institutions and Faculty Networks .........................31

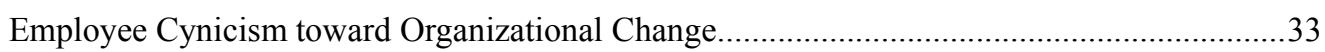

Origin and Development of Cynicism ..........................................................................

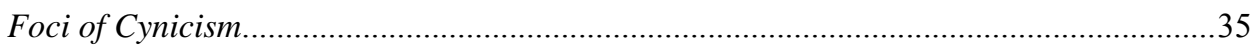

Theoretical Frameworks of Cynicism Studies ...................................................................40

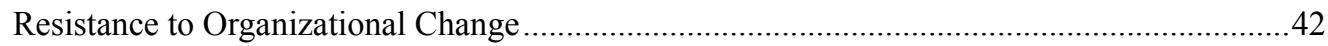

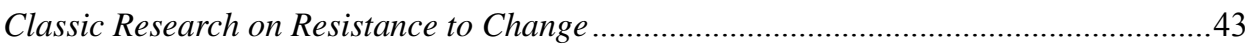

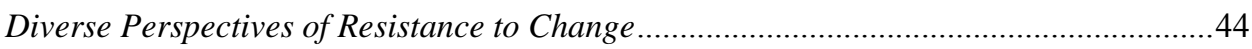

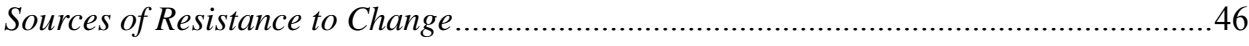

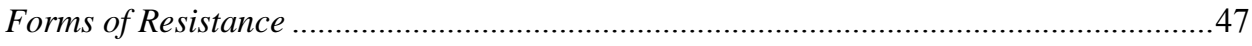

Dimensions of Resistance to Change ……...................................................................... 48 
Participation in Decision Making........................................................................................49

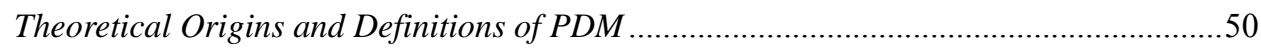

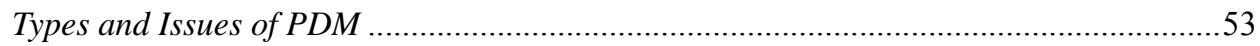

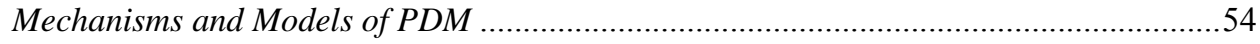

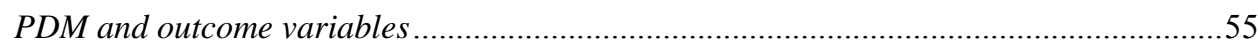

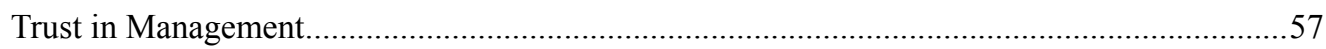

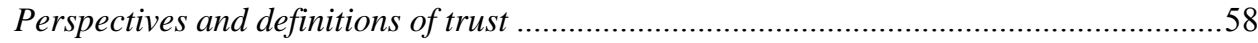

Common Themes of Trust ...........................................................................................6 61

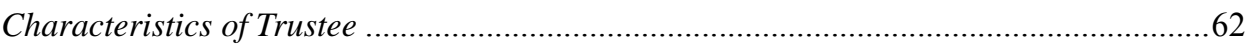

Trust in Management and Employee Cynicism toward Organizational Change...............63

Study Rationale and Chapter Summary .............................................................................65

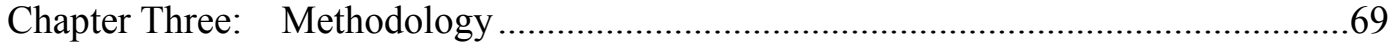

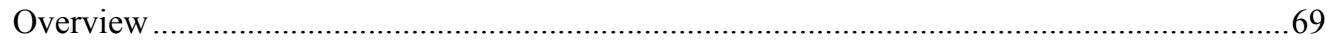

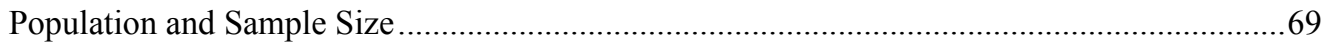

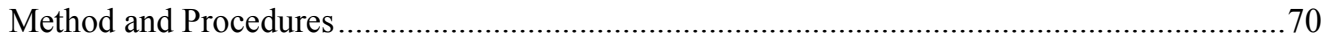

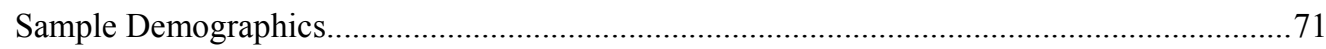

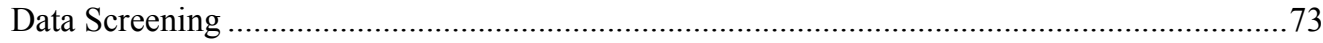

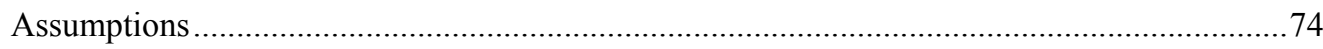

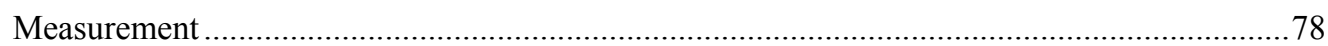

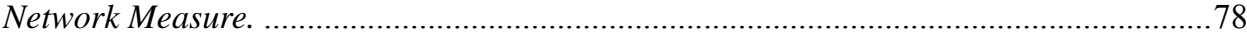

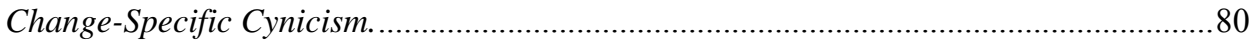

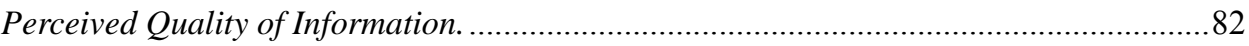

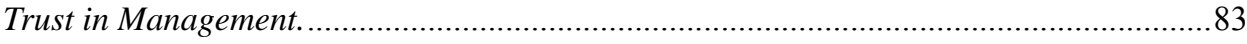

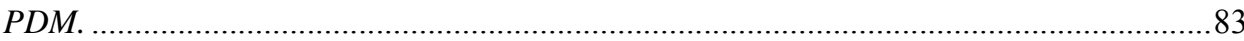

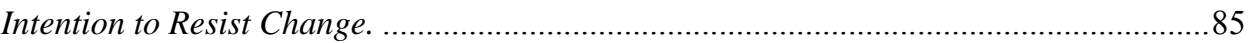

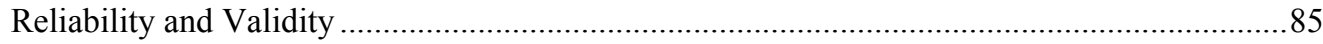

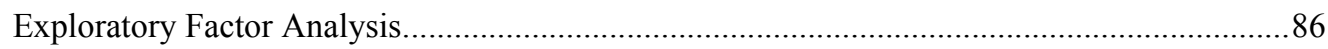

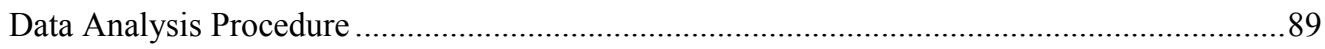

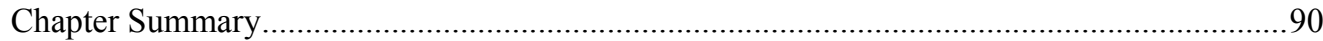

Chapter Four: $\quad$ Results ......................................................................... 91

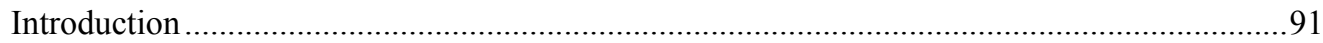

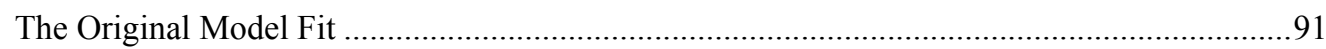

The Revised Model Fit ............................................................................................. 95

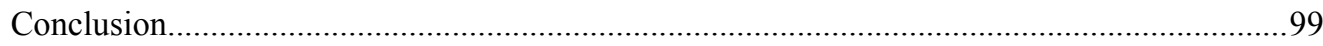

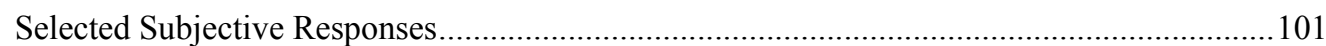

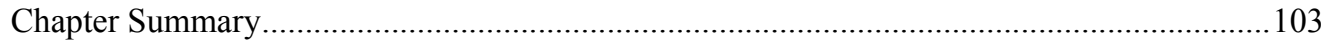

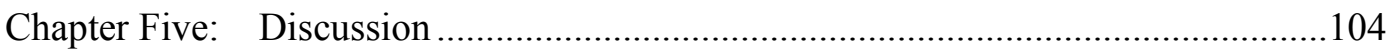

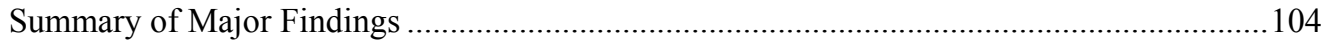

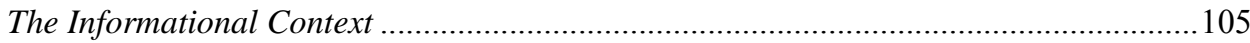

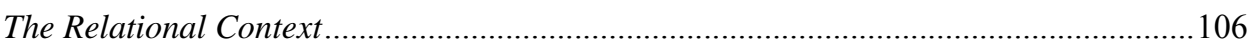


Impact of Change-Specific Cynicism …….......................................................... 108

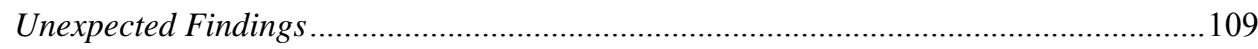

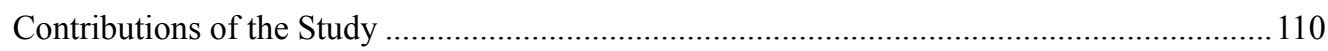

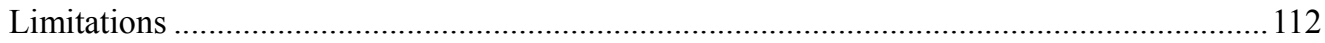

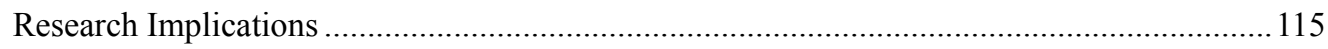

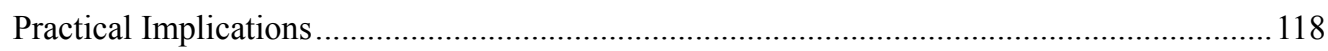

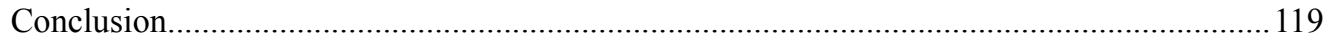

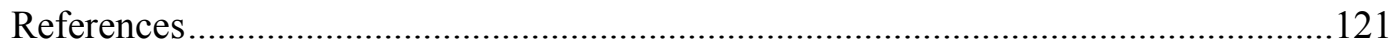

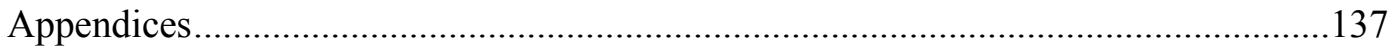

Appendix A: Letter to Participants................................................................................... 137

Appendix B: Survey Questionnaire........................................................................................ 138

Appendix C: The Reliability Coefficients for the Survey Questionnaire...............................141

Appendix D: Principle Component Analysis ...................................................................... 146

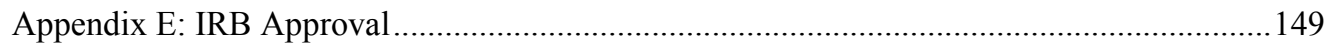




\section{List of Tables}

Table 3-1: Comparison of sample size between participants and non-participants ........72

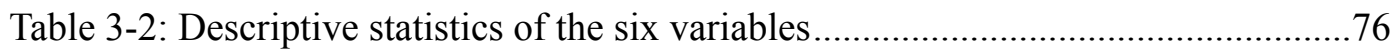

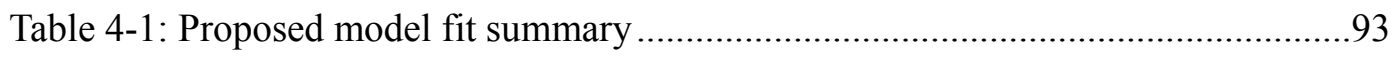

Table 4-2: Causal effects among the variables in the proposed model .........................94

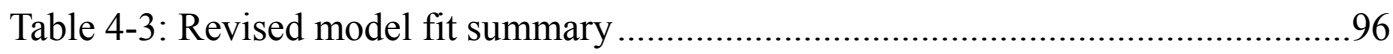

Table 4-4: Causal effects among the variables in the revised model ............................97 


\section{List of Figures}

Figure 1-1: Model of employee cynicism toward organizational change......................18

Figure 4-1: The original model with path coefficients ..............................................98

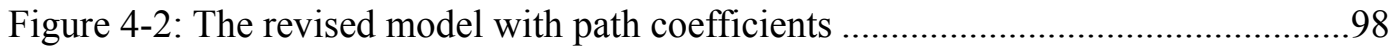




\section{Chapter One: Introduction}

\section{Statement of the Problem}

The higher education environment has been undergoing tremendous changes

during the past two decades, including reductions in financial resources, changing student demographics, and questioning from the public about the nature and purpose of higher education (Lindholm, 2003). As a consequence, higher education institutions have to engage in planned changes to adapt to the shifting educational environment. Research has documented how presidents, or change agents, initiate, frame, and/or guide planned changes (Eddy, 2003; Gioia \& Chittepeddi, 1991; Lueddeke, 1999). However, the importance of faculty reactions to planned changes has not received its due attention by researchers.

One particular trend in planned changes in higher education is that leaders increasingly resort to traditional, profit-driven business practices to improve efficiency and effectiveness. However, higher education institutions are guided by traditional academic values, such as "intellectual creativity," "academic freedom," and "shared governance," more than just by the "bottom-line performance" in corporate organizations (Eisenberg, Murphy, \& Andrews, 1998). When change efforts disturb the deep-rooted academic culture, faculty tend to respond with cynicism (Ramaley, 2002). For example, some refer to business practices as "corporate buzzwords" or "management fads" (Birnbaum, 2000). Similarly, Young (1997) argued that academic values are challenged by capitalist values, which are reflected in an emphasis on economic worth and intense competition among universities and departments. Bok 
(2003) noted that business terms "widen the gulf between faculty and administration," (p. 20) and the most prevalent reactions of faculty toward business on campus are suspicion and resistance. As Kanter and Mirvis (1989) have mentioned, when the pursuit of profits is paramount over work ideals, cynicism tends to occur. Although few studies of cynicism have been conducted in educational settings, cynicism is not rare among faculty during planned changes in higher education. The strategic planning practices and documents of several universities have shown that cynicism is prevalent on campus. Certain situations are particularly likely to trigger faculty cynicism. Faculty members display cynicism when they have been exposed to constant failures of past changes. According to Cerra (2005), a typical response is reflected in comments such as, “The university has tried this before and it didn't work. What's different this time?" (Cerra, 2005). Cynicism also occurs when an administration cannot provide timely response and support for the change efforts of academic units, especially in times of budgetary difficulty (European University Association, 2005). Cynicism can also be observed from the research site in the present study. Faculty cynicism was epitomized in a cartoon in a local newspaper: A man wearing a pair of glasses with dollar signs is squeezing the neck of a chicken. The man is captioned as "the administrators" and the chicken as "the faculty." The present study examines one specific form of cynicism-employee cynicism in response to a specific organizational change (i.e., change-specific cynicism) in a higher education setting. Research has indicated that organizational change is particularly likely to engender cynicism (Dean, Brandes, \& Dharwadkar, 
1998). Employees tend to be cynical toward constant changes in organizations.

Wanous, Reichers, and Austin (2000) argued that cynicism could become its own self-fulfilling prophecy, and thereby inhibit the success of further change efforts. This topic merits more research attention considering the potential for widespread organizational changes due to a turbulent economic environment.

Very few studies have focused on employee cynicism toward organizational change, and the studies that do exist have been primarily conducted by researchers in the fields of management and psychology. Communication scholars have remained silent on this topic. The majority of research on cynicism in the communication field has centered on the political arena. Primarily these are studies of news media influence on political cynicism (de Vreese, 2005; Lee, 2005; Lin \& Lim, 2002). Nonetheless, one recent study has regarded cynicism in the workplace as "an ongoing production of subjective space" (Fleming, 2005, p. 48). The cynics gain a sense of control over their identities by expressing cynicism but, at the same time, reproduce the dominant culture. In this sense, Fleming (2005) argued that, "cynicism was treated as a harmless safety valve rather than a meaningful challenge to power" (p. 47). One of the major contributions of this research is that it conceptualizes cynicism within organizations as an ongoing communication process.

The purpose of the present study is to explore the role of communication processes and factors in predicting change-specific cynicism. Specifically, this study will employ social information processing (SIP) theory to investigate the informational context and relational context in contributing to change-specific 
cynicism. SIP is used because it explains the communication processes in influencing work-related attitudes, and SIP has received solid empirical support (Zalesny \& Ford, 1990). Change-specific cynicism, as one type of attitude in the workplace, is amenable to study within the SIP theoretical framework. In this study, cynicism is conceptualized as a communication problem rather than a stable personality trait. Cynicism is socially constructed and emerges from a social context.

This chapter will begin with the background of the problem. Then, I will briefly review the definitions of cynicism in the workplace and provide a tentative definition of change-specific cynicism for the dissertation. Next, the theoretical framework of SIP will be explained, followed by a description of the model under the present study. Finally, the significance of this study will be discussed.

\section{Background of the Problem}

This study is situated in a midwestern university with a long history. Like many other higher education institutions, this university is facing challenges born of a rapidly changing educational environment. In 2005, university trustees appointed a new president. Over the next year, the new president made other high level executive appointments. This new leadership group initiated a large-scale strategic planning process which included establishing goals associated with achieving national prominence, increasing diversity, increasing outreach, and reallocating resources. Among all the change initiatives, the resource reallocation plan has stimulated much debate on campus. While some faculty members welcomed it as a long-overdue change that would address historical inequities, others complained that the metrics for 
measuring performance favored some academic units over others (inside documents, 2006).

Before the change, this university relied on a traditional incremental budgeting system based on historical patterns and incremental adjustments of resources. The new budget plan was called performance-based budgeting (PBB), which involved annual performance evaluations of academic units as well as adjustments of resources based on a unit's performance. The budget plan is also commonly known as "incentive-based budgeting," "responsibility center budgeting," or "value centered budgeting."

This resource allocation method is not unique to this university. In response to the federal and state budget decline in higher education, PBB has been widely acknowledged among universities and colleges. Although PBB existed in private universities early in the 70 s and 80 s, its adoption in public universities is of recent origin (Hearn, Lewis, Kallsen, Holdsworth, \& Jones, 2006). Many controversies have arisen from the application of this budgeting practice in higher education settings.

Scholars and practitioners have debated over PBB's advantages and disadvantages. Proponents argue that PBB decentralizes decision making concerning resource allocation, and enhances responsiveness to internal market systems (Johnson \& St. John, 2002). They also maintain that PBB increases accountability at the level of academic units, and encourages efficient resource management (Hearn et al., 2006). Opponents complain that PBB privileges economic value over academic value (Adam, 1997). Moreover, in higher education institutions, there is no "bottom-line 
performance;" So, it is difficult to set the metrics for performance. Some critics point out that PBB encourages competition between academic units, and might lead to "turf battles" across units (Hensley et al., 2001), or inefficient service delivery (Meisinger, 1994).

Much of the debate is reflected on this campus, and a climate of cynicism toward the new budget change exists among some faculty. Using this university as my research site, the present study intends to build a communication model to predict employee cynicism toward organizational change. Before proposing the model, a tentative definition of employee cynicism for this study is provided.

\section{Definition of Employee Cynicism toward Organizational Change}

Researchers have attempted to provide various definitions of cynicism. However, existing research on cynicism is varied yet sparse, and it is still at the initial stage of scientific research development (Andersson \& Bateman, 1997; Stanley, Meyer, \& Topolnytsky, 2005; Wanous et al., 2000). Thus, a consensus about the definition and measurement of cynicism has not yet been formulated. There are two research traditions on cynicism: one treats cynicism as a general construct reflecting a stable personality trait, and the other treats cynicism as a specific construct directed toward society, occupations, institutions, and organizational change (Dean et al., 1998). The former shows a personal attribution, and the latter a situational attribution of cynicism.

Accordingly, literature has documented five research foci for cynicism: personality cynicism, societal cynicism, occupational cynicism, employee cynicism, 
and cynicism about organizational change (Abraham, 2000; Dean et al., 1998). Early research defined cynicism as a stable personality trait reflecting the negative perceptions of human nature and other people (Cock \& Medley, 1954). Societal cynicism is described as individuals' feelings of disillusionment and frustration because of unmet expectations of society (Kanter \& Mirvis, 1989). Occupational cynicism or work cynicism refers to loss of faith in people, of the enthusiasm of high ideals of serving people, and of the pride for the job. Much of the occupational cynicism research was conducted among police officers, and based on Niederhoffer's (1967) scale of police cynicism. The latter two foci of cynicism are of recent research origin. The definition for this dissertation will derive from research on employee cynicism and cynicism about organizational change.

Andersson and Bateman (1997) describe employee cynicism as "the feelings of frustration and disillusionment as well as negative feelings toward and distrust of a person, group, ideology, social convention, or institution” (p. 450). This definition captures many of the similarities in cynicism research. A comprehensive definition of organizational cynicism is provided by Dean et al. (1998). They define organizational cynicism as:

A negative attitude toward one's employing organization, comprising three dimensions: (1) a belief that the organization lacks integrity; (2) negative affect toward the organization; and (3) tendencies to disparaging and critical behaviors toward the organization that are consistent with these beliefs and affect. (p. 345) 
This multidimensional definition of organizational cynicism reflects all three aspects of the conceptualization of this attitude.

Currently, only two studies have specifically examined employee cynicism toward organizational change. Wanous et al. (2000) first proposed the construct "cynicism about organizational change" (CAOC) and developed a measure for this construct. They defined CAOC as "a pessimistic viewpoint about change efforts being successful because those responsible for making change are blamed for being unmotivated, incompetent, or both" (p. 133). They found that CAOC results from situational factors rather than dispositional negative affectivity.

Stanley, Meyer, and Topolnytsky (2005) note that CAOC reflects cynicism about organizational change in general, but does not reveal employee cynicism toward a specific change. Therefore, they developed a concept called "change-specific cynicism.” According to Ajzen and Fishbein (1980), specific attitudes are better predictors of individual intention and behavior. Consequently, change-specific cynicism should be a better predictor of individual intention to resist a specific change. Stanley et al. (2005) defined change-specific cynicism as "a disbelief of management's stated or implied motives for a specific organizational change" ( $p$. 436).

Based on the definitions given by Andersson and Batesman (1997), Dean et al. (1998), Wanous, et al. (2000), and Stanley, et al. (2005), a tentative definition of change-specific cynicism for this dissertation is proposed as follows: 
Change-specific cynicism refers to a negative attitude toward a specific organizational change consisting of three dimensions: a disbelief in management's stated or implied motives for the change; a feeling of pessimism and frustration about the change efforts; and tendencies to disparaging and critical behaviors toward the specific organizational change.

Theoretical Framework and the Proposed Model

Previous research mainly adopts psychological contract violation theory to explain employee cynicism. The present study aims to explore the role of communication processes in developing cynicism. The theoretical framework of social information processing (SIP) is employed in this study. The essence of SIP is that work-related attitudes are not given, but socially constructed. To be specific, they are derived from social context and subject to informational social influence. On one hand, individuals form attitudes based on social cues or information from others in social context. On the other hand, what others think could also directly influence individual attitude through social norms. Therefore, social context implies two aspects: informational and relational. Early research on SIP emphasized the informational aspect (e.g., Miller \& Monge, 1985). More recent research focuses on the relational aspect of the social influence process through social network analysis (e.g., Meyer, 1994).

The present study takes both informational and relational aspects into consideration. The informational context entails the variable, perceived quality of information. The relational context includes two variables: cynicism of colleagues 
toward the change and trust in management. Participation in decision making (PDM) is also considered in this model. These variables constitute the antecedents of change-specific cynicism, and intention to resist change is the consequence of change-specific cynicism.

\section{Change-Specific Cynicism and Intention to Resist Change}

The components in the proposed model are theoretically and empirically related to one another. Previous literature has shown that the two endogenous variables, change-specific cynicism and intention to resist organizational change, are closely associated. Stanley et al. (2005) found that change-specific cynicism is a predictor of intention to resist organizational change. Several studies have identified cynicism as one of the sources of resistance to organizational change (del Val \& Fuentes, 2003; Ford, Ford, \& Mcnamara, 2001; Maurer, 1996; Reichers et al., 1997). In addition to the empirical support, the two variables are closely related conceptually.

Resistance to organizational change has been widely studied for the past half century. Researchers have attempted to define resistance and explain the causes of resistance from various perspectives. They conceptualize resistance to change as a result of a restraining force in systems, power relations within organizations, a psychological trait, and communication processes in the situational context. For example, Lewin (1952) defined resistance as a restraining force moving in the direction of maintaining the status quo. This definition indicates that resistance could occur anywhere in the system. However, most research following Coch and French (1948) submitted that resistance can be found in people, mainly employees in 
organizations. Jermier, Knights, and Nord (1994) treated resistance as "a reactive process where agents embedded in power relations actively oppose initiatives by other agents" (p.9). This definition suggests the dichotomy between labor and management, control and resistance.

Generally speaking, resistance to change can be attributed to an individual trait or situational factors. Oreg (2000) considered resistance to change as an individual trait determined by such characteristics as routine seeking, emotional reaction to imposed change, short-term focus, and cognitive rigidity. Communication researchers argue that resistance is socially constructed, and can be attributed to problems in communication processes (Lewis, 2006). The importance of the social dimension of resistance has been echoed by researchers in other disciplines as well. Lawrence (1954) noted that change has two aspects: a technical aspect and a social aspect. Employees often resist the social aspect of change but not the technical aspect. Ford et al. (2001) found that resistance to change is socially constructed through the background conversations within the organization, and one type of conversation is cynicism. The present study adopts the last conceptualization of resistance by considering resistance as a consequence of communication processes. Most research regards resistance as a type of behavior. For example, Zander (1950) defined resistance as "behavior which is intended to protect an individual from the effects of real or imagined change" (p.9). However, Piderit (2000) conceptualized resistance as a response to change consisting of three dimensions: cognitive, emotional, and intentional. This conceptualization draws from the tripartite view of 
attitudes, which are structured along the above three dimensions (Ajzen, 1984).

Piderit's research attempted to integrate the three dimensions into the concept of resistance to change. However, she also admited that "intentions are so loosely connected with other dimensions of attitudes that they have been treated as entirely separate constructs" (p. 786). Intention is viewed as a plan or resolution to take some action. The present study focuses on the intentional dimension of resistance.

The above definitions show that cynicism and intention to resist change share some common characteristics. They are both considered as negative attitudes toward organizational change and resulting from communication processes. They are both portrayed as confrontations between superiors and subordinates. Therefore, cynicism is often coupled with intention to resist change or behavioral resistance in practice and in the literature. However, cynicism and resistance are two distinct concepts. While intention to resist change implies a plan or resolution to actively oppose change initiatives (Jermier et al., 1994), cynicism is viewed more as a passive reaction. Cynicism does not indicate the overt expression of aggression (Dean, et al., 1998). Prolonged and widespread cynicism could become the precursor of more aggressive expression of discontent toward organizational change - intention to resist change.

There are four predictor variables in this study: perceived quality of information, PDM, cynicism of colleagues, and trust in administration. The first variable taps into the informational aspects and the latter two variables explains the relational aspects of social context. In the following section, I will provide evidence that these predictor variables have causal relationships with change-specific cynicism. 
Perceived Quality of Information and Change-Specific Cynicism

An abundance of research has found that high levels of information adequacy and quality are associated with positive work-related attitudes, such as job satisfaction and openness to change. Although any information is perceived as more helpful than no information (Miller \& Monge, 1985), research shows that the quality of information directly influences attitudes toward organizational change. For example, studies find that information helpfulness is a predictor of anxiety about change, and the quality of information leads to openness to change (Miller, Johnson, \& Grau, 1994; Miller \& Monge, 1985). People experience a high level of uncertainty in highly ambiguous situations, such as during the period of organizational change. Perceived high quality of information could reduce employee uncertainty about the change, and thereby making the change more acceptable emotionally. Cognitively, perceived high quality of information might provide the rationale for change and persuasive messages to encourage cooperation with the change.

Theoretically, according to SIP, individuals develop attitudes based on the information available in the social context. When individuals perceive information as being high in quality, they tend to develop positive attitudes toward change. On the contrary, perceived low quality of information about change will lead to negative attitudes about change. People will doubt whether or not a "hidden agenda" is being made, and thus forming a sense of distrust toward management, which could incur change-specific cynicism. 
PDM and Change-Specific Cynicism

Ever since Coch and French (1948) proposed that PDM could lead to reduced resistance to change, abundant subsequent studies have examined the effect of PDM on change attitudes and work outcomes. For example, Sagie, Elizur, and Koslowsky (1996) found that PDM is positively related to change acceptance. Wanous et al. (2000) noted that lack of PDM could lead to CAOC. For the past five decades, research has shown that PDM is associated with various positive work outcomes, such as job satisfaction, and job productivity (Miller \& Monge, 1986). In a thorough review of PDM, Locke and Schweiger (1979) suggested that PDM influences work outcomes through two mechanisms, cognitive and motivational. Cognitively, PDM leads to an enhanced understanding of the reasons for change and change decisions, thus facilitating change acceptance. Further, through active participation, individuals gain first-hand information about the change. The "self-discovery" information is more influential than information obtained indirectly from others, and it gives individuals a sense of partnership (Armenakis \& Harris, 2001). From the motivational aspect, participation enhances individuals' feelings of control and reduces uncertainty (Bordia, Hobman, Jones, Gallois, \& Callan, 2004). Employees are more affectively willing to accept changes affectively as a result of PDM.

In addition, PDM can be considered as an enactment in social environment, which subsequently influences individual attitudes. As Salancik and Pfeffer (1978) indicated, "individuals develop attitudes consistent with their commitment to an activity" (p. 231). Therefore, employees are likely to be more identified with changes 
in which they actively participated. The above empirical studies and theoretical analysis show that PDM in change processes can reduce employee negative attitudes toward change. Hence, I propose that PDM during organizational change has a causal relationship with change-specific cynicism. Cynicism of Colleagues and Change-Specific Cynicism

The argument that individual attitude is subject to social influence is not new. Pavitt (1993) posited that "the study of social influence is probably the sole interest shared among the widely diverging concerns and approaches adopted by communication scholars" (p. 216). Various studies have documented the effect of mass media and interpersonal influence on group decision making, acceptance of health-related programs, and adoption of new technologies (Rogers, 1995; Valente \& Saba, 1998). SIP theory emphasizes social influence processes in developing work-related attitudes. Salancik and Pfeffer (1978) argue that work-related attitudes are influenced by coworkers through their overt statements or interpretation of environmental cues. The overt statements provide descriptive information, which increases saliency of certain aspects of the social context. Coworker interpretation of environmental cues provides evaluative information, which influences individual attitudes through social norms. To specify the mechanism of social influence, researchers have incorporated social network analysis into the SIP model to explore the specific social influence processes in formulating various attitudes (e.g., Fulk, 1993; Meyer, 1994; Pollock, Whitbred, \& Contractor, 2000; Rice \& Aydin, 1991). 
Although no empirical studies have been conducted on the impact of social influence on change-specific cynicism, it can be argued that change-specific cynicism is "contagious" in organizations. As the grapevine research (Crampton, Hodge, \& Mishra, 1998) shows, rumors are spread quickly through informal social networks. Similarly, cynicism may be diffused through informal networks instead of formal organizational networks. Cynical employees usually have conversations of cynicism with their close colleagues, rather than openly challenging change initiatives through formal networks. According to SIP, the conversations of cynicism call the attention to negative aspects of the change, and increase the saliency of those aspects. Hence, cynicism of colleagues could predict a focal individual's cynicism.

Further, the characteristics of higher education institutions create a context in which faculty attitudes are most likely to be influenced by their close colleagues. Educational institutions are considered as loosely-coupled systems. In loosely-coupled systems, the traditional managerial communication tools that rely on a chain-of-command for diffusing information often do not work. Communication tends to occur through social or professional networks (Weick, 1982). Birnbaum (1990) posited that with increased faculty specialization, "schools or departments become the locus of decision making" (p. 17). Therefore, it can be argued that faculty cynicism is very likely to be influenced by cynicism of other faculty, in particular, faculty in their own academic units. 
Trust in Management and Change-Specific Cynicism

Stanley et al. (2005) defined change-specific cynicism as "a disbelief of management's stated or implied motives for a specific organizational change” (p. 436). This definition indicates that trust in management might be an important determinant of cynicism. However, they also maintain that cynicism and trust/distrust are distinct concepts, and thereby there is no redundancy in the two concepts. Mayer, Davis, and Schoorman (1995) defined trust as "a willingness of a party to be vulnerable to the actions of another party based on the expectation that the other will perform a particular action important to the trustor, irrespective of the ability to monitor or control the party" (p. 712). This definition indicates that trust requires vulnerability on the part of the individuals who trust. However, one can be cynical without being vulnerable (Dean et al., 2000). Further, Andersson (1996) argued that cynicism is broader in scope than trust, as cynicism entails an affective component and trust is just a belief. Despite the differences, trust and cynicism are closely related conceptually and empirically. An individual who is cynical about an attitude object is unlikely to display trust toward it. Similarly, an individual who shows high level of trust toward an object is unlikely to be cynical toward it. Therefore, trust could be a possible predictor of cynicism. Albrecht (2002) found that trust in senior management is a determinant of cynicism toward change. He also noted that integrity of senior management directly influence trust in senior management and cynicism toward change.

Based on the above analysis, the following model is proposed in Figure 1-1: 


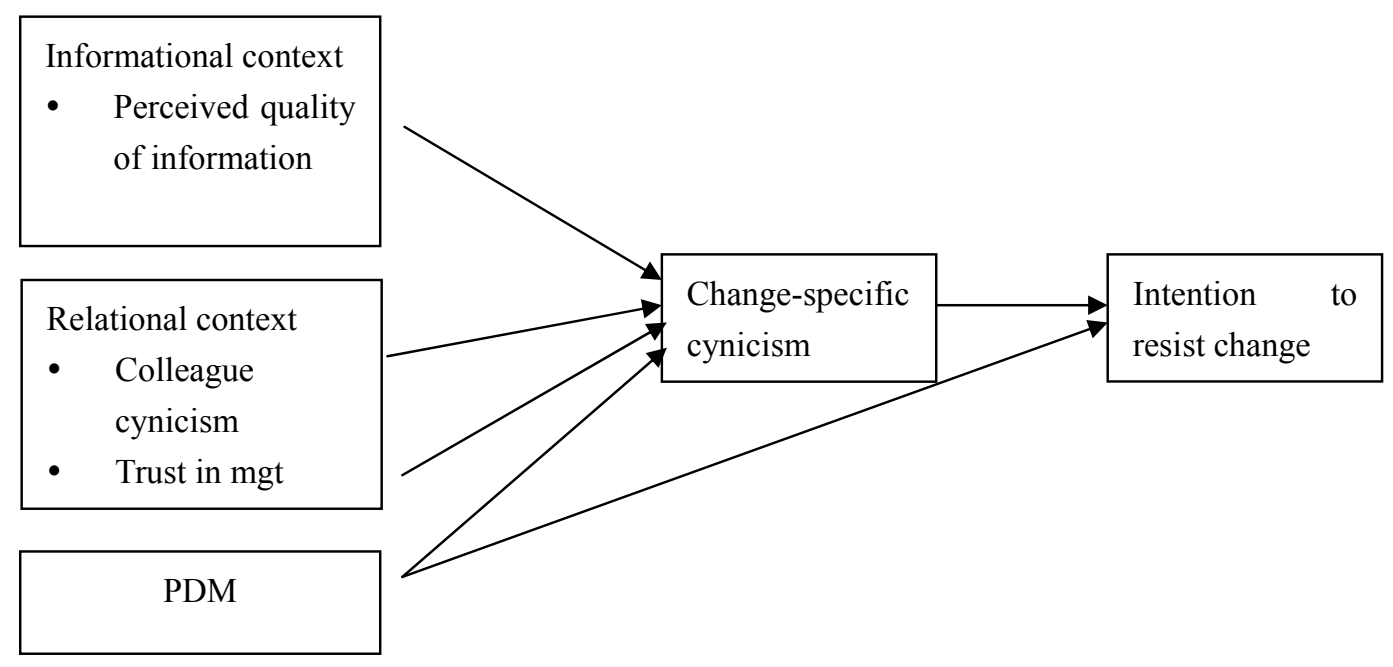

Figure 1-1: Hypothesized Model of Employee Cynicism toward Organizational

\section{Change}

In this model, change-specific cynicism and intention to resist change are the endogenous variables, which are explained by the model. Whereas, perceived information quality, cynicism of colleagues, trust in administration, and PDM are the exogenous variables, which are assumed to be explained by other variables outside the causal model under study. The above path diagram shows that the four exogenous variables cause change-specific cynicism, which, in turn, causes faculty intention to resist change. In addition, past research has found that lack of PDM causes intention to resist change directly.

The direct causal relationships between the variables in this model are shown with straight arrows, with the arrowheads indicating the assumed direction of causation. The exogenous variables have indirect causal effect on intention to resist 
change through the intervening variable, change-specific cynicism. The relationships among the exogenous variables are not analyzed. The unanalyzed portion might represent some degree of causal effect that has not been included in this model, which results in a degree of uncertainty in the final model fit.

In this model, there are three missing paths, the paths from perceived quality of information, colleague cynicism, and trust in management, to intention to resist change respectively. These paths are excluded based on the theoretical frameworks and associated literature. That means three of the exogenous variables-perceived quality of information, cynicism of colleagues, and trust in administration — only affects intention to resist change through their effects on the intervening variable, change-specific cynicism.

\section{Research Questions}

The present study intends to examine whether or not the communication variables combined in this model could predict change-specific cynicism, and ultimately intention to resist change. Although previous literature identified various sources of change-specific cynicism and intention to resist change, very little research has developed models from a communication perspective to explain the two types of attitudes toward organizational change. From the above analysis, it is reasonable to propose that communication processes directly or indirectly cause the formation of cynicism and resistance. The research questions for this study are specified as follows: 
(1)

Is this model, which describes the causal effects among the six variables, consistent with the observed correlations among these variables?

If this model is consistent, what are the estimated direct, indirect, and total causal effects among the variables?

Significance of the Study

This study will contribute to the literature in the following aspects: First, it explores change-specific cynicism from a communication perspective. Previous studies on cynicism were conducted in the fields of management and psychology. And they mainly employ psychological contract violation theory, expectancy theory and attribution theory to explain the concept of cynicism and its antecedents and consequences. This present study applies SIP in analyzing and predicting change-specific cynicism, and emphasizes the role of social context in formulating this attitude. It points to a new direction which warrants the research attention of communication scholars.

Second, this study examines change-specific cynicism in higher education settings. Much research has been made on police cynicism and cynicism in some service occupations, but no known study has been found in higher education settings. However, cynicism is widespread in educational settings, as employees in educational settings have to compromise academic value with economic value in an increasingly competitive educational environment. Moreover, everyday interactions breed cynicism among faculty, since in loosely-coupled systems, communication or the 
diffusion of information is more likely to occur through social or professional networks (Weick, 1982). Cynicism in higher education is not restricted to "a few bad apples," but is spread quickly through informal networks.

In addition, different from business organizations, higher education institutions are considered as autonomous professional organizations in which "the work of the professional is subject to his own rather than administrative jurisdiction" (Hall, 1967, p. 462-463). Hall (1967) argued that, in this setting, the relationship between the professional and the organization is characterized by conflict. In the higher education context, faculty members tend to identify more with their disciplines than with their universities or colleges. Cynicism could arise when faculty members perceive the organizational change as incompatible with their professional autonomy and academic values. Therefore, it is of practical importance to conduct cynicism research in the higher education context.

Third, this study integrates the measurements of previous research into a new measurement of change-specific cynicism, which includes all three dimensions of this attitude. Stanley et al. (2005) define change-specific cynicism only from the cognitive dimension, and did not mention the affective and behavioral dimensions which capture important features of the concept. Though Dean et al. (1998) note the multidimensional view, they measure organizational cynicism in general. This study will be useful for future studies in providing a multidimensional measurement of change-specific cynicism. 
Finally, this study examined both informational and relational aspects of SIP.

Previous studies focused either on the role of information or the role of social networks in shaping attitudes. The present study considers both aspects of SIP, and gives a holistic picture of the social context.

\section{Chapter Summary}

The remaining of the dissertation will be developed in the following way: Chapter two reviews the literature relevant to the proposed model. It includes five sections: SIP theory, employee cynicism, resistance to organizational change, PDM, and trust in management. Chapter three explains in detail the methodology used for the present study, which contains the research design, sample, and instrumentation. Chapter four analyzes and reports the study results. Chapter five presents the discussions and conclusions of the dissertation.

\section{Abbreviations Used Throughout This Dissertation}

Social information processing (SIP)

Cynicism about organizational change (CAOC)

Participation in decision making (PDM) 


\section{Chapter Two: Literature Review}

\section{Introduction}

The purpose of this chapter is to review the literature relevant to the predictor and outcome variables in the model of the current study. The review will lay the theoretical foundation for the study by providing definitions of terms, tracing the development of the literature on each variable, and emphasizing the causal relationships proposed in the current model. This chapter is divided into five sections, including social information processing theory, employee cynicism, resistance to change, participation in decision making, and trust in management.

SIP is the main theoretical framework used in the study. Therefore, the chapter first reviews the literature on SIP and discusses my contributions to the literature. The first section emphasizes two variables in relation to SIP, perceived quality of information and social networks. Characteristics of higher education and faculty networks are discussed to reveal the context of the study. The second section, employee cynicism toward organizational change, reviews the origin and development of cynicism research, different forms of cynicism, and the theoretical assumptions underlying cynicism research. The third section, resistance to change, covers the diverse perspectives of the research on resistance to change, explains the sources of resistance to change with the focus on employee cynicism, followed by the forms and dimensions of resistance to change. The fourth section, PDM, begins with the theoretical origins and definitions of PDM, then discusses the types and issues of PDM, and details the mechanisms and models of PDM so as to provide the rationale 
for the effect of PDM on various variables. Finally, the relationships between PDM and different outcome variables, especially resistance to change and cynicism to change, are explained. The final section, trust in management, describes the perspectives and definitions of trust, common themes of trust, characteristics of trustee, and ends with the relationship between trust in management and employee cynicism toward organizational change.

\section{Social Information Processing Theory}

The study of work-related attitudes commonly resorts to two explanatory frameworks: situational constraints and personal attributes. The traditional need-satisfaction models attribute job attitudes to personal characteristics. Specifically, need-satisfaction models assert that job attitudes are determined by how well job characteristics can satisfy innate individual needs. Social information processing (SIP) theory was put forward by Salancik and Pfeffer (1978) as an alternative to need-satisfaction models to explain job attitudes. Salancik and Pfeffer posited that job attitudes are influenced by social context and consequences from past experiences. The essence of SIP is that needs and attitudes are not given. They are socially constructed. Individuals form attitudes and needs based on the available information in the social environment. Salancik and Pfeffer stated, "people learn what their needs, values, and requirements should be in part from their interactions with others" (p. 230). Therefore, individual attitudes are subject to informational social influence in a given context. 
Ever since SIP was proposed, a growing body of empirical studies has tested this theory. During 1980s, research on SIP was characterized by laboratory experimental methodology. The majority of the literature has evidenced the effects of social cues on perception and attitude formation, but "the strength of the effects for the cues, however, has varied across investigations and type of dependent measures assessed" (Zalesny \& Farace, 1986, p. 271). The reviews and research on SIP during this period revealed that the theory of SIP provides a general framework to understand attitude formation from a situational perspective, but it has "loose ends and unanswered questions" (Salancik and Pfeffer, 1978, p. 227). Zalesny and Ford (1990) critiqued that SIP model did not indicate the boundaries and conditions for its operationalization. It could be used to explain all types of perceptions and attitudes, which results in the mixed support for this theory.

The present study intends to apply the SIP theory to examine employee cynicism and addresses some of the critiques of the theory. First, SIP researchers have studied various dependent variables, such as anxiety toward organizational change, openness to change, and job satisfaction (Miller, Johnson \& Grau, 1994; Miller \& Monge, 1985; Pollock, Whitbred, \& Contractor, 2000). However, no research has been found on using SIP to explain employee cynicism during organizational change. In this sense, this study is a further test of the boundaries of SIP theory.

Secondly, the empirical research on SIP has found that exposure to social cues (either positive or negative) will increase their saliency and enhance individual attitudes toward them, but few studies have investigated mixed or contradictory cues 
(both positive and negative) in field research (Blau \& Katerber, 1982; Thomas \&

Griffin, 1983). In addition, most of the research manipulated the social cues in a laboratory environment, and thus reduced the external validity of the research. This study addresses this problem by applying SIP in a field setting in which mixed cues exist. Colleagues and administrators might provide contradictory and mixed information about the organizational change. The field research will enhance the external validity of this study.

Thirdly, the present study is conducted in a highly ambiguous situation, during an organizational change in higher education settings. Rice (1993) maintained that people are more vulnerable to social influence when confronted with ambiguous situations. Blau (1985) argued, "It is logical to assume that there would be a lower social cues threshold for a more complex/ ambiguous task versus a simple/clear task." (p. 549). Therefore, it can be argued that informational social influence has a stronger effect on employee attitudes during organizational change.

The present study is an improvement in the application of SIP theory in the above areas. Further, previous studies include either the informational context or the relational context as the predictors of work attitudes. This study considers both by incorporating the predictor variables of perceived quality of information and colleague cynicism toward change. In the following, the relationship between the predictor variables and work attitudes will be examined. 
Perceived Quality of Information and Work Attitudes

SIP theory highlights the role of social information in shaping work-related attitudes. Salancik and Pfeffer (1978) asserted that "individuals develop attitude or need statements as a function of the information available to them at the time they express the attitude or need" (p. 226). They argued that social information influences attitudes through such ways as the overt statements of coworkers, structuring a person's attentional processes, and making certain aspects more salient, aiding the interpretation of environmental cues, and aiding employees in the interpretation of needs. Most research has confirmed the role of social information on work-related attitudes.

Social information entails two aspects: the quantity/adequacy of information and the quality of information. Traditional research has concluded that information adequacy is positively related to work attitudes, especially job satisfaction (Trombetta \& Rogers, 1988). However, recent research found that information adequacy is not always positively related to job satisfaction and information should be carefully designed and delivered purposefully to employees (Zhu, May, \& Rosenfeld, 2004). Therefore, researchers have realized that it is the perceived quality of information instead of the quantity that directly influences job attitudes (Miller \& Monge, 1985; Miller et al., 1994). The mechanism through which the perceived quality of information could influence work attitudes can be explained by uncertainty reduction theory. Perceived high quality of information could reduce the anxiety and uncertainty of employees about the change (Miller \& Monge, 1985). Conversely, poor quality of 
information is likely to enhance the uncertainty of employees and distrust toward the change agents. One of the major components of employee cynicism is distrust toward the motives of the management. Therefore, perceived quality of information could be one of the predictors of employee cynicism toward organizational change.

\section{Social Networks and SIP}

A common critique of SIP theory is that it does not specify the mechanism or processes through which social cues influence individuals' perceptions or attitudes. In response to this critique, network researchers have incorporated social network analysis into SIP model to explore the specific social influence processes in formulating attitudes during the $90 \mathrm{~s}$. By combining the two theories, researchers have attempted to explain individuals' attitudes toward new technology (Fulk, 1993; Fulk, et al., 1995; Rice \& Aydin, 1991), job satisfaction (Pollock, et al., 2000), and various organizational phenomena (Meyer, 1994).

Several mechanisms of social information processing are identified by network researchers, such as network proximity, network centrality, and cohesive work groups. Rice and Aydin (1991) examined three types of network proximity as a mechanism for SIP: relational proximity, positional proximity, and spatial proximity. Relational proximity refers to the extent to which individuals interact directly and indirectly. People who are relationally proximate are strongly tied to each other and communicate frequently. Positional proximity suggests "individuals occupy the same position, or structurally proximate, to the extent that they occupy the same roles and thus sets of obligations, status, and expectations" (p. 223). People who are proximate 
in position are not linked with each other, but they are linked to similar others.

Spatial proximity simply means that individuals are close in space, which allows them more opportunities to communicate. The results of the study indicate that both relational and structural equivalence network partners' attitudes predicted a focal individual's attitudes toward email, and the effects are modest in size.

In addition to network proximity, Ibarra and Andrews (1993) also investigated network centrality. They found that both network centrality and network proximity influence job-related perceptions, with the former stronger than the latter. They argued that people who are centrally located in social networks have more access to and control over valued resources, and enjoy more benefits and opportunities unavailable to those on the periphery of the network. Therefore, centrally located individuals tend to show more favorable attitudes toward their work situations. Further, network proximity makes people share similar views on job-related perceptions because of frequent interactions and social comparison.

Meyer (1994) examined three mechanisms of social information processing: simple interaction contact, norm enforcing cohesive groups, and the occupation of structurally equivalent positions. Simple interaction contact influences attitudes through direct and frequent interactions. Norm enforcing cohesive groups operate on attitudes through group norms and social conformity pressures. Occupying structurally equivalent positions makes people to link with similar others and experience similar socialization into their roles. The results show that all three 
mechanisms influence individual perceptions over some organizational phenomena, with norm enforcing cohesive groups the strongest influence over perceptions.

Fulk, Schmitz, and Ryu (1993) used an SIP model to study individuals’ attitudes and behaviors toward new communication technologies. They integrate SIP theory and social learning theory to develop a social influence model of media use. The social influence model is useful in explaining how individuals' behaviors are learned and socially constructed. The results suggest that individuals' perceptions of their colleagues' attitudes and behaviors of electronic mail use predict their own attitudes and behaviors. In this study, they use ego social networks to measure individuals' cognitions of their colleagues' attitudes and behaviors. Ego social network refers to the focal individual's supervisor and five people who communicate most frequently with the focal individual.

The present study will examine the role of one type of network proximity, relational proximity, on employee cynicism toward organizational change. As illustrated in the above network research, relational proximity has been consistently found to be an important factor in influencing individual attitudes. Methodologically, ego social networks will be adopted to measure the influence of proximate others on a focal individual's attitude. Although ego network does not provide an overall picture of the social structure within organizations, it is most useful in measuring an individual's immediate social networks (Morrison, 2002). 
Characteristics of Higher Education Institutions and Faculty Networks

Higher education institutions have some unique characteristics which have an impact on the social relationships and structure of faculty. First, higher education institutions are often referred to as loosely-coupled systems. Weick (1976) defined a loosely coupled system as one in which "coupled events are responsive, but that each event also preserves its own identity and some evidence of its physical or logical separateness" (p. 3). A loosely-coupled system has its advantages. Loose coupling provides a sensitive sensing mechanism, as each coupled element can sense and preserve some part of the environment. However, loosely-coupled systems have their dysfunctions too. A loosely-coupled system tends to preserve old ideas, and it is slow in responding to innovations. Birnbaum (1990) posited that "loose coupling makes coordination of activities problematic and makes it difficult to use administrative processes to effect change." (p. 40).

As loosely-coupled systems, higher education institutions are organized according to academic units. Each unit is a separate entity loosely coupled with other units. Further, increased faculty specialization in expertise and knowledge makes academic units the locus of decision making in instruction and curriculum design (Birnbaum, 1990). Faculty feel more affiliated with their own academic units than the larger institution. Birnbaum stated that, "the larger institution may become an academic holding company, presiding over a federation of quasi-autonomous subunits." (p. 17). Therefore, it can be reasoned that faculty socialize more in the 
workplace with other faculty in their academic units, and academic units can be used as the boundaries of faculty social networks.

The other characteristic of higher education institutions is shared governance. As loosely coupled systems, higher education institutions share governance among boards of trustees, administrators, and faculty members. Corson (1960) first noted that universities and colleges exist in a unique dualism structure: the conventional administrative hierarchy and faculty governance structure. Therefore, there is divided authority in higher education institutions. The administrative authority is based on the control and coordination of activities of organizational members. The professional authority is based on specialized knowledge and autonomy. Because of this, Kezar (2001) noted that power in higher education institutions tends to be informal, through networks of influence. Faculty members are likely to be influenced by communication with colleagues who share their values.

The above characteristics of higher education suggest that faculty attitudes and perceptions tend to be influenced by the informal social networks within their academic units. Academic units can serve as the appropriate boundary of social network because of faculty's disciplinary identification. Therefore, the effect of faculty network on perceptions cannot be ignored in higher education institutions.

The present study explores the relationship between colleagues' cynicism and employee cynicism toward organizational change through social network analysis. Although previous studies have examined the effect of informal social networks on various attitudes and behaviors (Fulk, et al., 1993; Pollock, et al., 2000), few studies 
have investigated negative attitudes, in particular, employee cynicism toward organizational change. However, as the grapevine research has shown, rumors tend to spread through informal social networks (Davis, 1953). Similarly, cynicism, commonly seen as a negative attitude, is more likely to be diffused through informal social networks than formal organizational channels. When colleagues in an individual's ego social network express more cynicism, the individual tends to pay more attention to the negative side of the change, and thus showing cynicism himself/herself. Hence, colleagues' cynicism might be a predictor of employee cynicism toward organizational change.

\section{Employee Cynicism toward Organizational Change}

Cynicism is widespread within organizations today. Over forty percent of the American workforce fits the profile of the cynic (Kanter \& Mirvis, 1989). Cynicism is believed to be the source of various undesirable consequences in the workplace.

Research has found that organizational cynicism is negatively associated with job satisfaction, organizational commitment, and organizational citizenship behaviors (Abraham, 2000; Andersson \& Bateman, 1997). As an emerging problem in many organizations, cynicism warrants further research attention.

The current study focuses on one particular type of cynicism, employee cynicism toward organizational change. Research has shown that organizational change is particularly likely to engender cynicism (Shapiro, 1996). Cynicism about organizational change could become its own self-fulfilling prophecy. A lack of support from cynics can lead to failure of the change which, in turn, reinforces 
cynicism among organizational members. A few studies have examined the antecedents and consequences of employee cynicism toward organizational change. However, the communication processes of cynicism have not been put into the central focus in most studies. This study will explore the antecedents and consequences of employee cynicism toward organizational change from a communication perspective.

This section will review the literature on cynicism in general, with the emphasis on employee cynicism toward organizational change. The review will trace the origin and development of cynicism research, and explain the various foci of cynicism. The antecedents and consequences of employee cynicism toward organizational change are also reviewed. Finally, the limitations of previous studies are pointed out and the contributions of the present study in this area are discussed. Origin and Development of Cynicism

The concept of cynicism can be traced back to the philosophers of $4^{\text {th }}$ century B.C. and the Cynic School of the $5^{\text {th }}$ century B.C. in ancient Greece. The early philosophers, Antisthenes and Diogenes, were the first few proponents of cynicism. They showed contempt for established order and societal conventions by means of cynical words and behaviors. The ancient Greek cynics aspired to high moral standards and mocked at the relentless pursuit of power, wealth, and materialism by their fellow citizens (Goldfarb, 1991). They lived a rough and simple life, known as a dog's life. Cynicism in ancient times was both a school of thought and a lifestyle. However, contemporary understandings of cynicism have deviated from the meanings in ancient times to some extent. Cynics in modern times see little use in 
adhering to high moral and ethical standards. Instead, they separate themselves from the evils prevailing in society (Andersson, 1996). Cynicism is characterized by distrust in human nature and social institutions and disillusionment from unfulfilled promises of society (Kanter \& Mirvis, 1989). Since 1990's, cynicism has received increasing research attention in various disciplines, such as psychology, sociology, and management. The meanings of cynicism have evolved through various research directions.

Foci of Cynicism

Like other attitudinal variables, cynicism can be attributed to two explanations: personality and situational explanations. Accordingly, cynicism research generally falls in two directions: One considers cynicism as a general construct reflecting a stable dispositional trait, whereas, the other treats cynicism as a specific construct directed toward society, occupation, institutions, and organizational change (Dean et al., 1998). Hence, five forms of cynicism have been examined and reviewed in previous studies (Abraham, 2000).

Early research views cynicism as a stable personality trait, which is characterized by negative perceptions of human nature and other people in general. People who possess the cynicism personality tend to show more distrust and hostility towards other people. The most representative along this line of research is Cook and Medley's (1954) hostility scale, a subset of the Minnesota Multiphasic Personality Inventory (MMPI). The hostility scale measures a type of person characterized by a dislike and distrust for others. Typical items on the hostility scale are, "I would 
certainly enjoy beating the crook at his own game," "When someone does me a wrong I feel I should pay him back if I can, just for the principle of the thing," "I have often met people who are supposed to be expert who are no better than I.” (p. 417). Individuals who score high on the scale consider other people as selfish, untrustworthy, dishonest, and immoral in nature, and thereby, individuals with the cynicism personality tend to be guarded in social interactions and show distrust in the motives of others. However, researchers also point out that the cynics do not display overt expression of aggression (Dean et al., 1998). The definition given by Oxford English Dictionary is consistent with the research tradition of personality cynicism. It defines a cynic as, "one who shows a disposition to disbelieve in the sincerity or goodness of human motives and actions, and is wont to express this by sneers and sarcasms; a sneering fault-finder.” This research tradition treats cynicism as a personality trait that is persistent across situations. Therefore, the personality cynics are cynical about everything. They are often considered as the "bad apples" in organizations by the managers.

Later research found that cynicism cannot be satisfactorily explained by personality. For example, the research conducted by Wanous et al. (2000) shows that cynicism about organizational change has little to do with the dispositional roots in one's general negative affectivity, but is a learned response from experiences in the workplace. Most researchers who view cynicism as a specific construct endorse the situational explanation. Societal cynicism is one type of situational attributions of cynicism. Kanter and Mirvis (1989) maintain that cynicism derives from the changing 
social, political, and economic environment. They argued, "Cynicism permeates a society whenever the high hopes of many are raised and frustrated and their deep disappointment gives way to disillusion.” (p. 11). They situated cynicism within a larger social and historical background in the twentieth century, and claim that cynicism is widespread because society, government, and organization fail to meet the high expectations of people which are raised in the "good old days."

While societal cynicism blames society as a whole in breeding cynicism, occupational cynicism attributes cynicism to stress and burnout in certain occupations, such as police and service occupations. The seminal work on occupational cynicism was conducted by Niederhoffer (1967). In one of his studies, he found that police officers are susceptible to cynicism because of their stressful occupation. They are cynical toward their organizations and the service of the people and the law. Niederhoffer also developed the first scale to measure police cynicism. In addition to police occupation, cynicism is also prevalent in service occupations. Stressful interactions with consumers make workers depersonalize or distance themselves from consumers as an adaptive strategy (Abraham, 2000). Occupational cynicism is characterized by loss of faith in people and lack of enthusiasm in the service of people and society. Although occupational cynicism research directs scholarly attention to the workplace, it limits cynicism within some particular occupations in which stress and burnout are prevalent. However, cynicism permeates all types of occupations and organizations. Since 1990s, research has broadened the scope of cynicism to include various targets/objects in the workplace. Two forms of cynicism are influential to the 
development of cynicism in organizations: employee cynicism and organizational change cynicism.

Employee cynicism is directed toward three specific targets in the workplace, including business organizations in general, corporate executives, and other workplace objects (Andersson \& Bateman, 1997). It is defined as "both a general and specific attitudes, characterized by frustration and disillusionment as well as negative feelings toward and distrust of a person, group, ideology, social convention, or institution" (p. 450). Andersson and Bateman explored the causes and effects of cynicism in the workplace. They found that executive compensation, poor organizational performance, and harsh and immediate layoffs are some of the major causes of employee cynicism. Employee cynicism is negatively related to intentions to perform organizational citizenship behaviors and intentions to comply with requests to engage in unethical behaviors. This study considers employee cynicism as a result of experiences in the workplace instead of a stable, innate trait. The underlying assumption of the study indicates that employee cynicism is caused by perceived unfair treatment or unmet expectations by organizational management. This assumption is consistent with Kanter and Mirvis's (1989) conceptualization of societal cynicism.

Another emerging research interest in cynicism in recent years is cynicism toward organizational change. Both scholars and practitioners are concerned with how to ensure a successful organizational change in the turbulent business environment. Widespread cynicism is believed to be one of the sources of the failure of 
organizational change. Wanous et al. (2000) argued that cynicism could become its own self-fulfilling prophecy. However, the research on cynicism toward organizational change is very limited. Further research attention is warranted.

Though limited, two studies have paved the way for further research on cynicism toward organizational change. In one of the studies, Wanous et al. (2000) examined the antecedents and consequences of cynicism about organizational change (CAOC) and developed a measurement of CAOC. The results show that there are three antecedents of CAOC: amount of change perceived by employees, leadership effectiveness, and participation in decision making. Negative affectivity, which reflects a general outlook on life, does not predict CAOC. CAOC is negatively related to the motivation to support change efforts. It can spill over to factors outside the area of organizational change and negatively influence organizational commitment and the number of labor grievances. CAOC is also found to weaken the instrumentality perception between performance and money earned. In this study, Wanous et al. (2000) conceptualized CAOC as consisting of two components: a pessimistic view about change and the blame on "those responsible." This definition is based on two theories: expectancy theory and attribution theory. Expectancy theory is pertinent because CAOC is believed to be a result of expectations regarding consequences in the organizational environment, in this case, the insufficient efforts made by those responsible. Attribution theory is used because CAOC place the blame on those responsible for their incompetence or lack of motivation, or both, for the failure of the change. Dispositional attribution (other-blame) is inherent in this definition. 
Different from the preceding research, Stanley, Meyer, and Topolnytsky (2005) studied cynicism toward a specific change (change-specific cynicism) instead of cynicism toward organizational change in general. They argued that, by introducing this concept, they avoid "the potential problems associated with overly complex constructs that vary across contexts" (p. 435). The study suggests that change-specific cynicism is distinct from other related concepts, skepticism about change, more general forms of cynicism, and trust in management. The results also show that change-specific cynicism is a predictor of intentions to resist change. As is mentioned by Ajzen and Fishbein (1980), specific attitudes can better predict individuals' behavioral intentions. Therefore, change-specific cynicism might be a better predictor of intentions to resist change than cynicism about organizational change in general.

\section{Theoretical Frameworks of Cynicism Studies}

The literature shows that cynicism research is diverse yet sparse. Researchers have attempted to explore the causes and consequences of cynicism from various theoretical lens. Abraham (2000) analyzed the five forms of cynicism and clarified their theoretical bases. She posited that societal, employee, and organizational change cynicism are attributed to psychological contract violations; occupational cynicism is caused by burnout and person-role conflict; and personality cynicism is based on innate hostility.

The most recent cynicism research, especially employee cynicism and organizational change cynicism, is mainly based on the theoretical framework of psychological contract violation. In organizational context, psychological contract 
violation is considered as one form of social exchange that develops between employers and employees (Johnson \& O’Leary-Kelly, 2003). Employees develop certain expectations of the employers and their organizations based on employers' actions and prior experiences. Cynicism is believed to come out of the disillusionment when the expectations are not fulfilled. As Kanter and Mirvis (1989) described, "unmet job expectations lead to disillusionment and then to cynicism" (p. 50). The overarching theme in Kanter and Mirvis's book is that society and organizations raise the high hopes of individuals, but fail to meet the expectations, which cause disillusionment and finally cynicism.

Andersson (1996) first proposed that psychological contract violations are the primary determinants of employee cynicism. Johnson and O’Leary-Kelly (2003) also used this theory to explain cynicism and work-related attitudes. They found that organizational cynicism mediates the relationship between psychological contract breach and some work-related attitudes, such as organizational commitment and job satisfaction. The studies seem to assume that employee cynicism is incurred because some factors in the organization fail to meet the expectations of employees. Therefore, the job of managers is to detect those factors and reduce the negative effects of cynicism.

Obviously, the above research is based on psychological research orientation. Few studies have approached cynicism from a communication perspective. However, communication plays a key role in developing positive or negative employer-employee relationship. In particular, during organizational change, the 
problems in communication processes, such as perceived quality of information and social relationships with other organizational members, might contribute a lot to employee cynicism. Two recent studies (Reichers, et al., 1997; Wanous, et al., 2000) have found that the communication variables, lack of information about change and PDM, could predict cynicism about organizational change.

The present study will use the theoretical framework of SIP to explore the communication variables in predicting employee cynicism toward organizational change. In this study, cynicism is not considered as a stable dispositional trait, nor does it solely depend upon the satisfaction of some fixed expectations. Instead, cynicism is believed to emerge out of the communication process during organizational change. Therefore, communication perspective will bring about more promising observations about the topic, employee cynicism.

\section{Resistance to Organizational Change}

Resistance to organizational change is a topic of concern for both researchers and practitioners in various disciplines, especially in the fields of management, psychology, and labor process. The review in this section outlines the development and diverse perspectives of research on resistance to change. The focus of the current study is a communication perspective.

Most research on resistance to change is concerned with the sources of resistance. Though various sources have been identified, very few studies have considered employee cynicism as a possible predictor of resistance to change. The current study will make a breakthrough by exploring the causal relationship between 
cynicism and resistance to change. The different forms and dimensions of resistance are also discussed in this section to lay the ground for the measurement development in the next chapter.

Classic Research on Resistance to Change

Resistance to organizational change has received much scholarly attention ever since Coch and French (1948) published the article, "Overcoming resistance to change." In this article, they conducted a series of experiments on workers in a pajama factory in Virginia called Harwood Manufacturing Company. They divided the workers into non-participating, participating, and participating through representation groups. The findings showed that workers who were allowed to participate in the design and development of the change of work procedures were less resistant to change than those who did not. The participation through representation group showed slower recovery to the previous production rate than the participation group. Based on the results, Coch and French concluded that managers should communicate the need for change and involve employees in the planning of organizational change.

This study has inspired abundant research on participation in decision making and resistance to change. Most of the research was conducted from a management perspective with the purpose of overcoming resistance to change. The research provided prescriptions for resistance to change and suggestions for managers and change agents (Flower, 1962; Lawrence, 1954; Zander, 1950). However, critics argue that the early research tends to blame employees for problems. The term "overcoming 
resistance to change" implies that the source of the problem lies with the employees, and managers have to come up with strategies to deal with resistance. In addition, this line of research considers resistance as natural and resistance should be expected by managers. Therefore, a self-fulfilling prophecy might emerge (Dent \& Goldberg, 1999).

Diverse Perspectives of Resistance to Change

Later research on resistance to change has been developed from different perspectives and disciplines. Lewin (1952) treated resistance as a system concept, a restraining force moving in the direction of maintaining the status quo. Thereby, resistance could exist anywhere in the system and affect both managers and employees. Recent empirical research supported the system concept of resistance. For example, Larson and Tompkins (2005) found that employee resistance could be supported, indirectly, by managers when managers showed identification with the traditional value premises of the company. Dent and Goldberg (1999) endorsed the system concept and attributed the notion of resistance to change to Kurt Lewin. They critique the change in meaning of resistance from a system concept to a psychological concept. They argued that, throughout these years, the term "resistance to change" has been crystallized into the dichotomy between management and labor, deviating from Lewin's original conceptualization of the term. However, they maintain that recent studies have begun to restore the system concept of resistance to change.

Critical theorists and labor process scholars define resistance as "a reactive process where agents embedded in power relations actively oppose initiatives by other 
agents" (Jermier, Knights, \& Nord, 1994, p. 9). In this line of research, resistance was intertwined with subjectivity. The researchers "avoid mechanistic and dualistic models of control and resistance, primarily by identifying modes of subjective consciousness that mediate interpretations of, and responses to, situations of domination" (p. 9). They also argued that the interests of managers should not be privileged over the interests of workers when studying organizational change (Piderit, 2000). As resistance is shaped by a particular context, the nature of resistance will vary across space and time.

Different from the above research, which emphasizes the situational antecedents of resistance to change, psychology scholars approach resistance from an individual difference perspective. They articulate that some individuals are more prone to resistance than others. They explored the personality characteristics that drive the resistance. For example, Oreg (2003) developed the Resistance to Change Scale to measure an individual's tendency to resist change. The scale contains four factors of personality characteristics: routine seeking, emotional reaction, short-term focus, and cognitive rigidity. The research suggests that resistance exists in the individual instead of the context or system.

However, communication scholars believe that resistance to change could be attributed to problems in the communication processes. For example, Lewis (2006) found that employees' evaluations of the quality of information are negatively related to resistance to change, and the forced nature of the change is positively related to resistance. Further, the perceived value of employee input is positively related to 
employee perceptions of the success of the change. Researchers in other disciplines also recognized the significance of communication in resistance to change. Lawrence (1954) found that employees often resist the social aspect of the change instead of the technical aspect. Social aspect refers to "the way those affected by the change think it will alter their established relationships in the organization" (p. 52). Therefore, managers should act as facilitators of communication and understanding between people of different points of view. The present study takes a communication perspective and explains the communication variables which contribute to resistance to change.

Sources of Resistance to Change

Taken as a whole, the research from different perspectives has attempted to answer one central question: why is there resistance to change in organizations? Literature has examined various sources of resistance. The frequently mentioned sources are lack of participation, inertia, adherence to well-established, ingrained schemas, misunderstanding and communication barriers, and threat to job status/security (Coch \& French, 1948; Griffin, 1993; Hutt, Walker \& Frankwick, 1995; Kreitner, 1992; Labianca, Gray, \& Brass, 2000). Classic research on resistance has elaborated much on the relationship between participation and resistance. PDM is widely accepted to be one of the predictors of resistance.

However, cynicism, as one of the sources of resistance to change, has been ignored in traditional research. Only in recent years have researchers begun to recognize cynicism as a source of resistance to change (del Val \& Fuentes, 2003; 
Maurer, 1996; Reichers et al., 1997). The most relevant research on the relationship between cynicism and resistance was conducted by Stanley et al. (2005). The results indicate that employee cynicism is a predictor of intention to resist change. In another study, Ford, Ford, and McNamara (2001) took a social constructivist perspective to explore the role of background conversations of change in resistance. They argue that resistance is a socially constructed reality which draws upon background conversations of the change rather than the current change itself. They identified three types of background conversations: complacency, resignation, and cynicism.

Complacent background is based on historical success, which makes people think nothing new or different is needed. Conversely, the resigned background is constructed from historical failure, in which people tend to think this change probably won't work either. The cynical background is similar to the resigned background in that it is also constructed from historical failure. However, in the resigned background, the failure is attributed to oneself or one's group or organization; whereas, in the cynical background, the failure is attributed to other people and groups and to some "real" or fixed external reality. In brief, one is based on self-blame, and the other, other-blame. The literature shows that cynicism works as the precursor to resistance to change.

\section{Forms of Resistance}

Resistance to change takes various forms. Jager (2001) distinguished two forms of resistance: rational and irrational. He maintained that rational resistance could be subdued by reasonable explanations for the proposed change. Rational 
resistance occurs because people do not feel involved or they do not want to learn something new. In terms of irrational resistance, no explanations or attempts at persuasion are sufficient to subdue the resistance. Obviously, Jager took a management perspective in describing the two forms of resistance.

Other than employees, decision makers or power holders might resist change as well. Agocs (1997) proposed the concept of institutionalized resistance, which refers to "the pattern of organizational behavior that decision makers in organizations employ to actively deny, reject, refuse to implement, repress or even dismantle change proposals and initiatives.” (p. 918). Accordingly, Agocs categorized institutionalized resistance into four forms: "denial of the need for change, refusal to accept responsibility for dealing with the change issue, refusal to implement change that has been agreed to, and action to dismantle change that has been initiated" (p. 920).

Although institutionalized resistance focuses on power holders or decision makers, the various forms of resistance can also be expressed through employees when they are part of the decision makers and change implementers.

\section{Dimensions of Resistance to Change}

Although classic research focused on the behavioral dimension of resistance to change, recent studies have proposed that resistance is a multidimensional concept. Piderit (2000) identified three dimensions of resistance - cognitive, emotional, and intentional — which are consistent with the tripartite view of attitudes. The cognitive dimension of resistance refers to negative thoughts about the proposed change. The emotional dimension entails such negative feelings about the change as aggression, 
frustration, and anxiety. While many studies examined the behavioral dimensions of resistance, such as undesirable behaviors (Coch \& French, 1948), Piderit (2000) emphasized the intentional dimension, a plan or resolution to take some action. She argued that the cognitive dimension reflects intentions more than past behaviors because employees facing organizational change are responding to a novel event. She also mentioned that intentions are loosely connected with the other two dimensions and thereby have been treated as a separate construct in many cases. In the current study, only the intentions of resistance to change are taken into consideration.

The present study takes a communication perspective to examine intention to resist organizational change. The communication processes, perceived quality of information and relationships with colleagues and administration, are directly associated with employee cynicism, which, in turn, lead to intention to resist change. Consistent with the classic research, PDM is also hypothesized to be negatively related to intention to resist change. The four forms of resistance prescribed by Agocs (1997) will be used as a guide to construct the scale of intention to resist change. Further, only the intentional dimension of resistance is considered, and intention to resist change is taken as a separate construct from other two dimensions.

\section{Participation in Decision Making}

Participation in decision making (PDM), as a classic research topic, has created an abundance of literature for the past half century. The expanding literature consists of theoretical conceptualizations, meta-analysis and reviews, and empirical studies. Several wide-ranging reviews have been made on this topic (Cotton, Vollrath, 
Froggatt, Lengnick-Hall, \& Jennings, 1988; Dachler \& Wilpert, 1978; Locke \& Schweiger, 1979; Miller \& Monge, 1986; Strauss, 1982). The reviews revealed some major aspects documented in the current literature, including the theoretical assumptions, definitions, forms, and mechanisms of PDM, and its relationships with other important organizational outcome variables. The following part will summarize these aspects in order to provide a solid theoretical foundation of and empirical support for the relationship between PDM and the outcome variables under the current study.

\section{Theoretical Origins and Definitions of PDM}

The voluminous literature on PDM has examined the topic from diverse perspectives and disciplines, such as psychology, sociology, and economics. However, the diversity is also accompanied by the fragmentation of the participation research. As Dachler and Wilpert (1978) noted, "participation literature includes a plethora of undefined terms and characteristically lacks explicitly stated theoretical frameworks" (p. 1). Therefore, tracing back the theoretical origins of PDM will help understand the rationales and diverse interests on PDM.

The enduring interest in PDM derives not only from its pragmatic functions on organizational outcomes but also from it ideological and moral implications. Research has found two basic rationales for PDM, one is pragmatic and the other is democratic (Locke \& Schweiger, 1979; Margulies \& Black, 1987). Democratic theory is deeply rooted in the belief that individuals have the right and potential to participate in decisions affecting their lives. As Locke and Schweiger pointed out, the idea of PDM 
comes from intellectuals rather than from workers. Participative democracy has been considered an ideal of governance in all social, political and economic organizations (Dachler \& Willpert, 1978). As a value in itself, PDM is promoted and enforced in many organizations. For the same reason, research shows a pro-PDM bias (Locke \& Schweiger, 1979). Besides the ideological connotations, many empirical studies have examined the pragmatic functions of PDM, as an instrument to achieve increased job satisfaction and productivity (Miller \& Monge, 1986).

Dachler and Willpert (1978) identified four theoretical assumptions underlying PDM: democratic theory, socialistic theory, human growth and development, and productivity and efficiency. Democratic theory maintains that the collective wisdom and intelligence of human beings can contribute to wise and effective decisions. Therefore, broad participation in decision making should be encouraged in all types of social institutions. Socialistic theory deems workers' PDM as an important means of liberating workers economically and achieving revolutionary change. Both democratic and socialistic theories focus on a macro-level and treat PDM as a societal issue.

The other two theories are developed on a micro-level and emphasize the organizational and group factors. Psychologists acknowledge the role of human growth and development in economic efficiency and productivity. They argue for developing human potentials by satisfying human beings' higher order needs, such as needs for autonomy and needs for self-actualization (Maslow, 1954). In this way, employees will be more internally motivated to increase work efficiency and 
productivity. PDM could satisfy the needs for autonomy, and thereby employees will be more responsible for and committed to the decisions they helped to make. Different from the above theories, the theoretical orientation in productivity and efficiency makes productivity and efficiency as the primary and ultimate objective. PDM is instrumental to achieving this objective. The various theoretical assumptions trace the historical development of PDM and provide rationales for participation research in diverse disciplines. The variety and complexity of participation research is also reflected in the definition of PDM.

Despite the voluminous literature, PDM lacks a consistent definition. Researchers have provided various definitions of PDM characterizing different aspects. For example, Davis (1963) defined PDM as “an individual's mental and emotional involvement in a group situation that encourages him to contribute to group goals and to share responsibility for them." (p. 57). This definition emphasized the active ego involvement in group/organizational activities. French, Israel, and As (1960) defined PDM as "a process in which two or more parties influence each other in making certain plans, policies, and decisions" (p.3). This definition is consistent with the one provided by Oxford English Dictionary, in which participation is defined as "the fact or condition of sharing in common (with others or with each other)." Similar to French et al. (1959), most recent research has defined PDM as "a process in which influence or decision making is shared between hierarchical superiors and their subordinates" (Wagner \& Gooding, 1987, p. 241; see also Locke \& Schweiger, 1979; Mitchell, 1973). The current study will adopt the latter definition. 
Types and Issues of PDM

There are different types of PDM. Locke and Schweiger (1979) identified three dimensions of participation types: forced/voluntary, formal/informal, and direct/indirect. Forced PDM is a result of contract or law between management and labor, whereas voluntary PDM occurs when employees agree to the idea of PDM initiated by management. Formal PDM entails officially recognized decision-making bodies, such as, unions and committees. Informal PDM is based on interpersonal interactions between superiors and subordinates. Direct PDM refers to the participation of each employee within an organization, whereas, in indirect PDM, not every employee has the opportunity to participate, but they can elect representatives to form committees and speak for them. Similarly, Dachler and Wilpert (1978) pointed out three forms of PDM: formal and informational, direct and indirect, and access to PDM. Access to PDM suggests how much influence individuals can exert on decision making. They considered employees' PDM as a continuum from noninvolvement to complete control over decision making. Cotton et al. (1988) posited that variations in forms of PDM would lead to differences in organizational outcomes, such as satisfaction and performance.

Employees could participate in diverse organizational issues. Locke and Schweiger (1979) summarized four broad categories of participation issues: routine personnel functions, work itself, working conditions, company polices. Researchers also acknowledged that outcomes of PDM will vary depending upon the issues of participation. 
Mechanisms and Models of PDM

The mainly positive relationships between PDM and various outcome variables pose one question: how does PDM work in these relationships?

Researchers have attempted to explain the mechanism of PDM from various perspectives. Locke and Schweiger (1979) identified two mechanisms through which PDM works. The first is a cognitive mechanism. PDM will result in improved upward communication, which, in turn, will increase information and knowledge utilized in decision making. This aspect assumes that collective decision making will lead to a better integration of knowledge than individual decision making. This assumption is consistent with the democratic theory of decision making. In addition, PDM could make employees, who are to execute the decisions, to better understand the goals, methods to accomplish the work, and reasons for the decisions (Locke \& Schweiger, 1979). In this way, PDM could improve job performance.

The second mechanism is motivational. One of the commonly discussed benefits of motivational mechanism is reduced resistance to change (Coch \& French, 1948). Being consulted on proposed change, employees will have more trust in their superiors, and thereby be less resistant to change. In addition, employees will have greater feelings of control and reduced anxiety because of PDM.

On the other hand, the motivational mechanism works through employees' greater ego involvement and more identification with their organization as a result of PDM. Under group pressure, employees are more likely to accept and support 
changes or decisions. Therefore, PDM is believed to be positively related to acceptance of and commitment to changes or decisions (Lawler \& Hackman, 1969).

Different from Locke and Schweiger (1979), Miller and Monge (1986) proposed three models of participation to explain the mechanism of PDM. The first one is a cognitive model, which is similar to the cognitive mechanism described by Locke and Schweiger (1979). That is, PDM brings about increased information and knowledge drawing from individual's expertise. The second is an affective model. This model is based on human growth and development theory. The affective model argues that PDM could satisfy individual's higher-order needs, such as autonomy, respect, and equality, which, in turn, could lead to job satisfaction. PDM does not have a direct effect on productivity but works indirectly through increased job satisfaction and motivation. The final model is a contingency model, which suggests that the effects of PDM do not hold the same across individuals and situations. This model proposes that individuals with higher needs for independence and personalities with low authoritarianism are more likely to be influenced by PDM. In addition, some decisions are more appropriate for participation than others. Finally, some employees value PDM more than others, such as those in research or service industries.

\section{PDM and outcome variables}

The two most discussed outcome variables of PDM are job satisfaction and job productivity. However, research has provided mixed results in terms of the above relationships. Based on the findings of over 50 empirical studies, Locke and Schweiger (1979) concluded that participative leadership does not have much 
advantage over directive styles in enhancing productivity, but in terms of satisfaction, results generally favor a participative style.

Ever since Coch and French (1948) identified PDM as an effective intervention strategy to reduce resistance to change, numerous studies have shown a negative relationship between PDM and resistance to change. The rationale for this relationship can be explained by the motivational or affective mechanisms mentioned above. PDM appeals to people's higher-order needs, and thereby enhancing their satisfaction with the proposed change. In addition, PDM gives employees' greater feelings of control and reduced anxiety, and thus reducing their resistance to change.

Although the causal relationship between PDM and resistance to change has been widely studied, very few studies have explored the relationship between PDM and employee cynicism toward organizational change. One recent study found that lack of PDM is one of the antecedents of cynicism about organizational change (Wanous, et al., 2000). They argue, "supervisors control the amount of employee participation, and participation tends to reduce blaming leaders because employees have more say in decisions and greater understanding of them" (p. 136-137). Previous literature shows that PDM is positively related to positive attitudes toward change, such as openness to change and acceptance of change, but negatively related to negative attitudes toward change, such as anxiety to change and resistance to change (Lines, 2004; Sagie et al., 1996; Wanberg \& Banas, 2000;). Therefore, employee cynicism toward organizational change, commonly referred to as a negative attitude, might be negatively related to PDM. 
The present study will attempt to test whether or not PDM is causally related to resistance to change and employee cynicism toward organizational change. Though strong theoretical support can be found in the causal relationship, few empirical studies have been conducted on the relationship between PDM and employee cynicism toward organizational change. This study will be an extension of current models on PDM and work-related attitudes.

Trust in Management

Various studies have agreed that trust plays an important role in the well-functioning of organizations (Dirks \& Ferrin, 2001). Organizations are composed of people who are interdependent. In a web of interdependence, people rely on others to accomplish their personal and organizational goals (Mayer, Davis, \& Schoorman, 1995). In addition, trust is necessary for effective cooperation and efficient operations within organizations (Tschannen-Moran \& Hoy, 1998). Powell (1990) vividly described the function of trust in organizations as "a remarkably efficient lubricant to economic exchange [that] reduces complex realities far more quickly and economically than prediction, authority, or bargaining" (p. 305).

Research has shown that trust has an effect on various organizational outcomes, such as job satisfaction and organizational citizenship behavior (Driscoll, 1978; Robinson, 1996). Trust in organizations entails trust in management and trust in peers. The current study intends to test whether or not trust in management can predict employee cynicism toward organizational change. This section first describes the various perspectives in conceptualizing trust and offers different definitions. Next, 
the common themes of various definitions are explained. Then, characteristics of trustees (people who are given trust) are depicted. Finally, the section details the relationship between trust in management and employee cynicism toward organizational change.

\section{Perspectives and definitions of trust}

The topic of trust has been studied at great length by scholars from various disciplines, including psychology, sociology, and economics. From different perspectives, scholars have attempted to conceptualize trust. However, no consensus on the definition of trust has been formed so far. Early researchers consider trust as a stable personality trait (Rotter, 1967). For example, Rotter (1967) defined trust as “an expectancy held by an individual or a group that the word, promise, verbal or written statement of another individual or group can be relied upon" (p. 651). This definition views trust as a general attitude, which remains stable across situations. People who have the "disposition to trust" tend to hold positive expectations of other people across various situations.

However, the dispositional perspective of trust ignores the contextual factors that enhance or inhibit the development of trust. Sociologists believe that trust should be conceived as "a property of social relationships, not of isolated individuals" (Lewis \& Weigert, 1985, p. 968). They view trust as specific to a transaction and the person with whom one is transacting. Lewis and Weigert (1985) regard trust as a multi-faceted concept comprising three dimensions: cognitive, emotional, and behavioral. The cognitive dimension indicates that trust is based on good reasons, and 
familiarity with the object of trust is the precondition for trust. The emotional dimension suggests that trust is based upon the emotional bond among people in the trusting relationship, and betrayal of trust often arouses strong negative emotions. The behavioral dimension means that "to trust is to act as if the uncertain future actions of others were indeed certain in circumstances wherein the violation of these expectations results in negative consequences for those involved" (p. 971). The trustor is willing to undertake risky courses of action based on the belief that the trustee is reliable and competent. In this line of research, repeated interactions over time between trustor and trustee are the bases for trust.

Economists perceive trust as either calculative or institutional. Calculative trust is based on a rational choice. Trust emerges when one calculates that "even on the basis of strictly utilitarian motives, it is to the other party's benefit to behave in a trustworthy manner because the costly sanctions in place for breach of trust exceed any potential benefits from opportunistic behavior" (Tschannen-Moran \& Hoy, 2000, 561). Institutional trust emphasizes the effects of organizational and institutional structures on the development of trust. Institutional trust is supported by either formal social structures, such as license, certification, and contracts, or informal social norms.

The diverse perspectives of trust give rise to a variety of definitions of trust. From the perspective of social psychology, Mayer, Davis, and Schoorman (1995) define organizational trust as "the willingness of a party to be vulnerable to the actions of another party based on the expectation that the other will perform a 
particular action important to the trustor, irrespective of the ability to monitor or control that other party" (p.712). This definition is most frequently cited in the literature of trust. Similarly, Rousseau, Sitkin, Burt \& Camerer (1998) define trust as "a psychological state comprising the intention to accept vulnerability based upon positive expectations of the intentions or behavior of another" (p. 395). Though this definition entails the components of vulnerability and positive expectations as in the first definition, it does not specify that the trustee's actions are without supervision in the trusting relationships. Bhattacharya, Devinney, and Pillutla (1998) employed a statistical and mathematical approach in an attempt to derive a rigorous definition of trust integrating various disciplinary perspectives. They proposed, "Trust is an expectancy of positive (or nonnegative) outcomes that one can receive based on the expected action of another party in an interaction characterized by uncertainty" ( $p$. 462). This definition characterizes trust as specific to an interaction, but does not highlight the essential component of vulnerability in the concept of trust. Tschannen-Moran and Hoy (1998) offer a multidimensional definition of trust, which takes into account the characteristics of trustee. They stated, “trust is one party's willingness to be vulnerable to another party based on the confidence that the latter party is (a) benevolent, (b) reliable, (c) competent, (d) honest, and (e) open" (p. 556). The current study employs the definition provided by Mayer et al. (1995), as my study adopts a social psychological view of trust and the definition captures the main features of trust in organizations. 
Common Themes of Trust

Although no consistent definition of trust exists, the various definitions reveal several common themes of trust. First, the concept of vulnerability is stated and implied in most definitions of trust (Mayer et al. 1995; Rousseau et al. 1998; Tschannen-Moran \& Hoy, 1998). Mishra (1996) posits that, in the absence of vulnerability, the concept of trust is not necessary because the outcomes do not have any consequence to trustors. In the trusting relationships, trustors have something meaningful at stake and are cognizant of the potential for betrayal and harm from the other (Kee \& Knox, 1970). Bigley and Pearce (1998) noted, "Willingness to be vulnerable or actual exposure to potential harm may subsequently follow from the trust decision" (p. 408).

Second, confidence is another essential element in the conceptualization of trust. The reason that trustors are willing to be vulnerable to the other party is because the trustors have confidence or positive expectations that the other party will perform a particular action that is beneficial. However, trust and confidence are two distinct concepts. Luhmann (1988) noted the difference between the two concepts and proposed that risk is recognized and assumed in trust, but not in confidence. Therefore, the degree of trust is perceived as the degree of confidence that one holds in the face of risk or uncertainty (Kee \& Knox, 1970).

Finally, interdependence is a necessary condition for trust. There would be no need for trust if the two parties were not interdependent. Trust is required when the interests of one party cannot be achieved without reliance upon another (Rousseau et 
al., 1998). The degree of interdependence may alter the nature of trust and the forms trust might take (Sheppard \& Sherman, 1998). For example, shallow interdependence is associated with poor coordination and calculus-based trust. Deep interdependence is associated with identification-based trust.

The above themes cutting across multiple disciplines provide the common ground to understand the concept of trust. Even though most definitions of trust share the above common features, the degree of trust varies depending on situations, especially on the characteristics of the trustee. Considerable research has been conducted on what characteristics make a person trustworthy.

\section{Characteristics of Trustee}

The earliest research on the characteristics of the trustee can be traced back to the source credibility study of Hovland, Janis, and Kelley (1953). They proposed two factors of source credibility: expertise and trustworthiness. Later research has developed a number of trustee characteristics that lead to trust. Some researchers identified as many as ten conditions of trust, such as integrity, openness, motives, and consistency of behavior, etc. (Butler, 1991). Although different characteristics are delineated in different studies, three characteristics are commonly referred to in the literature: competence, benevolence, and integrity.

\section{Competence is an important element that determines a person's}

trustworthiness. In some studies, similar constructs, such as ability or expertise, were used instead of competence. The domain of competence is usually specific, since a person who is competent in one area is not necessarily competent in other areas. 
Therefore, a person can only be trusted in the specific area that he/she is competent. In brief, competence reflects the task-specific nature of trust. Although competence serves as the essential condition for trust, without good intentions, a person will not be judged as trustworthy. For this reason, benevolence is considered as another characteristic of the trustee. It refers to the goodwill that a trustee extends to a trustor. A benevolent trustee will have a positive orientation toward the trustor, and thus show no intention or motive to harm the trustor. The third determinant of a person's trustworthiness is integrity. Mayer et al. (1995) describe integrity as "the trustor's perception that the trustee adheres to a set of principles that the trustor finds acceptable" (p. 719). Numerous research has found that integrity is an important dimension of trustworthiness (for example, Butler, 1991; Lieberman, 1981). The three characteristics of the trustee - competence, benevolence, and integrity — combine to serve as the conditions or antecedents of trust.

Trust in Management and Employee Cynicism toward Organizational Change

The above description indicates that trust is situation-specific and referent-specific. In organizational settings, trust has two types of referents: peers and management. This study focuses on trust in management. Trust in management has been found to be related to positive organizational outcomes. Recent studies have shown that trust in management is negatively related to employee cynicism toward organizational change (Albrecht, 2002; Stanley et al., 2005).

Stanley et al. (2005) compared and distinguished the two concepts, trust and cynicism. They maintain that the two concepts are related, as they share the same 
antecedents, competence, benevolence, and integrity. However, they also argued that the two concepts are distinct, and thereby are not redundant with each other. Their research findings show that trust in management and change-specific cynicism are indeed distinguishable from each other, but they also found that management cynicism and trust in management are highly correlated with each other. They reason that cynicism might be a sufficient but not necessary condition for mistrust. One of the limitations of this research is that it does not lead to any conclusions about the causal connections between trust and cynicism.

Albrecht's (2002) study investigated the relationship between two antecedents of trust: trust in senior management and cynicism toward organizational change. The results show that perceptions of integrity directly influence trust in senior management and cynicism toward change. Trust in senior management also has a direct influence on cynicism toward change. However, perceptions of competence do not directly influence trust in senior management and cynicism toward change. This study established the negative relationship between trust in senior management and cynicism toward organizational change in general.

Although the literature on the relationship between trust and cynicism is limited, the existing research has found that the two concepts are distinct and have some negative relationship. The current study will test whether or not trust in management predicts change-specific cynicism, which has not yet been fully examined by previous studies. 
Study Rationale and Chapter Summary

The objective of the current study is to test a communication model of employee cynicism toward a specific organizational change (change-specific cynicism). This chapter reviewed the literature pertaining to the proposed model (see page 21). In this model, the four exogenous variables - perceived quality of information, cynicism of colleagues, trust in management, and PDM—are hypothesized to predict change-specific cynicism, which, in turn, lead to intention to resist change. PDM is also hypothesized to directly predict intention to resist change. The straight arrows in the model show the direction of the causal relationships between the variables.

The theoretical and empirical studies in the previous literature show consistent support for the relationships among the variables in the model. Based on the theoretical framework of SIP, work attitudes derive from the relevant informational and relational context. Therefore, change-specific cynicism, as a type of work attitudes, is also influenced by the variables in the social context. Specifically, the variable, perceived quality of information, reflects the informational context, whereas, the two variables, cynicism of colleagues and trust in management, constitute the relational context.

The literature has demonstrated that perceived low quality of information can incur a high level of uncertainty and anxiety about change (Miller \& Monge, 1985), which can lead to change-specific cynicism. The cynicism of colleagues might cause change-specific cynicism because individual attitudes are contagious within informal 
social networks. This is particularly true in high education settings, where communication is mainly based on informal professional networks. That being said, the relationship with the management, in particular, trust in management, also plays a substantial role in change-specific cynicism. Literature has supported the causal relationship between trust in management and change-specific cynicism (Albrecht, 2002; Stanley et al., 2005).

The three exogenous variables - perceived quality of information, cynicism of colleagues, and trust in management — directly lead to change-specific cynicism, and indirectly influence intention to resist change through the mediating role of change-specific cynicism. SIP is assumed to explain work-related attitudes instead of behavioral intentions. Therefore, the three variables reflecting the social context are not hypothesized to directly predict intention to resist change. The two endogenous variables, change-specific cynicism and intention to resist change, are hypothesized to be causally related because research found that specific attitudes are good predictors of intentions to perform an act (Ajzen \& Fishbein, 1980).

Another exogenous variable in this model, PDM, is hypothesized to directly predict both change-specific cynicism and intention to resist change based on the literature (Coch \& French, 1948; Wanous et al., 2000). The mechanism through which PDM operates on the two endogenous variables is both cognitive and affective (Locke \& Schweiger, 1979). Cognitively, PDM could enhance employees' better understanding of the reasons for change and facilitate change acceptance. Affectively, 
PDM gives employees greater feelings of control, reduced anxiety and more trust on their superiors, which could result in less cynicism and less intention to resist change.

Besides providing support for the proposed model, the literature review also highlights the communication perspective of each variable. It provides a broad and solid background for all the variables in the current study, but generally in isolation from one another in the literature. Further, it conceptualizes most of the variables, such as employee cynicism, intention to resist change, and trust in management, as socially constructed instead of innate personality traits. Hence, the variables and the whole model are based on the communication processes.

The literature also reveals that change-specific cynicism has not been fully explored as a central concept in a model. Previous studies only examined the relationships between two or three variables in the model in separate studies. Very limited research has developed an integrative model of employee cynicism toward organizational change from a communication perspective. The current study will contribute to the literature by building such a model using the theoretical framework of SIP.

Based on the literature review, two research questions are proposed for the current study.

(1) Is this model, which describes the causal effects among the six variables_-"perceived quality of information," "cynicism of colleagues," "trust in management," "PDM," "change-specific cynicism," and "intention to resist 
change" - consistent with the observed correlations among the variables? In simple words, does the model fit the data?

(2) If this model is consistent, what are the estimated direct, indirect, and total causal effects of the exogenous variables on the two endogenous variables, "change-specific cynicism," and "intention to resist change?" 


\section{Chapter Three: Methodology}

\section{Overview}

This study was designed to test a predictive model of employee cynicism toward organizational change in a field setting. A cross-sectional survey was administered to all full time tenure track faculty in a large mid-western university in the United States. This university has been undergoing a comprehensive strategic planning process since November 2004. The new strategic plan, labeled as New Vision (pseudo-name), entailed the goals for national prominence, diversity, partnership, and resource reallocation. The research was conducted during the first year of the implementation of the new strategic plan.

This chapter proposed the methodology for the current study. First, the population and sample size were specified for the study. Second, the method and procedures for conducting the study were described, followed by the assumptions for path analysis. Next, the instruments used in the study were explained. Finally, the reliability and validity of the scales were discussed.

\section{Population and Sample Size}

All full time tenure track faculty in this university constituted the targeted population of the present study. As of the academic year of 2006-2007, the university had a total of 949 full time tenure track faculty members in its eight colleges. The largest college had 339 faculty members, and the smallest had 43 faculty members. Faulty in the regional campuses were also included in the population. The sample size of the study was determined according to the recommendations of multiple regression 
formula, since path analysis was considered as an extension of multiple regression. Research indicated that several factors should be considered in determining the sample size: the level of significance $\alpha$, desired power, effect size, and the number of predictors (Stevens, 2002). The $\alpha$ level, or the probability of making type I error, was set at the conventional .05 . According to the $4: 1$ ratio of type II to type I error recommended in behavioral sciences, the type II error would be $.20\left(4^{*} .05\right)$, and the power would be $0.8\left(1-4^{*} .05\right)$. The study assumed moderate tolerance of shrinkage $(\mathrm{C}=.05)$ and effect size $\rho^{2}$ at .25 . The table of sample size recommendations for multiple regression provided by Park and Dudycha (1974) suggests a sample size of 93 with the above parameters. Therefore, the minimum sample size for the study was set at 93. Stevens (2002) also recommended a general rule of at least 15 participants per predictor in multiple regression analysis. With four predictors, the minimum sample size would be 60 .

\section{Method and Procedures}

All full time tenure track faculty members of the eight colleges were invited to participate in the survey. The office of legal affairs was contacted and a list of the faculty's names, addresses, and emails was obtained. A cross-sectional web-based survey was administered to the 949 faculty members in the list. The data collection began in mid-July and ended in mid-September 2007. The first round of survey was sent to all full time tenure track members through emails which contained a hyperlink to the survey. Follow-up email reminders were sent every two weeks until mid-September. 
The survey contained three parts. In the first part, multiple instruments were used to measure the variables except for cynicism of colleagues in the proposed model. In the second part, participants were asked to identify three to five colleagues on campus, whom they communicated with about the change and/or had some knowledge about their attitudes. The last part of the survey asked about the participants' demographic information, such as tenure, gender, age, job ranks and departmental affiliation.

\section{Sample Demographics}

A total of 186 respondents completed the survey, which consisted of $19.6 \%$ of the population. Of the respondents, male faculty members accounted for $62.37 \%$ $(\mathrm{N}=116)$ of the sample and female faculty members accounted for $37.84 \%(\mathrm{~N}=70)$. The age of the respondents ranged from 25 to above 65 , and the age group of 46-55 accounted for the largest proportion of the sample (34.41\%). The respondents were comprised of 40 professors (21.51\%), 82 associate professors (44.09\%), and 64 assistant professors (34.41\%). At the time of this research, $57.3 \%$ of the respondents had worked at the university for less than 10 years, and $26.48 \%$ of the respondents worked between 11 to 20 years.

Demographic information obtained from the office of institutional research indicated that $63.54 \%$ of the full time tenure track faculty members were male and $36.46 \%$ were female. The average age of the population was 48 . With regard to job ranks, $25.61 \%$ of the population were professors, $38.88 \%$ were associate professors, and $35.19 \%$ were assistant professors. The average tenure was 11 years. 
In survey studies, there exists the concern about nonresponse bias. In other words, the respondents might not be representative of the research population. Although nonresponse cannot be avoided, the above demographic information shows that the demographics of the respondents were very close to those of the population in terms of gender, age, job ranks, and tenure.

In addition, crosstabulations were conducted to examine the differences in gender and job ranks between participants and non-participants. The Pearson Chi-Square indicated that there were no significant differences in gender $\chi^{2}(1, N=186)$ $=.138, \mathrm{p}>.05$, or job ranks, $\chi^{2}(2, \mathrm{~N}=186)=3.161, \mathrm{p}>.05$, between participants and non-participants.

Therefore, the participants of the survey were the appropriate representatives of the full time tenure track faculty in terms of gender, age, and job ranks. Nonresponse bias was not a problem in this study. The comparison of the demographics between the participants and nonparticipants is described in Table 3-1.

Table 3-1

Comparison of Sample Size Between Participants and Non-Participants

\begin{tabular}{|c|c|c|c|c|c|}
\hline & \multicolumn{2}{|c|}{ Gender } & \multicolumn{3}{|c|}{ Job Ranks } \\
\hline & Male & Female & Professor & Associate & Assistant \\
\hline & & & & Professor & Professor \\
\hline Participants & 116 & 70 & 40 & 82 & 64 \\
\hline Nonparticipants & 487 & 276 & 203 & 287 & 270 \\
\hline
\end{tabular}




\section{Data Screening}

The data were screened for missing values and outliers. No missing values were identified in the data as the online survey asked respondents to answer all required questions before submitting the questionnaire. Regression analysis is sensitive to outliers, which could adversely affect the interpretation of results (Stevens,1992). Outliers are cases with unusual or extreme values, which could distort the results of a statistical test. This study checked multivariate outliers which are cases with unusual combination of values on two or more variables. Three criteria for checking outliers in regression analysis were applied: Studentized Deleted Residual (SDR), Mahalanobis Distance, and Cook's Distance. First, the closer the SDR is to zero, the better prediction the regression fitting line can achieve. Any values which are more than 3 should be checked for outliers. Second, Mahalanobis Distance procedure was run to look for cases which exceed the chi-square criteria. Finally, outliers were also identified by Cook's Distance. Values which are greater than 1 would be considered as outliers. Two regression analyses were run in order to identify the outliers. In the first analysis, change-specific cynicism was the dependent variable, perceived quality of information, colleague cynicism, trust in administration, and PDM were the independent variables. In the second analysis, intention to resist change was the dependent variable, change-specific cynicism and PDM were the independent variables. The first analysis identified two outliers: case 5 and case 183 . The Mahalanobis Distance of case 5 exceeded 20.515, which was the critical value of chi-square at $\mathrm{p}<.001$ with degrees of freedom equal to five. Case 183 was considered 
as an outlier because its SDR was greater than 3. By running the second analysis, case 42 and case 75 were identified as outliers because their SDRs were greater than 3 . The Cook's Distance of all case values was less than 1 in both regression analyses. Based on the above information, cases 5,42, 75, and 183 were considered to be outliers and so were deleted from further analysis. The final data set contained 182 cases.

\section{Assumptions}

This study used path analysis to test the proposed model. There are several assumptions in path analysis. Meeting these assumptions is necessary in order to achieve the best estimations. Since path analysis is basically an extension of multiple regression, the assumptions associated with multiple regression are also applicable in path analysis.

In this section, three assumptions associated with multiple regression were discussed in detail: linearity, normality, and homoscedasticity. The assumption of linearity entails three specific requirements: (1) the relationships between exogenous and endogenous variables are linear; (2) the observations of endogenous variables are independent; (3) the errors are not correlated with the exogenous variables (Mertler and Vannatta, 2001). Multivariate normality refers to "the extent to which all observations in the sample for all combinations of variables are distributed normally" (p. 30). Homoscedasticity requires that the variance of the residuals across all values of the exogenous variables is constant. 
Linearity was assessed by examining the bivariate scatterplots of all variables. The bivariate scatterplots displayed elliptical shapes, which indicated multivariate linearity as well as multivariate normality. Therefore, the assumption of linearity was fulfilled.

A necessary, but not sufficient, condition of multivariate normality is univariate normality (Stevens, 2002). Univariate normality means that the frequency distribution of each variable is normally distributed. Univariate normality was assessed through examining the values of skewness, kurtosis, and Kolmogorov-Smirnov statistics of all variables in the model and by exploring the Q-Q normality plots. The values of skewness and kurtosis range from -1 to +1 . A value closer to zero indicates a more normal distribution. The skewness and kurtosis values of most of the variables were close to zero. The Q-Q plots showed that the plots all fell close to a straight line, which suggests normal distributions of all the variables. Kolmogorov-Smirnov statistics for all the six variables were significant at the conventional alpha level of .05 , but not significant at the more stringent alpha level of .01, except for the two variables of perceived quality of information and colleague cynicism. Meyers et al. (2006) suggest that the ideal statistical significance with Kolmogorov-Smirnov statistics should be set at a stringent alpha level of .001 $(\mathrm{p}<.001)$. The Kolmogorov-Smirnov statistics indicated that the distributions of most of the variables were fairly normal. In addition, the values of skewness and kurtosis, and the Q-Q plots all suggested that the assumption of univariate normality was 
fulfilled. The descriptive statistics of the six variables in the model were listed in

Table 3-2.

Table 3-2

Descriptive Statistics of the Six Variables

\begin{tabular}{lcccc}
\hline Variables & Skewness & Kurtosis & Mean & SD \\
\hline Perceived Quality of & -.167 & .062 & 17.72 & 5.46 \\
information & & & & \\
Colleague cynicism & .053 & -.194 & 10.16 & 2.62 \\
Trust in & .385 & -.379 & 12.09 & 4.57 \\
administration & & & & \\
PDM & .396 & -.034 & 25.84 & 6.42 \\
Change-specific & .096 & -.738 & 36.66 & 12.16 \\
cynicism & & & & \\
Intention to resist & .243 & & & \\
change & & & & \\
\hline
\end{tabular}

Note. SD means standard deviation.

Finally, homoscedasticity was evaluated by observing the residuals plots. The residual plots showed that all the points clustered along the horizontal line of zero in an elliptical shape. This was an indication that the variance of the residuals was constant. Therefore, the assumption of homoscedasticity was met. The residual plots further suggested that the assumptions of multivariate normality and linearity were 
fulfilled as all the points were evenly distributed above and below the horizontal line of zero.

Besides the above assumptions, path analysis also requires that the predictor variables are not highly correlated with each other. Two statistics could be used to assess multicollinearity: tolerance and variance inflation factor (VIF). The values of tolerance range from 0 to 1 . If the tolerance value is less than 0.1 , multicollinearity is a problem. In the two regression analyses in this study, the values of tolerance for all predictor variables were greater than 0.1 . The criterion of satisfactory VIF is 10 . Multicollinearity is a concern if VIF is greater than 10 . The values of VIF in this study were smaller than 10 . The two statistics indicated that multicollinearity was not a problem in this study.

In addition, path analysis has to meet the following assumptions with regard to correct model specification:

(1) The model must accurately reflect the actual causal sequence.

(2) The structural equation for each endogenous variable includes all variables that are direct causes of that particular endogenous variable.

(3) There is a one-way causal flow in the model.

(4) The relationships among variables are assumed to be linear, additive, and causal in nature; any curvilinear relations, etc. are to be excluded.

(5) All exogenous variables are measured without error. (Mertler \& Vannatta, 2001, p.205) 
Assumptions \#1 through \#3 were met based on the model specification illustrated in the previous two chapters. The model specification has been supported by previous theories and literature. Assumption \#4 deals with the linearity of variables and has been fulfilled as illustrated above. Assumption \#5 is an issue of research design, which will be mentioned in the next section of reliability.

All the above suggests that the assumptions for path analysis were fulfilled in the study. Therefore, the results of the study are trustworthy and unbiased. As researchers have indicated, testing the assumptions is largely an issue of research design and data collection as well as statistical procedures (Mertler \& Vannatta, 2001). The fulfillment of assumptions all depends on researchers' careful research design, sound theoretical development, and prior knowledge. The following section will discuss some research design issues, measurement, reliability and validity.

\section{Measurement}

Network Measure. Following the example of Fulk, Schmitz, and Ryu (1995), this study employed ego-centered networks to measure the influence of proximate others on a focal individual. Ego-centered network is defined as "the subset of the overall network that exists among the partners in an individual's network" (Monge \& Contractor, 2003, p. 39). Morrison (2002) posited that ego-centered networks do not provide an overall picture of the social structure within an organization, but they are useful to understand how an individual's unique web of contacts relates to variables, such as perceptions and attitudes, at the individual level of analysis. Therefore, using 
ego-centric networks is appropriate for a study examining the influence of proximate others on an individual's attitude.

Similar to Fulk et al. (1995), this study asked respondents to report their assessments of their colleagues' perceptions of the organizational change. Although Rice and Aydin (1991) argued that respondents' estimates of others' attitudes often do not reflect others' actual attitudes, it is the respondents' perceptions of others' attitudes instead of others' actual attitudes that influence the respondents' own attitudes most. Specifically, the cynicism of colleagues score corresponding to an individual was obtained by computing the numerical average of the perceived cynicism scores across the three to five colleagues referred to by the individual. The wording of the first half of the measure was modeled after Wolski (2003). Three items were drawn from the change-specific cynicism scale to measure the respondents' estimates of their colleagues' cynicism toward the change. These three items were selected because they reflected the more communicative dimension of cynicism, which can be easily observed by other people. The measure was described as follows:

Please take a moment and think about three to five colleagues of yours with whom you have (1) had discussions on the topic of New Vision and/or (2) some knowledge about his/her attitude toward New Vision.

For each person you had in mind, please indicate your estimate of his/her attitude toward New Vision on the 5-point scale by responding to the following statements:

1. He/she questions the administration's motives for this change. 
2. He/she criticizes this change with others.

3. He/she mocks New Vision.

Change-Specific Cynicism. Change-specific cynicism was measured by using a scale developed by the researcher based on the definition provided in the first chapter (See Apendix). The scale was adapted from three different cynicism scales:

Change-Specific Cynicism Scale (Stanley et al., 2005), Cynicism about Organizational Change (CAOC) Scale (Wanous et al., 2000), and Organizational Cynicism Scale (Brandes, Dharwadkar, \& Dean., 1999). According to the definition in the first chapter, change-specific cynicism entailed three dimensions: cognitive, emotional, and behavioral. The cognitive dimension refers to a disbelief of management's stated or implied motives for the change. Therefore, this study drew from the 8-item Change-Specific Cynicism scale by Stanley et al. (2005), which measured employee (dis)beliefs of management's motives for a specific change. A sample item was, "I question management's motives for this change." The reliability of the scale reported by Stanley et al. (2005) was quite satisfactory (Cronbach Alpha $=.94)$. Six items were modified to measure the cognitive dimension of change-specific cynicism in this study. To adapt to the higher education context, the words, "management" were replaced by "the administration." Item 1 and 5 were excluded from the scale because the content of the two items was redundant with other items. To ensure the succinctness of the scale, item 1 and 5 were deleted.

The emotional dimension of change-specific cynicism in my definition refers to a feeling of pessimism and frustration about the change. The items reflecting this 
dimension drew from two existing scales. The first one was CAOC scale, which measured employee cynicism about organizational change in general. It contained two factors, pessimism and dispositional attribution. A sample item was, "Most of the programs that are supposed to solve problems around here will not do much good." The reported Cronbach Alpha for this scale was .86. Only the first factor was included in the scale, as it was relevant to my definition. Two out of the four items in measuring pessimism were selected and modified to reflect employee cynicism toward a specific change instead of organizational change in general. For example, the above sample item was changed to, "Most of the change initiatives in the past did not do much good, and the new strategic change is no difference." Items 2 and 4 were excluded from the scale because they measured organizational change in general and the wording was not applicable in the current study.

The other two items (items 9 and 10) reflecting the emotional dimension of change-specific cynicism derived from Organizational Cynicism Scale, which was developed based on the definition provided by Dean et al. (1998). It measured three dimensions of organizational cynicism, beliefs, affect, and behavior. A sample item was, "How often do you experience tension when you think about Midwest Manufacturing?" The reported alpha of the scale was .87. As the target of cynicism in this scale was an organization, I adapted the scale to assess cynicism toward a specific organizational change. Specifically, the words, "Midwest Manufacturing" were replaced by "New Vision." Further, only the items measuring the affect and behavior dimensions of cynicism were retained, as the cognitive dimension has been captured 
by change-specific cynicism scale. Two out of four items reflecting the emotional dimension were selected to ensure succinctness of the scale because the meanings of the four items were overlapping. Three out of five items reflecting the behavioral dimension were selected in my scale because the other two items were not applicable in the current study. Based on the above three existing scales, the new scale included 13 items, which were assessed with a 5-point Likert-type format ranging from strongly disagree (1) to strongly agree (5).

Perceived Quality of Information. Perceived quality of information about the change was assessed based on the quality of information scale developed by Miller et al. (1994). This scale combined two scales developed by Miller and Monge (1985): previous information and information helpfulness. Miller et al. (1994) found that the two scales measured a single construct because the six items were internally consistent with an alpha of .86. The scale comprised several dimensions of information quality, including timeliness, usefulness, appropriateness, adequacy, and favorableness. The scale has been widely used by other researchers and has shown satisfactory reliabilities. For example, Wanberg and Banas (2000) adapted the scale to measure information about organizational change and reported a reliability of .87 . Paterson and Cary (2002) adapted the scale and another scale by Smeltzer (1991), reporting a reliability of .92 . I adapted Miller et al.'s scale to the current study. Specifically, "the implementation of work teams" was changed to "the change." The participants were asked to assess the perceived quality of information about the 
change from the university using a 5-point Likert scale ranging from strongly disagree (1) to strongly agree (5).

Trust in Management. Stanley et al. (2005) developed a scale on trust in management based on the definition by Mayer et al. (1995). The scale contained five items which measured willingness of employees to be vulnerable to decisions of management. A sample item was "If I was given a choice, I would not allow management to make decisions concerning employee well-being." Stanley et al. reported a Cronbach Alpha of .85 in their study. I used this scale to assess faculty trust in the administration. The word "management" was replaced by "the administration" in the new scale. Again, a 5-point Likert scale was used with strongly disagree and strongly agree as the endpoints.

PDM. PDM was measured by a nine-item scale. The new scale was adapted from four existing scales: Participation in Decision Making Scale (Bordia et al., 2004), Value for Employee Input (Lewis, 2006), Participation in Decision Making Scale (Miller et al., 1990), and Willingness to Participate (Msweli-Mbanga \& Potwana, 2006). The items in the new scale reflected three facets of PDM: Willingness to participate in change decisions, opportunities to participate in change decisions, and influence over change decisions. These three factors were integral to the measurement of PDM.

First, willingness to participate was measured by three items developed by Msweli-Mbanga and Potwana (2006). The original scale contained five items, and the 
reported Cronbach Alpha was .70. Only the first three items were retained as they were applicable to the current study.

Second, opportunity to participate was measured by items drawn from the Participation in Decision Making Scale (Bordia et al., 2004) and the Value for Employee Input Scale (Lewis, 2006). The scale developed by Bordia et al. contained four items, with an alpha of .94. A sample item was "I actively participate in decision-making regarding things that affect me at work." Three items were retained from this scale. Two of the items measured opportunities to participate, and one item measured influence over change decisions. Only one item was drawn from the Value for Employee Input Scale, as the wording of this item reflected clearly and explicitly the factor of opportunities to participate in change decisions. The item was, "I had many opportunities to express my opinions about this to the decision makers."

Finally, influence over change decisions was measured by the PDM scale developed by Vroom (1960) and revised by Miller et al. (1990). This scale contained three items, which measured the extent to which employees perceive they influence the decision making process. The reported Cronbach alpha of the scale was .78, and two of the items were included in the new scale. Another item was dropped because it was redundant with the other items.

I modified some of the items in the four scales and designed a new scale relevant to the present study. The new scale included 9 items drawn from the above four existing scales, and it contained three factors, willingness to participate, opportunities for PDM, and employees' influence over the change decisions. Items 25 , 
26, and 27 measured willingness to participate; Items 28, 29, and 30 measured opportunities for PDM; Items 31, 32, and 33 measured employees' influence over change decisions (see Appendix).

Intention to Resist Change. An 8-item scale was written for this particular study to measure faculty's intention to resist change. Three of the items were adapted from the Resistance to Change Inventory by Clarke (1996). The rest of the items were designed for this study based on the three forms of resistance proposed by Agocs (1997): denial, refusal, and repression. To be specific, he argued that people might deny the need for change, refuse to accept the responsibility for dealing with the change issue, refuse to implement change, and take actions to dismantle the change that has been initiated. A sample example is, "I refuse to perform the tasks required of me by the change." The scale was sent to faculty expert to check for clarity and content. Principle components analysis was run to explore the factor structure of the scale.

\section{Reliability and Validity}

DeVellis (2003) defined reliability as "the proportion of variance attributable to the true score of the latent variable" (p.27). There are several ways to assess reliability of a study, including internal consistency reliability, also known as Cronbach's $\alpha$; alternative forms reliability, test-retest reliability, and split-half reliability etc. In this study, internal consistency reliability was used to assess the reliability of the scales. Reliability tests were run by using SPSS 15.0 for all scales in the study. Corrected item-total correlation, $\alpha$ if item deleted, and scale reliability are 
reported in Appendix C. Corrected item-total correlation reflects how well each item is correlated with the total score. Higher correlations indicate that the items measure the same thing. $\alpha$ if item deleted reveals what would happen to a statistics if the item were deleted from the scale. Therefore, an $\alpha$ statistic lower than the scale reliability is preferred. As a general rule of thumb, a scale with Cronbach's $\alpha$ greater than .70 is considered as a reliable scale. All scales used in the study have satisfactory internal consistency reliability. The Cronbach's $\alpha$ for the six scales based on the empirical data in this study were listed as follows: perceived quality of information scale was .929, cynicism of colleagues was .915 , trust in management scale was .902, PDM scale was .844 , change-specific cynicism was .952 , intention to resist change was .840 . The above reliability statistics showed that the scales were quite reliable.

While reliability emphasizes the consistency and accuracy of scales, validity concerns whether the variable is the underlying cause of item covariation (Devellis, 2003). Validity is inferred from the manner in which a scale was constructed, its ability to predict specific events, or its relationship to measures of other constructs. This concept is important because it tells us if the scale really taps the latent variable that we want to test. Content validity was examined in this study by sending the scales to a group of professors and asking them to check for clarity and content. Based on the feedback, revisions were made on the above scales.

\section{Exploratory Factor Analysis}

In order to test the underlying factor structure of the newly developed scales in the study, principle component analysis with varimax rotation was conducted by using 
SPSS 15.0. Three of the scales were tested: change-specific cynicism scale, PDM scale, and intention to resist change scale. First, KMO and Bartlett's test was run to see if the data were suitable for principle component analysis. The KMO measure of sampling adequacy was $.935, .861$, and .857 for the three scales respectively, greater than the criterion value of .60. The Bartlett's test of sphericity was significant $(p<.001)$ for all three scales, indicating sufficient correlation between the variables to proceed with the analysis.

Next, four criteria were used to determine the appropriate number of components to retain: eigenvalue, variance, scree plot, and residuals. By applying the Kaiser-Guttman retention criterion of eigenvalues greater than 1.0, a two-component solution provided the clearest extraction for the change-specific cynicism scale. The two components accounted for $72.76 \%$ of the total variance. The scree plot showed that the eigenvalues after three components leveled off. Evaluation of residuals indicated that the residuals exceeding the .05 criterion reduced from $31(39 \%)$ to 15 (19\%) after including the third component. Therefore, three components were included to improve the model fit. Component 1 included 6 items which described the cognitive aspect of cynicism. After rotation, this component accounted for $35.19 \%$ of the variance. Component 2 included 5 items which described the behavioral aspect of cynicism and the frustrated feelings. Component 2 accounted for $29.17 \%$ of the variance. Component 3 included 2 items which reflect pessimism about change. This component accounted for $15.12 \%$ of the variance. The component structure basically reflected the three dimensions of change-specific cynicism. 
Two components were included for the PDM scale based on the eigenvalue criterion. The two components accounted for $68.70 \%$ of the total variance. The scree plot showed that the eigenvalues after the three components leveled off. Although the scree plot suggested the inclusion of the third component, evaluation of residuals indicated that any model improvement would be minimal. The residuals exceeding the .05 criterion changed from 12 to 13 after including the third component. Therefore, a two-component solution provided the clearest extraction for the PDM scale. Component 1 included 6 items which describe influence over change and opportunities to participate in change. This component accounted for $47.19 \%$ of the total variance after rotation. Component 2 included 3 items which describe willingness to participate in change. This component accounted for $21.51 \%$ of the total variance. The component structure suggested that the two aspects of influence over change and opportunities to participate should be combined.

Two components were included for the intention to resist change scale based on the eigenvalue criterion. The two components accounted for $63.21 \%$ of the total variance. The scree plot showed that the eigenvalues after three components dropped off. However, evaluation of residuals indicated that the model improvement would be minimal after the inclusion of the third component. The residuals exceeding the .05 criterion increased from 17 to 18 . Therefore, a two-component solution provided the clearest extraction for the intention to resist change scale. Component 1 included 6 items which describe intention to resist change actively, for example, "to form coalitions to repress change." This component accounted for $42.57 \%$ of the total 
variance after rotation. Component 2 included 2 items which described the intention to resist change passively, for example, "avoid attending meetings." This component accounted for $20.64 \%$ of the total variance. The component structure was not consistent with the original theoretical assumption of this concept. The factor loadings of the items in the three scales are presented in Appendix D.

\section{Data Analysis Procedure}

Path analysis technique was used in this study to test the two research questions for several reasons. First, path analysis allows researchers to draw causal inferences between variables. Meyers, Gamst, and Guarino (2006) posited, "Path analysis was developed to assess the direct and indirect effects of some variables that were theorized to be causes of other variables" (p.585). Second, path analysis can be used to test the overall fit of the model to the data. If the hypothesized model and the data are consistent, the model is supported. If serious inconsistencies exist between the model and the observed data, the model will be revised based on the empirical data.

In order to test the overall model fit, AMOS 7.0 was used to analyze the data. AMOS has many advantages over SPSS in analyzing a path model. AMOS typically uses maximum likelihood to calculate path coefficients, whereas SPSS uses a multiple regression approach. The multiple regression approach requires separate analysis for each endogenous variable and uses hand calculation to estimate reproduced path coefficients. Maximum likelihood estimates all the path coefficients simultaneously through AMOS program. Therefore, maximum likelihood approach is preferred over 
multiple regression approach in path analysis, though the two approaches generally provide similar results.

\section{Chapter Summary}

This chapter outlined the research design and method for conducting data analysis. Preliminary data analysis set the necessary condition for analyzing the results presented in the next chapter. Specifically, sample demographics demonstrated that the respondents were representative of the population, which enhanced the validity of this study. Next, the assumptions of path analysis were tested and found to be fulfilled in the data, which ensured the accuracy of estimation. Finally, the instruments used in the study were described and their reliability and validity were proved to be satisfactory. 


\title{
Chapter Four: Results
}

\author{
Introduction
}

The current study aimed at building a communication model of employee cynicism toward organizational change. In this model, four exogenous variables — perceived quality of information, cynicism of colleagues, trust in administration, and PDM — were hypothesized to predict change-specific cynicism of employees, which, in turn, could directly cause intention to resist change. Besides the indirect causal effect, lack of PDM was also believed to have a direct causal effect on intention to resist change. This chapter tested the proposed model and presented the results of the research analysis.

To achieve the goal of the study, two research questions were asked at the beginning of the research proposal and answered through the data analysis in this chapter. The two research questions are restated as follows:

Is the proposed model, which describes the causal effect among the six variables, consistent with the observed correlations among the variables? Or, does the model fit the empirical data?

(2) If this model is consistent, what are the estimated direct, indirect, and total causal effects among the variables? If not, the model will be revised.

\section{The Original Model Fit}

Before the analysis was conducted, a necessary condition was that the model must have a positive value for its degree of freedom. The degree of freedom was 
calculated by subtracting the number of estimated parameters from the number of known elements. In this model, there are 21 estimated parameters and 18 known elements, resulting in 3 (21-18) degrees of freedom.

To answer the first research question, the following indexes were applied to assess the model fit results: the chi-square test, the comparative fit index (CFI), the normed fit index (NFI), and the root mean square error of approximation (RMSEA). The chi-square statistic tests the difference between predicted and observed correlations. A non-significant chi-square indicates consistency between predicted and observed correlations and a good model fit. CFI and NFI indexes assess "the fit of the proposed model relative to the independence model, which assumes that there are no relationships in the data" (Meyers, Gamst, \& Guarino, 2006, p. 632-633). The criterion of acceptable value is .95 . The RMSEA is "the average of the residuals between the observed correlation from the sample and the expected model estimated from the population" (p. 633). A value less than .08 is deemed as a good fit. In this study, the chi-square test was non-significant, $\chi^{2}(18, \mathrm{~N}=182)=4.05$, $\mathrm{p}>.05$, indicating a good match between the proposed model and the observed data. The CFI and NFI indexes were .999 and .995 respectively, exceeding the .95 criterion. The RMSEA value was .044 , less than the .08 criterion. All three indexes suggested a good fit of the model. The model fit indexes are listed in Table 4-1. 
Table 4-1

Proposed Model Fit Summary

CMIN

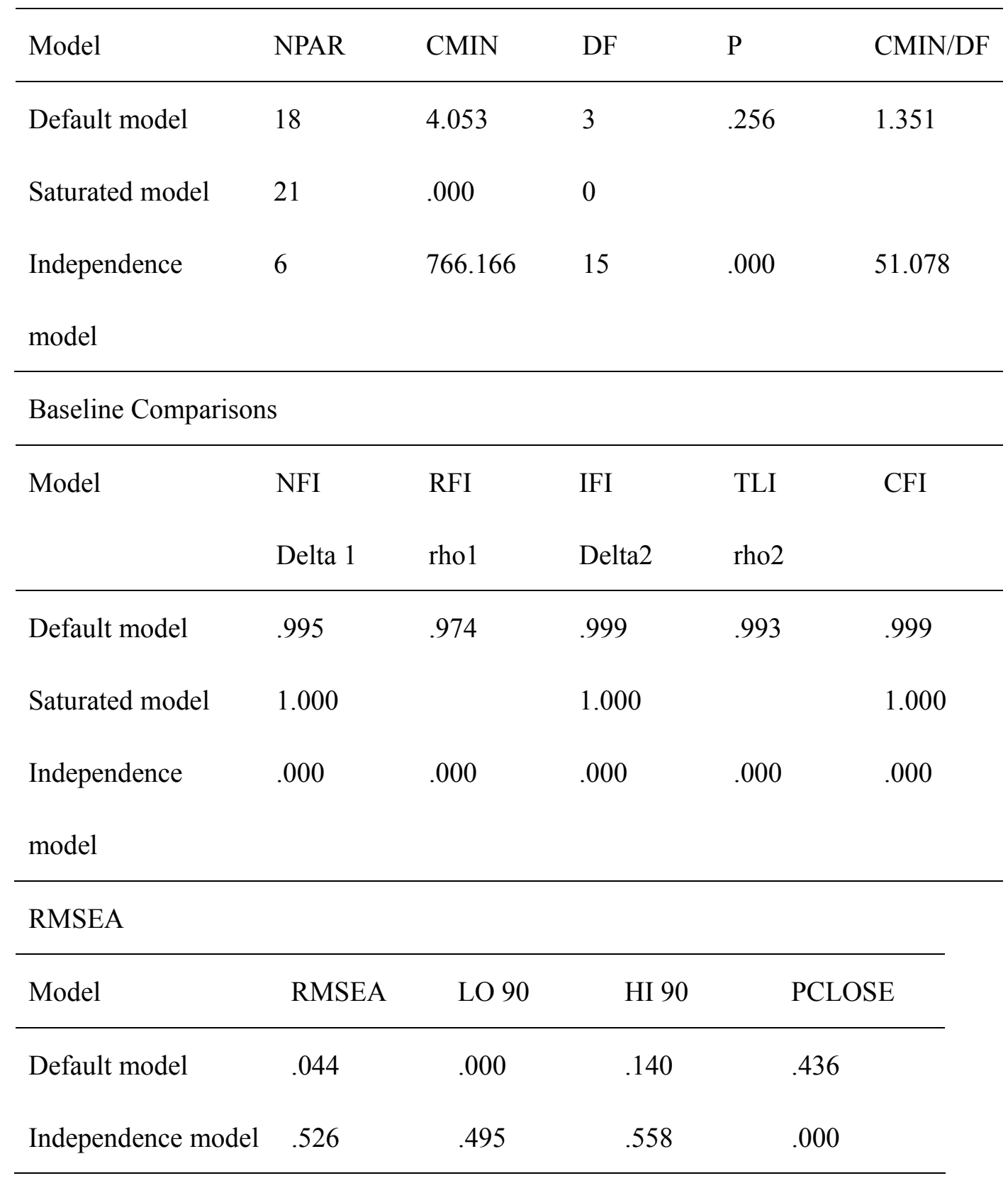

To specify the causal effects among the variables, the path coefficients from the predictor variables to the dependent variables were calculated using AMOS 7.0. 
Four of the six path coefficients demonstrated statistical significance $(p<.05)$.

However, the path from PDM to change-specific cynicism and the path from PDM to intention to resist change did not achieve statistical significance. The negative coefficients represent the negative relationships between variables. The direct, indirect, and total effects among the variables in the proposed model are presented in Table 4-2.

Table 4-2.

Causal Effects among the Variables in the Proposed Model.

\begin{tabular}{|c|c|c|c|c|}
\hline & & \multicolumn{3}{|c|}{ Causal Effects } \\
\hline Outcome & Predictors & Direct & Indirect & Total \\
\hline Change-specific & Quality of information & $-.378^{*}$ & - & -.378 \\
\hline cynicism & Colleague cynicism & $.326^{*}$ & - & .326 \\
\hline \multirow[t]{2}{*}{$\left(\mathrm{R}^{2}=.727\right)$} & Trust in mgt & $-.221 *$ & - & -.221 \\
\hline & PDM & -.065 & - & -.065 \\
\hline Intention to & Quality of information & - & -.286 & -.286 \\
\hline resist change & Colleague cynicism & - & .246 & .246 \\
\hline \multirow[t]{4}{*}{$\left(\mathrm{R}^{2}=.618\right)$} & Trust in mgt & - & -.167 & -.167 \\
\hline & PDM & -.046 & -.049 & -.095 \\
\hline & Change-specific & $.757^{*}$ & & .757 \\
\hline & cynicism & & & \\
\hline
\end{tabular}

* Direct effect is significant at the $\alpha=.05$ level. 
As indicated in the above table, overall, the four exogenous variables explained $72.7 \%$ of the variance in change-specific cynicism. The proposed model explained $61.8 \%$ of the variance in intention to resist change. The variable of change-specific cynicism had the greatest total causal effect on intention to resist change, with a path coefficient of .757. Even though the indexes of the overall model fit appear acceptable, the two direct paths from PDM to change-specific cynicism and intention to resist change were not supported by the data. As noted by Meyers, Gamst, and Guarino (2006), an acceptable fit could be obtained simply because some paths have extremely high path coefficients. To gain additional insight, the original model was revised. The two non-significant paths were dropped from the initial model. As a result, the variable of PDM was removed from the original model as well. The revised model stated that three exogenous variables - perceived quality of information, colleague cynicism, and trust in administration — predict change-specific cynicism, which leads to intention to resist change.

The Revised Model Fit

By removing the variable of PDM, the revised model was evaluated through AMOS 7.0. The chi-square test was non-significant, $\chi^{2}(12, \mathrm{~N}=182)=3.96, \mathrm{p}>.05$. The CFI and NFI indexes were .998 and .994 respectively. The RMSEA value was .042. The indexes showed a good fit of the revised model. The indexes are presented in Table 4-3. 
Table 4-3

Revised Model Fit Summary

CMIN

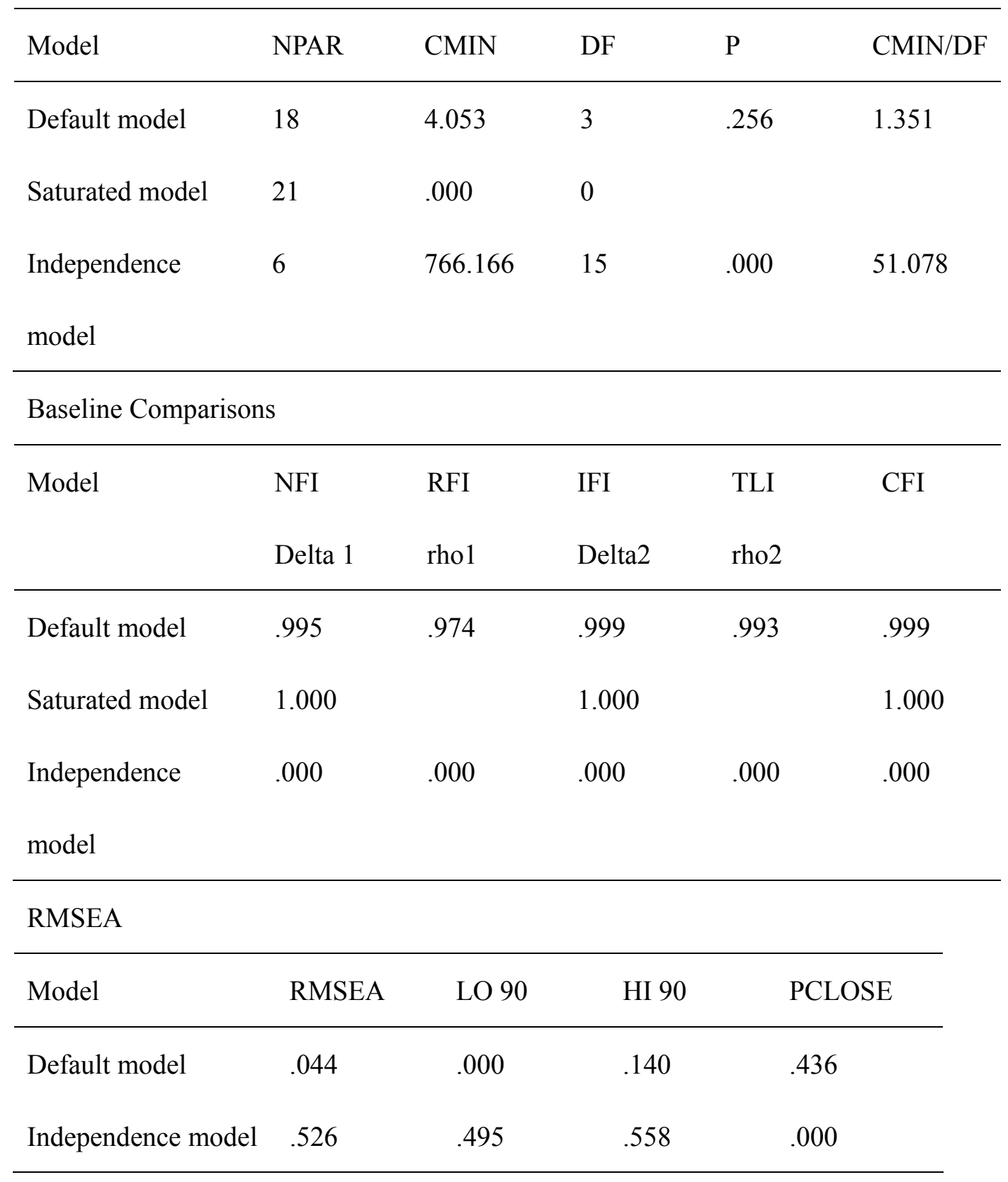

The path coefficients from the predictor variables to the dependent variables were estimated via AMOS 7.0. All of the four direct path coefficients in the revised 
model demonstrated statistical significance $(\mathrm{p}<.05)$. The direct, indirect, and total causal effects among the variables in the revised model were also estimated through AMOS 7.0. The results were described in Table 4-4.

Table 4-4

Causal Effects among the Variables in the Revised Model.

\begin{tabular}{|c|c|c|c|c|}
\hline & & \multicolumn{3}{|c|}{ Causal Effects } \\
\hline Outcome & Predictors & Direct & Indirect & Total \\
\hline Change-specific & Quality of information & $-.403 *$ & - & -.403 \\
\hline cynicism & Colleague cynicism & $.333 *$ & - & .333 \\
\hline$\left(\mathrm{R}^{2}=.725\right)$ & Trust in mgt & $-.240 *$ & - & -.240 \\
\hline Intention to & Quality of information & - & -.316 & -.316 \\
\hline resist change & Colleague cynicism & - & .262 & .262 \\
\hline \multirow[t]{3}{*}{$\left(\mathrm{R}^{2}=.617\right)$} & Trust in mgt & - & -.188 & -.188 \\
\hline & Change-specific & $.785^{*}$ & & .785 \\
\hline & cynicism & & & \\
\hline
\end{tabular}

* Direct Effect is significant at $\alpha=.05$ level.

In the revised model, the three exogenous variables explained $72.5 \%$ of the variance in change-specific cynicism. The revised model explained $61.7 \%$ of the variance in intention to resist change. The removal of the non-significant paths from PDM to the two endogenous variables or of the variable of PDM did not influence the 
overall explanatory power of the model much. All of the path coefficients improved somewhat after removing the two paths. For a quick review of the results, the original model and the revised model, including the path coefficients, are presented in Figure 4-1 and Figure 4-2 respectively.

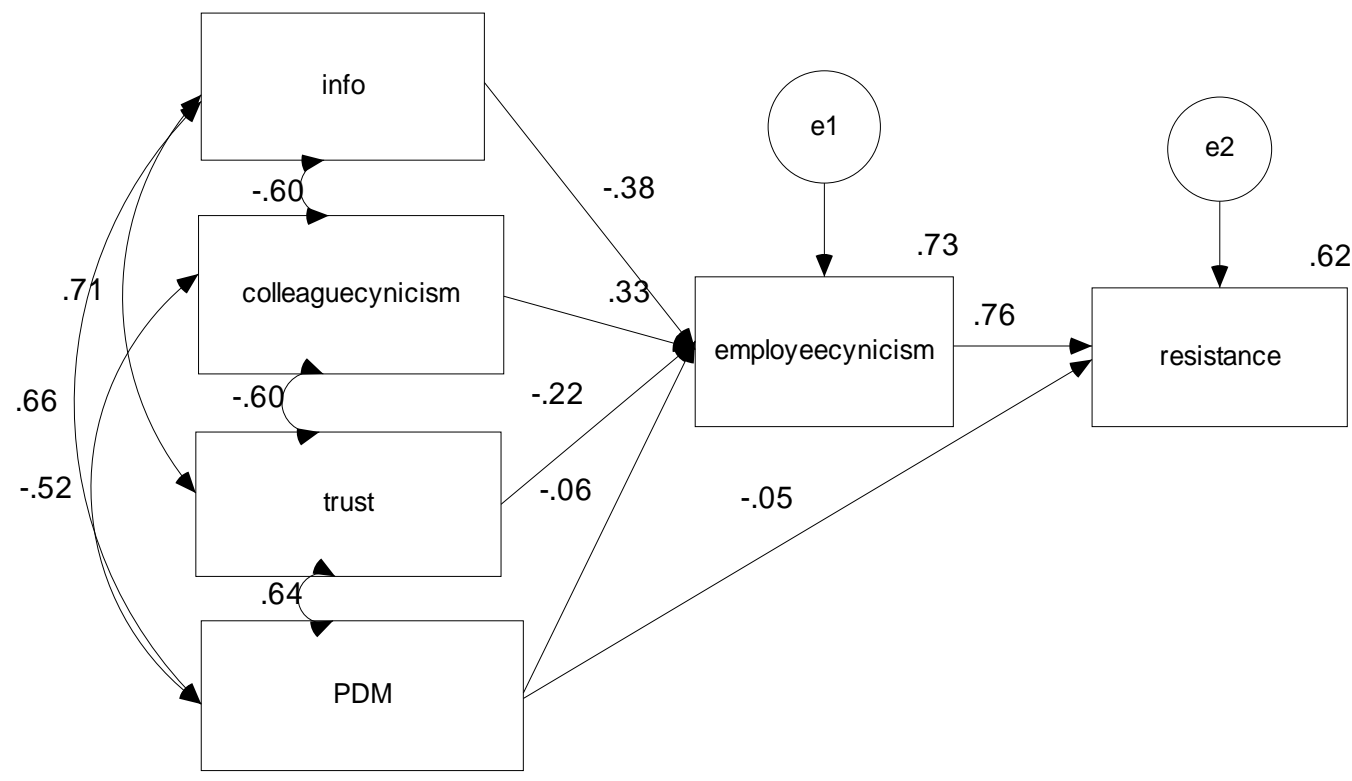

Figure 4-1: The Original Model with Path Coefficients

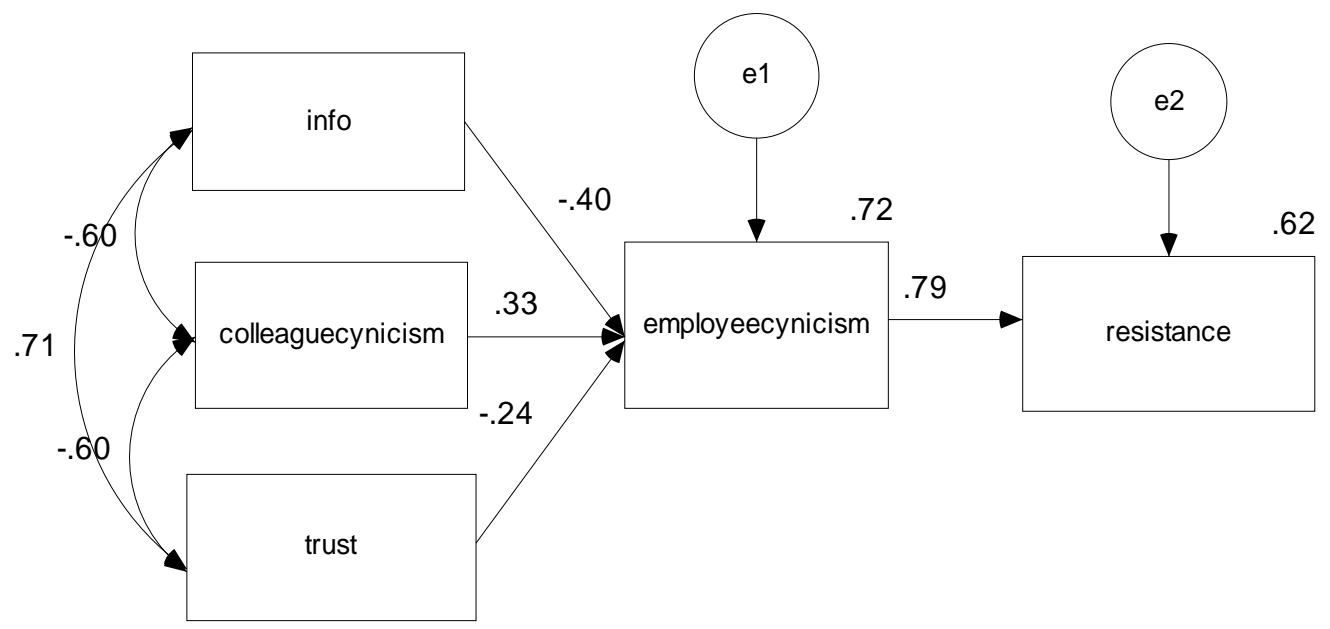

Figure 4-2: The Revised Model with Path Coefficients 
Note. The names of the variables in Figure 4-1 and 4-2 are abbreviations in order to fit in the boxes. Info refers to perceived quality of information; trust refers to trust in the administration; employee cynicism refers to change-specific cynicism; resistance refers to intention to resist change.

\section{Conclusion}

The results of the analysis showed that both models fit the empirical data in the current study. The models explained a significant amount of variance in the outcome variables. However, the original model has two non-significant path coefficients from PDM to the two endogenous variables. Based entirely on statistical considerations, the original model was revised by removing the variable of PDM. All the path coefficients were statistically significant at the .05 level in the revised model.

Even though path analysis suggested revision of the original model, the decision was made purely on statistical considerations. One of the limitations of path analysis should be taken into account. Mertler and Vannatta (2002) posited that it was just a matter of degree in concluding the misspecification of a model and " $\mathrm{T}(\mathrm{t})$ here is no statistical test that will definitely indicate whether or not the misspecification is within reasonable limits" (p. 205). Theoretical justifications for the model revision should also be considered.

The revised model supported social information processing theory, which stated that individual attitudes were influenced by the social context. In the revised model, the variable of perceived quality of information reflected the informational context. The relational context entailed relationships with colleagues and the 
administration respectively, which were captured in the two variables of cynicism of colleagues and trust in administration. Contrary to the theoretical assumption that PDM was negatively associated with intentions to resist change, the results of the study found that PDM had very weak causal effect on the outcome variables. As illustrated in chapter two, the literature has demonstrated a pro-PDM bias. In reality, PDM might not have such a strong influence on job attitudes. Empirical studies have reported mixed results in terms of the associations between PDM and positive work outcomes. The results of the current study revealed that social context played a primary role in faculty attitude toward change. In comparison with the social context, the role of PDM was negligible.

In the revised model, there were three missing paths: the paths from perceived quality of information, cynicism of colleagues, and trust in administration to intention to resist change respectively. As illustrated in the first chapter, exclusion of these paths was supported by theoretical assumptions. Specifically, SIP theory posits that social context contributes to work-related attitudes rather than behavioral intentions. For experimental purposes, the three paths were included to test if the three exogenous variables have significant direct causal effects on intention to resist change. The result showed that all three path coefficients were non-significant at the .05 level. This finding further supported the proposed and revised models in that the exogenous variables only affected intention to resist change indirectly through the intervening role of change-specific cynicism. 


\section{Selected Subjective Responses}

Although this was a quantitative study, the subjective responses could shed some light on the causes of change-specific cynicism and intentions to resist change. To gain further knowledge and insight, some selected subjective responses from the faculty are described in the following. The subjective feedbacks showed that trust in the administration, participation in the change, and information played some role in the negative attitudes of the faculty about the change.

First, faculty cynicism and resistance about the change might be a result of strong distrust in the administration leading the university, as was illustrated in the following comments by faculty members:

(The change) Basing all decisions on politically correct hoopla and whether the administration can capture more revenues to clone themselves and work faculty harder for fewer benefits and less than average salaries.

...In the abstract, the notion of responsibility-based budgeting makes very good sense, but I absolutely do not trust these administrators to set up and maintain that new system. Virtually all income is generated by academic units. So, real responsibility-based budgeting would allow the academic units to make decisions about how to spend their income in order to make for a better university. ...Instead, a certain privileged managerial class with no loyalty to this university--just a contract--makes the budget and sends a tax bill to the people who have long been loyal to this university and do produce the money.

I and many of my colleagues believe this is just another scheme cooked up by a lame president in order to have something to point to when he applies for a job elsewhere.

The negative attitudes of the faculty toward the change might also be incurred

by a lack of influence over the change results, although faculty members were offered multiple opportunities to participate in the change processes. The following comments 
from the faculty might provide some of the reasons that PDM did not explain much

of the variance in the proposed model.

It seemed to me that many things about New Vision were done properly, but I got the sense that the process was just a front and the input was not being truly considered - it seemed the administration had in mind what the Vision was, and wasn't that interested in ideas to the contrary. After a while this seemed to change, but it seemed to be too late to avoid the generally cynical attitudes that seem to linger with New Vision.

...I understand some of the criticism of New Vision in that, while we (faculty) were afforded opportunities for input, some of those opportunities appeared to come after feet had already been set on a particular course.

I avoided involvement with New Vision out of exhaustion and cynicism. What faculty need is more support for teaching and research and less time wasted in administrative meetings discussing broad, poorly-detailed plans. I decided my time was better allocated to students and keeping my own programs running smoothly.

Additionally, some faculty was concerned about whether or not information

about the change was communicated effectively.

I feel reasonably well informed, and as if information has been fairly forthcoming, but I am skeptical and cynical regarding the intentions as well as the potentiality of the results.

I am somewhat shocked that the New Vision committees were made up of the same old people, who were under no mandate to communicate with the rest of us. To this date I know nothing specific about anything. No one I know except my department chair was on any committees, and all I hear are the annoyingly vague pronouncements from the provost and University Communications.

Of course, there were many positive statements from faculty members about the change as well. Some faculty fully supported the work conducted by the administration during the change.

I think the administration has done a great job. I'm sick of all the negativity against all levels of administration. 
The negative/bitter people here at this university have done quite a bit to sour the reputation of this fine university in the media. The negative people here really make people want to leave. It would be nice if they pushed for good dialog like mature adults, instead of so much whining like babies.

The perception of New Vision that is portrayed in the local media is driven by a small number of quite vocal people with undue influence on the media. Most people are either happy with the changes or are content to let a representative government work and make decisions for them so that they can get their own work done.

\section{Chapter Summary}

This chapter reported the results of the study. The analysis showed that the originally proposed model fit the empirical data. However, there existed two non-significant path coefficients: the path from PDM to change-specific cynicism and the path from PDM to intention to resist change. The original model was revised by removing the two non-significant paths. The revised model was consistent with the empirical data and all the path coefficients achieved statistical significance. The revised model fully supported social information processing theory. The role of PDM in the proposed model was negligible. This chapter also presented some of the subjective responses from the faculty. The qualitative information complemented the findings of the study by providing further insights on the model. 


\section{Chapter Five: Discussion}

Organizations constantly change in order to adapt to the turbulent economic and social environment. To successfully implement planned organizational change, it is important to gain the support of all of the organization's members. However, organizational change is often met with resistance. Recent studies have identified employee cynicism as one of the major causes of resistance to organizational change (Stanley et al., 2005). The present study proposed a comprehensive model of employee cynicism toward organizational change from a communication perspective. The results suggest that factors in the work environment contribute to change-specific cynicism, which has a significant direct effect on intention to resist change.

While previous studies mainly used psychological contract violation theory to explain cynicism (Anderson, 1996), the present study embedded cynicism in the SIP theoretical framework. SIP theory provides a communication perspective to examine individual attitudes in the workplace. Through this research, the significance of communication in employee cynicism is verified. In the following, the major findings of the current study were presented in greater detail.

\section{Summary of Major Findings}

The results of the present study indicated that the proposed model of employee cynicism toward organizational change was a good fit of the empirical data. The model explained a large proportion of the variance in the two endogenous variables: change-specific cynicism and intention to resist change. However, there were two non-significant direct paths in the proposed model, the paths from PDM to 
change-specific cynicism and from PDM to intention to resist change, with low path coefficients of -.06 and -.05 respectively.

To find a better model, the two non-significant paths were removed from the original model. The revised model proposed that the three exogenous variables — perceived quality of information, colleague cynicism, and trust in administration — would predict change-specific cynicism, which, in turn, would lead to intention to resist change. The revised model fit the empirical data, and the amount of variance explained by the revised model was similar to those explained by the original model. In addition, all path coefficients were statistically significant at the .05 level. Perceived quality of information had the most effect on change-specific cynicism, followed by cynicism of colleagues, and finally trust in administration. Both models suggested that change-specific cynicism accounted for a very large proportion of variance in intention to resist change. The findings of the study were further explored by emphasizing the various determinants of the outcome variables in the model: the informational context, the relational context, the impact of change-specific cynicism, and the unexpected non-significant effect of PDM.

\section{The Informational Context}

As was shown in the proposed and revised models, perceived quality of information had the greatest total causal effect on change-specific cynicism. This finding is in consistent with SIP theory, which emphasizes the role of social context in formulating attitudes. When employees perceive change information as being high in quality, they tend to feel less anxiety about the change (Miller \& Monge, 1985). In the 
case of administrative-led change, an open informational environment is particularly important as not every faculty member has an opportunity to get directly involved in making the change plan. Top-down information dissemination could facilitate change acceptance by giving faculty members a sense of control over what's going on in the university. In addition, in higher education settings characterized by shared governance, faculty need to know the information about change in order to provide input. Cynicism will emerge when faculty members believe that they have been kept in the dark and information has been shared only with members of a particular interest group.

\section{The Relational Context}

Besides the informational context, the relational context also influences attitude formation during organizational change. People develop attitudes based on what others think (Salancik \& Pfeffer, 1978). In the present study, faculty members' relationships with two major groups in higher education context were discussed: relationships with their colleagues and relationships with the administrators. The former relationships influence faculty members' attitudes through the contagion process, whereas the latter relationships influence faculty members' attitudes through trust.

First, the results of the study showed that cynicism of colleagues has a significant direct causal effect on change-specific cynicism. This finding supports SIP theory in that individual attitudes are subject to social influence. People tend to rely on similar others to make sense of their own world and form their own attitudes. This 
same idea is conveyed in the big theoretical umbrella of contagion theories, which “seek to explain networks as conduits for 'infectious' attitudes and behavior" (Monge \& Contractor, 2003, p. 173). In this case, faculty members use their colleagues within their social networks as references for developing their own attitudes. In addition, as higher education institutions rely on referent and expert power, faculty members are influenced more by "communications from colleagues who are seen as sharing their values, than by salary increases or threats of administrative sanctions" (Birnbaum, 1988, p. 14). Therefore, the cynicism of colleagues had a great impact on faculty members' change-specific cynicism.

The second important pair of relationships in higher education institutions is between faculty members and administrators. Administrators' influence over faculty members' attitudes is mainly penetrated through trust instead of similarity-based contagion. Historically, there existed a culture gulf between administrators and faculty. Some faculty members even claimed that administrators are from Venus and faculty from Mars. The discrepancies which separate the administrative and academic cultures originate from their different backgrounds, expertise, and job roles. Even though some administrators started their careers as university faculty members, the different job roles have pushed them to think from different perspectives. In addition, as higher education institutions have become more complex, specialized expertise is needed to accomplish the administrative tasks, and the days of amateur administration have passed (Birnbaum, 1990). The changing situation enlarges the discrepancies between the administration and the faculty. In the current study, some responses from 
the faculty reflected the antagonism between the administration and the faculty.

The respondents criticized the administrators for only focusing on profits and

efficiency while showing little understanding of the university's history and culture.

One way to reduce the antagonism would be through building a trusting relationship.

As was shown in the results of the study, trust in the administration had a significant

direct effect on change-specific cynicism and an indirect effect on intention to resist change.

The above two types of relationships comprised the relational context in the higher education setting which informed faculty members' attitudes toward the change. Faculty members adapted their attitudes to what their colleagues thought and to the degree of trust they had in the administration. Combined with informational context, the relational context had a significant direct effect on change-specific cynicism. Impact of Change-Specific Cynicism

The present study found that change-specific cynicism had the greatest direct causal effect on intention to resist change. This finding confirmed Stanley et al.'s (2005) study, which shows that change-specific cynicism is associated with intention to resist change. Further, this study made an improvement by establishing the causal relationship between the two variables. Change-specific cynicism can be considered as an antecedent of intention to resist change. When faculty show disbelief toward the administration, express frustration and pessimism, and display critical behaviors, they are likely to move further and show a strong intention to resist change. The results 
also showed that the exogenous variables in the model only had an indirect causal effect on intention to resist change through the mediating role of change-specific cynicism. Change-specific cynicism has become the central element in the proposed model.

\section{Unexpected Findings}

Contrary to previous theoretical assumptions, PDM did not have a significant causal effect on the two endogenous variables, change-specific cynicism and intention to resist change. Several reasons could explain the unexpected finding. First, theoretical assumptions about PDM have demonstrated a pro-PDM bias (Locke \& Schweiger, 1979). For example, democratic theory considers PDM as an ideal form of governance in all organizations. People have the right to make decisions affecting their lives. However, empirical studies have provided mixed results between PDM and positive work attitudes and outcomes (Miller \& Monge, 1986). Second, the concept of PDM is not well defined in the literature. There is a lack of a good instrument to measure the concept of PDM.

Third, the weak effects of PDM on the outcome variables are also related to the higher education settings - a type of autonomous professional organizations. Faculty members tend to show more identification with their disciplines rather than their universities. As a result, faculty members might be less concerned with institutional activities, like the university-wide changes. Some respondents even considered PDM as a waste of time as compared to teaching and doing research. 
Finally, researchers have been interested in the degree of PDM but have ignored the process of PDM. How and when PDM is implemented in an organization could make a big difference on its effect. In this particular case, some faculty members reflected that they had been offered lots of opportunities to participate in decision making, but none of their opinions had been taken seriously. The administration had already set their minds and no change would take place based on faculty input. The offer of participation opportunities came too late. As one of the faculty members responded, "Some of those opportunities (to participate) appeared to come after feet had been set on a particular course." Others commented that they were too busy with teaching and research; PDM was a waste of time considering that no real change would result from their participation. Therefore, even though faculty reported a high degree of PDM, they might still show cynicism and intention to resist change. This situation explains the weak effect of PDM on the outcome variables. The result is further supported by the contingency model of PDM, which proposes that the effects of PDM do not hold the same across situations. Based on the empirical findings in this study, the paths from PDM to the two endogenous variables were dropped from the model.

\section{Contributions of the Study}

This study makes several contributions to the literature. First, the study proposed and tested the first communication model of employee cynicism toward organizational change. Prior research has pointed out some communication variables which contribute to cynicism about organizational change. For example, researchers 
found that lack of information about change and PDM are associated with cynicism about organizational change (Reichers et al., 1997; Wanous et al., 2000). However, the previous research on cynicism did not make communication processes as the focus of the study. This study addressed this problem by emphasizing the critical role of communication in change-specific cynicism. Furthermore, the model in this study included a combination of communication variables that has not been examined by other studies.

Second, this study extends SIP theory and tests the theory with a new outcome variable - change-specific cynicism. The results fully support SIP theory by showing that change-specific cynicism is influenced by social context in the workplace. In addition, previous studies considered only one aspect of the social context — either the information or the social network. The study incorporated both informational and relational context in the model.

Third, the study defined three dimensions of change-specific cynicism. Based on the definition, a new scale of change-specific cynicism was developed and tested with the sample in the study. The new scale showed a high reliability $(\alpha=.952)$ with the current sample. Exploratory factor analysis basically supported the three dimensional structure of change-specific cynicism.

Finally, the study examined the complex relationships in the higher education setting and how the relationships affected faculty's cynicism toward organizational change. Previous studies focused on the relationship between management and employees. They used social exchange theory to explain how the social exchange 
between employers and employees contributes to employee cynicism. For instance, employee cynicism might be incurred by such factors as unfair treatment and lack of support from organizational management. However, prior research has ignored the role of peer relationships on employee cynicism. No known studies have been found to examine the contagious effect of colleagues on employee cynicism. This study lays the foundation for further research in this direction.

\section{Limitations}

The present study has several limitations. First, the study was based on an organizational change at one university. The generalizability of the results to other higher education institutions might be limited. Replication of this study in other institutions is needed in future studies. However, the type of organizational change occurring in this university is typical in the higher education setting. Other colleges and universities have reported similar strategic changes at the time. Therefore, this study has significant implications for other higher education institutions as well.

Second, the study lacks sufficient qualitative data to cross-validate the research findings. The quantitative data reported the scores of various attitudinal and behavioral scales, but did not reveal the reasons behind reporting those attitudes and behaviors. For example, some faculty commented that they did not participate in the change because they did not find the time to do so with the already heavy workload or they thought that participation made no difference. The comments raised the concern that the true effects of PDM might not be captured in this study. Besides short 
subjective responses, In-depth interviews with faculty will complement the interpretations of the quantitative results.

The third limitation is associated with the specific data analysis method used in this study. As path analysis describes causal relationships through correlational data, researchers will have less confidence in drawing causal inferences from path analysis than from an experimental study (Mertler \& Vannatta, 2002). Despite this, path analysis has the advantage of analyzing "real" data in field settings. Therefore, it is necessary to test the model using path analysis given the lack of field studies on this topic. Another limitation of path analysis is that it is somewhat subjective to draw the conclusion that a model is misspecified. The decision to accept or revise a model lies with the researcher's judgment as no statistical test will definitely indicate whether or not a model should be revised (Mertler \& Vannatta, 2002). And revision of a model should also be supported by theoretical justifications. Despite the limitations of path analysis, it is most suitable for the present study considering the research purpose and design. And it is the most appropriate method to address the research questions posed in the study.

Fourth, the present study is a one-shot field study with self-report data. The one-shot field study cannot capture the attitudinal change of faculty during organizational change. Faculty might show different degrees of cynicism or resistance as the change evolves. Longitudinal study is needed in future studies. In addition, the self-report method opens to the possibility that the respondents might not report the data accurately and the data might be biased to some extent. For example, respondents 
might report more positive attitudes under the influence of social desirability, although confidentiality was ensured in the survey.

The fifth limitation is concerned with the network measure. The network measure asked respondents to report their perceptions of their colleagues' cynicism. Researchers argue that the perceptions of others' attitudes might not reflect the actual attitudes of others (Rice \& Aydin, 1991). However, there is a practical difficulty in data collection if the actual attitudes of colleagues are to be measured. Even though anonymity and confidentiality was assured in the survey, respondents still felt the insecurity about their identification, which could be a big concern for non-tenured assistant professors. Actually, several respondents have shown that concern in their email messages to the researcher. In addition, a very high response rate is required if the network measures actual attitudes of colleagues. It is impractical to achieve such a high response rate with a large sample in the study. Future research could try to measure actual attitudes with smaller groups of respondents.

Six, the colleague cynicism scores were calculated by taking the mean of perceived cynicism scores of one's close colleagues. This method of calculation failed to consider the variability of one's perceptions of colleague cynicism. For instance, some respondents reported similar perceptions across the three to five colleagues, whereas others reported a greater variability in perceptions of colleague cynicism. However, the mean scores of colleague cynicism might be the same in the above two cases. Hence, the variability of one's perceptions of colleague cynicism reveals much more information than the mean of one's perceptions. Future studies are needed to 
examine what role the variability of colleague cynicism scores plays in an individual's cynicism.

Finally, three of the scales used in this study have not been validated in previous research: change-specific cynicism scale, PDM scale, and intention to resist change scale. Moreover, exploratory factor analysis showed that the factor structure for the intention to resist change scale was not consistent with the original theoretical assumptions. So, this scale does not have strong factor validity. Alternative measures could be used in future studies. However, all three scales showed satisfactory reliability coefficients in the current sample. The Cronbach's Alpha for the three scales are $.952, .844$, and .840 respectively. The scales could be used in other samples to further test their reliabilities and validities.

\section{Research Implications}

This study seeks to generate and test a model of employee cynicism toward organizational change in higher education settings from a communication perspective. The study answers the call for more research on testing SIP theory with a variety of outcome variables (Miller \& Monge, 1985). This is the first known study to explore the concept of employee cynicism within the theoretical framework of SIP. As an initial attempt to build a communication model of change-specific cynicism, this study leaves much room for further development.

First, the existing literature on employee cynicism is limited, especially in the field of communication. Consistent with prior studies (Reichers, et al., 1997; Wanous, et al., 2000), the present study confirmed the key role of communication in fueling 
employee cynicism. More research should be conducted to apply various communication theories to examine the topic of employee cynicism, and to reconceptualize cynicism as a communication problem.

Second, the results of the study indicate that the communication processes — information and relationships in the work environment- have significant causal effect on change-specific cynicism. Future studies could expand the current model by exploring other communication variables, such as organizational identification and social support, in predicting change-specific cynicism. Moreover, change-specific cynicism could have several consequences. The present study has identified intention to resist change as an outcome of change-specific cynicism. Further research could be conducted to explore other potential consequences of change-specific cynicism, including positive consequences.

Third, quantitative in nature, the present study treats change-specific cynicism as an outcome variable. However, the quantitative data can not reveal the rich experiences of cynics and the various expressed forms of cynicism. To address this problem, future research could collect qualitative data to describe the content of employee cynicism. For example, by observing cynicism discourses, researchers could know how cynicism is communicated and how it emerges through daily discourses. In this sense, cynicism can be conceptualized as an ongoing communication processes instead of an outcome variable.

Fourth, in addition to informational context, the present study also incorporated relational context as contributors of change-specific cynicism. Two types 
of relationships were examined in this study: the informal social networks among faculty and the faculty-administrator relationship. The results of the study supported the contagious effect of network proximity on faculty attitudes. Further research is needed to investigate how other network structure and characteristics, such as network density and centrality, influenced change-specific cynicism in universities. Moreover, research could be conducted to identify the opinion leaders among faculty network if a high response rate can be achieved. In this way, the school administration could diffuse change information more purposefully and effectively through the opinion leaders. In addition, organizational change often widens the gulf between faculty and administrators. The finding of the study indicated that the lack of trust between faculty and administrators makes communication difficult, which leads to change-specific cynicism and eventually intention to resist change. However, trust in the administration is the exogenous variable in the model and thus is not explained by other variables. Future studies could explore what causes trust/distrust in the administration and thereby provide strategies to improve the communication between faculty and administrators.

Finally, the present study focused on faculty's reactions to organizational change. The reactions of other groups during organizational change, such as staff, administrators, board of trustees, and students, need to be examined in future studies. For example, research could be conducted to examine job stress of administrators in universities during organizational change, as they are facing the external pressure to 
cope with the intensely competitive educational environment and the internal pressure to meet the demands from the faculty.

\section{Practical Implications}

This study has several practical implications for administrators during organizational change. As the results indicate, change-specific cynicism has a large impact on intentions to resist change. Resistance is likely to be the next step taken by the faculty when cynicism is prevalent. Therefore, it is necessary to reduce change-specific cynicism by tracing its determinants.

First, the administrators are advised to provide timely information about the change to the faculty, as perceived quality of information has the greatest effect on change-specific cynicism. The administrators have to make sure that everyone has equal access to the change information. In the survey questionnaire, some faculty responded that they don't know what's going on about the change. And the change information was not communicated effectively to the regional campuses to the extent that faculty in the regional campuses felt like being excluded from the major discussions. The information from the administration should explain the need and directions for the change so that faculty will be clear about where the change is taking them.

Second, since faculty attitude tends to be influenced by their close colleagues, the administrators should be aware of employee interactions about the change. The change plan should be extended to the department level and not stop at the college level as faculty socializes more frequently with their colleagues within the same 
department. The administration is advised to give more autonomy to individual departments and encourage discussions at the department level in order to gain support from its members.

Thirdly, trust in the administration is one of the determinants of change-specific cynicism. In order to gain trust from the faculty, the administration needs to create opportunities for more administrator-faculty interactions. It is wise to understand the culture and history of the university and try to create a sense of community before making the change plan. Further, the administration should respond not only to the external pressure of competition but also to the internal demands from the faculty. Hardly can the change turn into reality without the support of the faculty.

Finally, the lack of effect of PDM on the outcome variables is not a warrant for ignoring PDM during organizational change. As some of the faculty members have suggested, their participation does not make any difference in the change results although opportunities of PDM are offered by the administration. The results indicate that PDM has effects only when faculty members perceive the change process as truly participative. Hence, administrators are advised to encourage PDM of faculty members and most importantly, to take their inputs seriously.

\section{Conclusion}

Cynicism is a common reaction among employees during organizational change. Widespread cynicism could inhibit the success of organizational change and have detrimental effect on other organizational aspects (Wanous et al., 2000). This 
phenomenon has invited the attention of both researchers and practitioners in recent years. In this study, a model was developed to explore the causes of employee cynicism toward organizational change and its consequences. The results indicated that change-specific cynicism has a strong direct causal effect on intention to resist change. Drawing on SIP theory, the model attributed change-specific cynicism to its social context - the information about change and social relationships in the workplace. Because of the significance of social context, managers and administrators are advised to create a work environment favorable to organizational change in order to reduce cynicism and resistance to change. 


\section{References}

Abraham, R. (2000). Organizational cynicism: Bases and consequences. Genetic, Social and General Psychology Monographs, 126 (3), 269-292.

Adam, E.M. (1997). Rationality in the academy: Why responsibility center budgeting is a wrong step down the wrong road. Change, 29(5), 58-61.

Agocs, C. (1997). Institutionalized resistance to organizational change: Denial, inaction, and repression. Journal of Business Ethics, 16, 917-931.

Albrecht, S.L. (2002). Perceptions of integrity, competence and trust in senior management as determinants of cynicism toward change. Public Administration and Management: An Interactive Journal, 7(4), 320-343.

Andersson, L.M. (1996). Employee cynicism: An examination using a contract violation framework. Human Relations, 49 (11), 1395-1418.

Andersson, L.M., \& Bateman, T.S. (1997). Cynicism in the workplace: Some causes and effects. Journal of Organizational Behavior, 18, 449-469.

Ajzen, I., \& Fishbein, M (1980). Understanding attitudes and predicting social behavior. Englewood Cliffs, NJ: Prentice Hall.

Armenakis, A.A., \& Harris, S.G. (2002). Crafting a change message to create transformational readiness. Journal of Organizational Change Management, 15(2), 169-183.

Bhattacharya, R., Devinney, T.M., \& Pillutla, M.M. (1998). A formal model of trust based on outcomes. The Academy of Management Review, 23 (3), 459-472. 
Bigley, G.A., \& Pearce, J.L. (1998). Straining for shared meaning in organization science: Problems of trust and distrust. Academy of Management Review, 23 (3), $405-421$.

Birnbaum, R. (2000). The life cycle of academic management fads. The Journal of Higher Education, 71(1), 1-16.

Birnbaum, R. (1990). How colleges work: The cybernetics of academic organization and leadership. San Francisco: Jossey-Bass Publishers.

Blau, G.J., \& Katerberg, R. (1982). Toward enhancing research with the social information processing approach to job design. Academy of Management Review, 7(4), 543-550.

Blau, G.J. (1985). Source-related determinants of perceived job scope. Human Communication Research, 11, 536-553.

Bok, D. (2003). Universities in the marketplace: The commercialization of higher education. Princeton, NJ: Princeton University Press.

Bordia, P., Hobman, E., Jones, E., Gallois, C., \& Callan, V.J. (2004). Uncertainty during organizational change: Types, consequences, and management strategies. Journal of Business and Psychology, 18(4), 507-532.

Brandes, P., Dharwadkar, R., \& Dean, J.W., Jr. (1999) Does organizational cynicism matter?: Employee and supervisor perspectives on work outcomes. Paper presented at the $36^{\text {th }}$ annual meeting of the Eastern Academy of Management, Philadelphia. 
Brooks, G.P., \& Barcikowski, R.S. (1999). The precision efficacy analysis for regression sample size method. Paper presented at the annual meeting of the American Educational Research Association, Montreal, Quebec, Canada.

Butler, J.K. (1991). Toward understand and measuring conditions of trust: Evolution of a conditions of trust inventory. Journal of Management, 17 (3), 643-663.

Cerra, F. (2005, October 19). Strategy of a well-positioned future. Retrieved November 15, 2006, from http://www1.umn.edu/systemwide/strategic_positioning/state_of_ahc.html

Clarke, J.S., Ellett, C.D., Bateman, J.M., \& Rugutt, J.K. (1996). Faculty receptivity/resistance to change, personal and organizational efficacy, decision deprivation and effectiveness in research I universities. Paper presented at the $21^{\text {st }}$ annual meeting of the Association for the Study of Higher Education, Memphis, TN.

Coch, L., \& French, J.R.P., Jr. (1948). Overcoming resistance to change. Human Relations, 512-532.

Cook, W.W., \& Medley, D.M. (1954). Proposed hostility and parasaic virtue scales for the MMPI. Journal of Applied Psychology, 38, 414-418.

Corson, J.J. (1960). Governance of colleges and universities. New York: McGraw-Hill.

Cotton, J.L., Vollrath, D.A., Froggatt, K.L., Lengnick-Hall, M.L. \& Jennings, K.R. (1988). Employee participation: Diverse forms and different outcomes. Academy of Management Review, 13 (1), 8-22. 
Crampton, S.M., Hodge, J.W., \& Mishra, J.M. (1998). The informal communication network: Factors influencing grapevine activity. Public Personnel Management, 27 (4), 569-584.

Dachler, H.P., \& Wilpert, B. (1978). Conceptual dimensions and boundaries of participation in organizations: A critical evaluation. Administrative Science Quarterly, 23, 1-39.

Davis, K. (1953). Management communication and the grapevine. Harvard Business Review, 31(5), 43-49.

Davis, K. (1963). The case for participative management. Business Horizons, 6, $55-60$.

Dean, J.W., Brandes, P., \& Dharwadkar, R. (1998). Organizational cynicism. Academy of Management Review, 23(2), 341-352.

De DeVellis, R.F. (2003). Scale development: Theory and applications ( $2^{\text {nd }}$ ed.) Thousand Oaks, London, New Delhi: Sage Publications.

Del Val, M.P., \& Fuentes, C.M. (2003). Resistance to change: A literature review and empirical study. Management Decision, 41(2), 148-155.

Dent, E.B., \& Goldberg, S.G. (1999). Challenging "resistance to change." The Journal of Applied Behavioral Science, 35 (1), 25-41.

De Vreese, C.H. (2005). The spiral of cynicism reconsidered. European Journal of Communication, 20(3), 283-301.

Dirks, K.T., \& Ferrin, D.L. (2001). The role of trust in organizational settings. Organization Science, 12 (4), 450-467. 
Driscoll, J.M. (1978). Trust and participation in organizational decision making as predictors of satisfaction. The Academy of Management Journal, 21 (1), 44-56.

Eddy, P.L. (2003, April). The influence of presidential cognition and power on framing change at community colleges. Paper presented at the annual conference of the American Educational Research Association, Chicago, IL.

Eisenberg, E.M., Murphy, A., \& Andrews, L. (1998). Openness and decision making in the search for a university provost. Communication Monographs, 65, 1-23.

Ellis, B.H. (1992). The effects of uncertainty and source credibility on attitudes about organizational change. Management Communication Quarterly, 6(1), 34-57.

European University Association (2005, February). Review of quality assurance in Irish universities: Sectoral report.

Fleming, P. (2005). Metaphors of resistance. Management Communication Quarterly, 19(1), 45-66.

Flower, O.D. (1962). Overcoming resistance to change [Film]. Beverly Hills, CA: Roundtable Productions.

Ford, J.D., Ford, L.W. \& McNamara, R.T. (2001). Resistance and background conversations of change. Journal of Organizational Change Management, 15 (2), $105-121$

French, J.R.P., Israel, J., \& As, D. (1960). An experiment in a Norwegian factory: Interpersonal dimensions in decision-making. Human Relations, 13, 3-19.

Frey, L.R., Botan, C.H., \& Kreps, G.L. (2000). Investigating communication: An introduction to research methods ( $2^{\text {nd }}$ ed.). Boston: Allyn and Bacon. 
Fulk, J. (1993). Social construction of communication technology. Academy of Management Journal, 36(5), 921-950.

Fulk, J., Schmitz, J. \& Ryu, Daehee (1995). Cognitive elements in the social construction of communication technology. Management Communication Quarterly, 8 (3), 259-288.

Gioia, D.A., \& Chittepeddi, K. (1991). Sensemaking and sensegiving in strategic change initiation. Strategic Management Journal, 12(6), 433-448.

Goldfarb, J.C. (1991). The cynical society: The culture of politics and the politics of culture in American life. Chicago: University of Chicago Press.

Griffin, R.W. (1993). Management (4 ${ }^{\text {th }}$ ed.). Boston: Houghton Mifflin.

Hall, R.H. (1967). Some organizational considerations in the professional-organizational relationship. Administrative Science Quarterly, 12 (3), $461-478$.

Hearn, J.C., Lewis, D.R., Kallsen, L., Holdsworth, J.M., \& Jones, L.M. (2006).

"Incentives for managed growth": A case study of incentives-based planning and budgeting in a large public research university. The Journal of Higher Education, 77(2), 286-316.

Hensley, P.A., Bava,D.J., \& Brennan, D.C. (2001, March). Responsibility center management: A financial paradigm and alternative to decentralized budgeting. Paper presented at the annual conference of the American Educational Finance Association, Cincinnati, $\mathrm{OH}$. 
Hovland, C.I., Janis, I.L., \& Kelley, H.H. (1953). Communication and persuasion.

New Haven, CT: Yale University Press.

Hutt, M.D., Walker, B.A., \& Frankwick, G.L. (1995) Hurdle the cross-functional barriers to strategic change. Sloan Management Review, 36 (3), 22-30.

Ibarra, H., \& Andrews, S.B. (1993). Power, social influence, and sense making: Effects of network centrality and proximity on employee perceptions. Administrative Science Quarterly, 38 (2), 277-303.

Jager, P. D. (2001). Resistance to change: A new view of an old problem. The Futurist, May-June, 24-27.

Jermier, J.M., Knights, D., \& Nord, W.R. (1994). Resistance and power in organizations: agency, subjectivity and the labour process. In J.M. Jermier, D.Knights, \& W.R.Nord (Ed.), Resistance and power in organizations (pp.1-24). London and New York: Routledge.

Johnson, J., \& St. John, E. (2002, June). The impact of incentive based budgeting on planning: Understanding the structural and policy aspects of budget reform. Paper presented at the annual forum of the Association for Institutional Research, Toronto, Canada.

Johnson, J., \& O’Leary-Kelly, A. (2003). The effects of psychological contract breach and organizational cynicism: Not all social exchange violations are created equal. Journal of Organizational Behavior, 24, 627-647.

Kanter, D.L., \& Mirvis, P.H. (1989). The cynical Americans: living and working in an age of discontent and disillusion. San Francisco: Jossey-Bass. 
Kee, H.W., \& Knox, R.E. (1970). Conceptual and methodological considerations in the study of trust and suspicion. The Journal of Conflict Resolution, 14 (3), $357-366$.

Kezar, A.J. (2001). Understanding and facilitating organizational change in the $21^{\text {st }}$ century: Recent research and conceptualizations. ASHE-ERIC Higher Education Report 28 (4). Jossey-Bass Higher and Adult Education Series.

Kreitner, R.(1992). Management (5 ${ }^{\text {th }}$ ed.). Boston: Houghton Mifflin.

Labianca, G., Gray, B., \& Brass, D.J. (2000). A grounded model of organizational schema change during empowerment. Organization Science, 11 (2), 235-257.

Larson, G. S., \& Tompkins, P.K. (2005). Ambivalence and resistance: A study of management in a concertive control system. Communication Monographs, 72 (1), $1-21$.

Lawler, E.E., \& Hackman, J.R. (1969). Impact of employee participation in the development of pay incentive plans: A field experiment. Journal of Applied Psychology, 53 (6), 467-471.

Lawrence, P.R. (1954). How to deal with resistance to change. Harvard Business Review, 32(3), 49-57.

Lee, T.T. (2005). Media effects on political disengagement revisited: A multiple-media approach. Journalism and Mass Communication Quarterly, 82(2), 416-433. 
Lewin, K. (1952). Group decision and social change. In G.E. Swanson, T.M.

Newcombe, \& E.L. Hartley (Ed.), Readings in social psychology $\left(2^{\text {nd }} e d . p p\right.$ 459-473). NY: Holt.

Lewis, J.D., \& Weigert, A. (1985). Trust as a social reality. Social Forces, 63 (4), 967-985.

Lewis, L.K. (2006). Employee perspectives on implementation communication as predictors of perceptions of success and resistance. Western Journal of Communication, 70 (1), 23-46.

Lieberman, J.K. (1981). The litigious society. New York: Basic Books.

Lin, Y., \& Lim, S (2002). Relationships of media use to political cynicism and efficacy: A preliminary study of young South Korean voters. Asian Journal of Communication, 12(1), 25-39.

Lindholm, J.A.(2003) Perceived organizational fit: Nurturing the minds, hearts, and personal ambitions of university faculty. The Review of Higher Education, 27(1), 125-149.

Lines, R. (2004). Influence of participation in strategic change: Resistance, organizational commitment and change goal achievement. Journal of Change Management,4 (3), 193-215.

Locke, E.A., \& Schweiger, D.M. (1979). Participation in decision making: One more look. Research in Organizational Behavior, 1, 265-339.

Lueddeke, G.R. (1999). Toward a constructivist framework for guiding change and innovation in higher education. The Journal of Higher Education, 70(3), 235-260. 
Luhmann, N. (1988). Familarity, confidence, trust: Problems and alternatives. In D. Gambetta (Ed.), Trust: Making and breaking cooperative relations (pp. 94-107). Oxford, UK: Basil Blackwell.

Margulies, N. \& Black, J.S. (1987). Perspectives on the implementation of participative programs. Human Resource Management Journal, 16, 385-412.

Maslow, A. (1954). Motivation and personality. New York: Harper.

Maurer, R. (1996). Using resistance to build support for change. The Journal for Quality and Participation, 19 (3), 56-66.

Mayer, R.C., Davis, J.H., \& Schoorman, F.D. (1995). An integrative model of organizational trust. Academy of Management Review, 20 (3), 709-734.

Meisinger, R.J. (1994). College and university budgeting: An introduction for faculty and academic administrators. Washington, DC: National Association of College and University Business Officers.

Mertler, C.A., \& Vannatta, R.A. (2001). Advanced and multivariate statistical methods: Practical application and interpretation. Los Angeles, CA: Pyrczak Publishing.

Meyer, G.W. (1994) Social information processing and social networks: A test of social influence mechanisms. Human Relations, 47(9), 1013-1047.

Meyers, L.S., Gamst, G.., \& Guarino, A.J. (2006). Applied multivariate research: Design and interpretation. Thousand Oaks: Sage Publications.

Miller, K.I., \& Monge, P.R. (1986). Participation, satisfaction, and productivity: A meta-analytic review. Academy of Management Journal, 29 (4), 727-753. 
Miller, K.I., \& Monge, P.R. (1985) Social information and employee anxiety about organizational change. Human Communication Research, 11(3), 365-386.

Miller, K.I., Ellis, B.H., Zook, E.G., \& Lyles, J.S. (1990). An integrated model of communication, stress, and burnout in the workplace. Communication Research,17 (3), 300-326.

Miller, V.D., Johnson, J.R., \& Grau, J. (1994). Antecedents to willingness to participate in a planned organizational change Journal of Applied Communication Research, 22, 59-80.

Mishra, A.K. (1996). Organizational responses to crisis: The centrality of trust. In R.M. Kramer \& T.R. Tyler (Ed.), Trust in organizations: Frontiers of theory and research (pp. 261-287). Thousand Oaks: Sage Publications.

Mitchell, T.R. (1973). Motivation and participation: An integration. Academy of Management Journal, 16, 670-679.

Monge, P.R., \& Contractor, N.S. (2003). Theories of communication networks. New York: Oxford University Press.

Morrison, E.W. (2002). Newcomers' relationships: The role of social network ties during socialization. Academy of Management Journal, 45, 1149-1160.

Msweli-Mbanga, P., \& Potwana, N. (2006). Modelling participation, resistance to change, and organisational citizenship behavior: A South African case. South African Journal of Business Management, 37 (1), 21-29.

Neiderhoffer, A. (1967). Behind the shield. Garden City, NJ: Doubleday. 
Oreg, S. (2003). Resistance to change: Developing an individual differences measure. Journal of Applied Psychology, 88 (4), 680-693.

Park, C., \& Dudycha, A. (1974). A cross validation approach to sample size determination for regression models. Journal of the American Statistical Association, 69, 214-218.

Paterson, J.M., \& Cary, J. (2002). Organizational justice, change anxiety, and acceptance of downsizing: Preliminary tests of an AET-based model. Motivation and Emotion, 26 (1), 83-103.

Pavitt, C. (1993). Does communication matter in social influence during small group discussion? Five positions. Communication Studies, 44, 216-227.

Piderit, S.K. (2000). Rethinking resistance and recognizing ambivalence: A multidimensional view of attitudes toward organizational change. Academy of Management Review, 25(4), 783-794.

Pollock, T.G., Whitbred, R.C. \& Contractor, N. (2000). Social information processing and job characteristics: A simultaneous test of two theories with implications for job satisfaction. Human Communication Research, 26(2), 292-330.

Powell, W.W. (1990). Neither market nor hierarchy: Network forms of organization. In B.M. Staw \& L.L. Cummings (Eds.), Research in organizational behavior (vol. 12, pp. 295-336). Greenwich, CT: JAI.

Ramaley, J.A. (2002). Moving mountains: Institutional culture and transformational change. In R.M. Diamond \& B. Adam (Ed.), Field guide to academic leadership (pp. 59-73). San Francisco: Jossey-Bass. 
Reichers, A.E., Wanous, J.P., \& Austin, J.T. (1997). Understanding and managing cynicism about organizational change. Academy of Management Executive, 11(1), 48-59.

Rice, R.E., \& Aydin, C. (1991). Attitudes toward new organizational technology: network proximity as a mechanism for social information processing. Administrative Science Quarterly, 36(2), 219-244.

Rice, R.E. (1993). Using network concepts to clarify sources and mechanisms of social influence. In W.D. Richards \& G.A. Barnett (Ed), Progress in Communication Sciences 12 (pp. 43-62). Norwood, NJ: Ablex.

Robinson, S.L. (1996). Trust and breach of the psychological contract. Administrative Science Quarterly, 41 (4), 574-599.

Rogers, E.M.(1995). Diffusion of innovations ( $4^{\text {th }}$ ed.). New York: Free Press.

Rotter, J.B. (1967). A new scale for the measurement of interpersonal trust. Journal of Personality, 35 (4), 651-665.

Rousseau, D.M., Sitkin, S.B., Burt, R.S., \& Camerer, C. (1998). Not so different after all: A cross-discipline view of trust. Academy of Management Review, 23 (3), $393-404$.

Sagie, A., Elizur, D., \& Koslowsky, M. (1995). Decision type, participative decision making (PDM), and organizational behavior: An experimental simulation. Human Performance, 8 (2), 81-94.

Salancik, G.R., \& Pfeffer, J. (1978). A social information processing approach to job attitudes and task design. Administrative Science Quarterly, 23(2), 224-253. 
Shapiro, E.C. (1996). The "glow and tingle" audit. The Wall Street Journal, January 26.

Sheppard, B.H., \& Sherman, D.M. (1998). The grammars of trust: A model and general implications. The Academy of Management Review, 23 (3), 422-437.

Stanley, D.J., Meyer, J.P., \& Topolnytsky, L. (2005). Employee cynicism and resistance to organizational change. Journal of Business and Psychology, 19(4), 429-459.

Stevens, J. (2002). Applied multivariate statistics for the social sciences ( $4^{\text {th }}$ ed.). Mahwah, NJ: Lawrence Erlbaum Associates.

Strauss, G. (1982). Workers participation in management: An international perspective. In B.M. Staw \& L.L. Cummings (Eds.), Research in Organizational Behavior (vol.4, pp. 173-265). Greenwich, CT: JAI.

Thomas, J., \& Griffin, R. (1983). The SIP model of task design: A review of the literature. Academy of Management Review, 8, 672-682.

Trombetta, J.J., \& Rogers, D.P. (1988). Communication climate, job satisfaction, and organizational commitment: The effects of information adequacy, communication openness, and decision participation. Management Communication Quarterly,1(4), 494-514.

Tschannen-Moran, M., \& Hoy, W.K. (2000). A multidisciplinary analysis of nature, meaning, and measurement of trust. Review of Educational Research, 70 (4), 547-593. 
Tschannen-Moran, M., \& Hoy, W.K. (1998). Trust in schools: A conceptual and empirical analysis. Journal of Educational Administration, 36 (4), 334-352.

Valente, T.W., \& Saba, W.P. (1998). Mass media and interpersonal influence in a reproductive health communication campaign in Bolivia. Communication Research 25 (1), 96-124.

Vroom, V.H. (1960). Some personality determinants of the effects of participation. Englewood Cliffs, NJ: Prentice Hall Inc.

Wagner, J.A., \& Gooding, R.Z. (1987). Shared influence and organizational behavior: A meta-analysis of situational variables expected to moderate participation-outcome relationships. Academy of Management Journal, 30 (3), 524-541.

Wanberg, C.R., \& Banas, J.T. (2000). Predictors and outcomes of openness to changes in a reorganizing workplace. Journal of Applied Psychology, 85 (1), 132-142.

Wanous, J.P., Reichers, A.E., \& Austin, J.T. (2000). Cynicism about organizational change: Measurement, antecedents and correlates. Group and Organization Management, 25(2), 132-153.

Weick, K.E. (1976). Educational organizations as loosely coupled systems. Administrative Science Quarterly, 21 (1), 1-19.

Weick, K. (1982). Management of organizational change among loosely-coupled elements. In Goodman (Ed.), Change in organizations: New perspectives on theory, research, and practice (pp.375-408). San Francisco: Jossey-Bass Publishers. 
Wolski, S. (2003). A multilevel study of interpersonal influence in academic 'influence networks.' Paper presented at International Communication Association Conference, San Diego.

Young, R.B. (1997). No neutral ground: Standing by the values we prize in higher education. San Francisco: Jossey-Bass Publishers.

Zalesny, M., \& Ford, K. (1990). Extending the social information processing perspective: New links to attitudes, behaviors, and perceptions. Organizational Behavior and Human Decision Processes, 47, 205-246.

Zalesney, M.D., \& Farace, R.V. (1986). A field study of social information processing: Mean differences and variance differences. Human Communication Research, 13(2), 268-290.

Zander, A.F.(1950). Resistance to change-its analysis and prevention. Advanced Management, 4 (5), 9-11.

Zhu, Y., May, S.K., \& Rosenfeld, L. B. (2004). Information adequacy and job satisfaction during merger and acquisition. Management Communication Quarterly, 18 (2), 241-270. 


\section{Appendices}

\section{Appendix A: Letter to Participants}

Appendix A contains the email sent to the respondents to invite them to participate in the research

\section{Dear Professor,}

I am a doctoral candidate in the School of Communication Studies at Ohio University. This email is to request your assistance with my dissertation research by participating in a survey. The purpose of the study is to explore the communication processes and variables which influence employee perceptions about organizational change in higher education settings.

As you know, this university is undergoing a large change since the initiation of New Vision (pseudo-name). By agreeing to participate in this survey, you will be asked some questions regarding your perceptions of the change incurred by New Vision. Your participation in this survey will take about 10-15 minutes. Your contributions to the study will facilitate both researchers and practitioners to address the communication problems during organizational change and improve the work environment. Your time and efforts are greatly valued by the researcher.

The data will be collected anonymously and your identity will remain strictly confidential. All records from the survey will be carefully protected by the researcher and can only be accessed by the researcher and the faculty advisor. The responses to the survey will be reported only in aggregate form. You may discontinue your participation at any time without penalty or loss of benefits to which you may otherwise be entitled. No risks or discomforts from participation are foreseen.

If you have any questions concerning the study, please feel free to contact me by phone 740-274-1972 or email, yq279103@ohio.edu. If you have any questions regarding your rights as a research participant, please contact Jo Ellen Sherow, Director of Research Compliance, Ohio University, (740)593-0664. A summary of the survey results will be available upon request.

By clicking the following link or paste it to your browser, you will be able to access the survey. http://oak.cats.ohiou.edu/ yq279103

Return of the survey will be considered as your consent to participate.

Thank you in advance for your participation.

Sincerely, Yuxia Qian 
Appendix B: Survey Questionnaire

Directions: In this survey, you will be asked some questions regarding your opinions about the change brought about by New Vision. "The change" in the survey all refers to the change upon the implementation of New Vision. Please respond to each statement on a 5-point Likert scale ranging from strongly disagree to strongly agree.

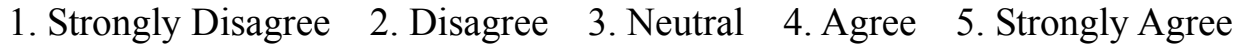

Section I:

1. I believe that the administration has a "hidden agenda" in promoting this change.

2. The administration has been honest in conveying the reasons for this change

3. The administration is trying to hide the reason for this change.

4. I question the administration's motives for this change.

5. I believe that the administration's intentions in introducing this change are very different than they are telling employees.

6. The administration has been honest in stating its objectives for this change.

7. Most of the change initiatives in the past did not do much good, and this change is no difference.

8. Suggestions on how to solve problems with New Vision will not produce much real change.

9. I often experience irritation when I think about this change.

10. I often experience tension when I think about this change.

11. I complained about this change to friends and family outside this organization.

12. I criticize this change with others.

13. I find myself mocking New Vision.

Section II: The following statements ask about your perceptions of the information you have received about New Vision

14. The information I have received about the change has been timely.

15. The information I have received about the change has been useful.

16. The information I have received about the change has adequately answered my questions about the change.

17. The information provided about the change was positive.

18. The information provided about the change was favorable.

19. The way in which the information about the change was communicated appropriately.

Section III: The following statements ask about your perceptions about the current school administration

20. If I were given a choice, I would not allow the administration to make decisions concerning employee well-being.

21. I am willing to follow the administration's lead even in risky situations. 
22. I trust the administration to make the right decisions in situations that affect me personally.

23. When it comes to making decisions that affect me, I have as much or more faith in the administration's judgment as I would in my own.

24. Even if a bad decision could have very negative consequences for me, I would trust the administration's judgment.

Section IV: The following statements ask about the extent to which you participated in the decision making process of New Vision

25. I am unwilling to participate in change decisions because the decisions do not affect my day-to-day job.

26. Participation in change decisions is time consuming because on must attend a number of meetings, and I don't have the time.

27. I am willing to participate in change decisions because I want to have an input in how the university is run.

28. The administration seeks my input on important decisions concerning the change.

29. I actively participated in decision-making regarding this change.

30. I had many opportunities to express my opinion about this change to the decision makers.

31. My ideas and opinions are valued and paid attention to in making this change.

32. I have some influence or say over what goes on about the change.

33. It is easy to get my ideas across to the administration if I have a suggestion.

Section V: Please indicate your behavioral intentions toward the change by checking the corresponding box.

34. I avoid attending meetings at which the change is to be discussed.

35. Either singularly or with one or more colleges, I participate in a public display/protest against the change (i.e., letter to the editor, placard demonstration, etc.).

36. I would not resist the change in any way.

37. I openly questioned the rationality of this change in some public forums.

38. I intend to form coalitions with others and repress the change.

39. I refuse to perform the tasks required of me by the change.

40. I only do the minimum required of me by the change.

41. I deny the needs for the change in faculty meetings.

Section VI: Please take a moment and think about three to five colleagues of yours with whom you have had discussions with on the topic of New Vision and/or some knowledge about his/her attitude toward New Vision.

Then, for each person you had in mind, please indicate your estimate of his/her attitude toward the change in New Vision by responding to the following questions.

42. He/she questions the administration's motives for this change.

43. He/she criticize this change with others.

44. He/she mocks New Vision. 
(Questions 45-56 will repeat the above three questions. Respondents can skip questions 51-56 if they only have three people in mind)

Section VI: Demographic Information

1. Please indicate your gender $\mathrm{F}$

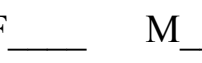

2. Which college are you affiliated with?

3. Please indicate your age range: $\begin{array}{llll}\text { a. } 25-35 & \text { b. } 36-45 & \text { c. } 46-55 & \text { d. } 56-65\end{array}$ e. above 65

4. How many years have you worked at this university?

5. Please indicate your job title: a. professor b. associate professor c. assistant professor d. instructor

6. Were you a committee member of New Vision? Yes

No

7. What is the most significant change you think in New Vision?

8. Any other comments you'd like to offer about New Vision? 
Appendix C: The Reliability Coefficients for the Survey Questionnaire

\section{Change-specific Cynicism Scale}

Item-Total Statistics

\begin{tabular}{|c|c|c|c|c|}
\hline & $\begin{array}{l}\text { Scale Mean } \\
\text { if Item } \\
\text { Deleted }\end{array}$ & $\begin{array}{c}\text { Scale } \\
\text { Variance if } \\
\text { Item Deleted }\end{array}$ & $\begin{array}{l}\text { Corrected } \\
\text { Item-Total } \\
\text { Correlation } \\
\end{array}$ & $\begin{array}{l}\text { Cronbach's } \\
\text { Alpha if Item } \\
\text { Deleted } \\
\end{array}$ \\
\hline $\begin{array}{l}\text { I believe that the } \\
\text { administration has a } \\
\text { "hidden agenda" in } \\
\text { promoting this change. }\end{array}$ & 33.9011 & 124.797 & .816 & .946 \\
\hline $\begin{array}{l}\text { The administration is trying } \\
\text { to hide the reason for this } \\
\text { change. }\end{array}$ & 34.0165 & 126.304 & .830 & .946 \\
\hline $\begin{array}{l}\text { I question the } \\
\text { administration's motives for } \\
\text { this change. }\end{array}$ & 33.7857 & 124.965 & .791 & .947 \\
\hline $\begin{array}{l}\text { I believe that the } \\
\text { administration's intentions } \\
\text { in introducing this change } \\
\text { are very different than they } \\
\text { are telling employees }\end{array}$ & 33.9451 & 124.594 & .852 & .945 \\
\hline $\begin{array}{l}\text { Most of the change } \\
\text { initiatives in the past did } \\
\text { not do much good, and this } \\
\text { change is no difference. }\end{array}$ & 33.5714 & 134.876 & .525 & .953 \\
\hline $\begin{array}{l}\text { Suggestions on how to } \\
\text { solve problems with New } \\
\text { Vision will not produce } \\
\text { much real change. }\end{array}$ & 33.4890 & 129.533 & .687 & .949 \\
\hline $\begin{array}{l}\text { I often experience irritation } \\
\text { when I think about this } \\
\text { change. }\end{array}$ & 33.7747 & 123.479 & .846 & .945 \\
\hline $\begin{array}{l}\text { I often experience tension } \\
\text { when I think about this } \\
\text { change. }\end{array}$ & 33.9505 & 128.732 & .696 & .949 \\
\hline $\begin{array}{l}\text { I complained about this } \\
\text { change to friends and } \\
\text { family outside this } \\
\text { organization. }\end{array}$ & 34.0934 & 125.776 & .716 & .949 \\
\hline
\end{tabular}


I criticize this change with others.

I find myself mocking New

Vision.

newq2

newq6

33.8846
34.0110
33.7582
33.7308

124.755

123.602

125.996

128.286
142

\begin{tabular}{l|l|}
.771 & .947 \\
.776 & .947 \\
.814 & .946 \\
.697 & .949 \\
\hline
\end{tabular}

Note: Item 2 and item 6 were reverse-coded

Reliability Coefficients Alpha $=.952$

$\mathrm{N}$ of Cases $=182 \quad \mathrm{~N}$ of Items $=13$

Perceived Quality of Information Scale

Item-Total Statistics

\begin{tabular}{|l|r|r|r|r|}
\hline & $\begin{array}{c}\text { Scale Mean } \\
\text { if Item } \\
\text { Deleted }\end{array}$ & $\begin{array}{c}\text { Scale } \\
\text { Variance if } \\
\text { Item Deleted }\end{array}$ & $\begin{array}{c}\text { Corrected } \\
\text { Item-Total } \\
\text { Correlation }\end{array}$ & $\begin{array}{c}\text { Cronbach's } \\
\text { Alpha if Item } \\
\text { Deleted }\end{array}$ \\
\hline $\begin{array}{l}\text { The information I have } \\
\text { received about the change } \\
\text { has been timely. }\end{array}$ & 14.5824 & 21.460 & .759 & .921 \\
$\begin{array}{l}\text { The information I have } \\
\text { received about the change } \\
\text { has been useful. } \\
\begin{array}{l}\text { The information I have } \\
\text { received about the change } \\
\text { has adequately answered } \\
\text { my questions about the } \\
\text { change. }\end{array}\end{array}$ & 14.8626 \\
$\begin{array}{l}\text { The information provided } \\
\text { about the change was } \\
\text { positive. } \\
\text { The information provided } \\
\text { about the change was } \\
\text { favorable. } \\
\text { The way in which the } \\
\text { information about the } \\
\text { change was communicated } \\
\text { appropriately. }\end{array}$ & 15.0495 & 20.185 & .828 & .912 \\
\hline
\end{tabular}

Reliability Coefficients $\quad$ Alpha $=.929$ 
$\mathrm{N}$ of Cases $=182 \quad \mathrm{~N}$ of Items $=6$

Trust in the Administration Scale

Item-Total Statistics

\begin{tabular}{|l|c|c|c|c|}
\hline & $\begin{array}{c}\text { Scale Mean } \\
\text { if Item } \\
\text { Deleted }\end{array}$ & $\begin{array}{c}\text { Scale } \\
\text { Variance if } \\
\text { Item Deleted }\end{array}$ & $\begin{array}{c}\text { Corrected } \\
\text { Item-Total } \\
\text { Correlation }\end{array}$ & $\begin{array}{c}\text { Cronbach's } \\
\text { Alpha if Item } \\
\text { Deleted }\end{array}$ \\
\hline $\begin{array}{l}\text { I am willing to follow the } \\
\text { administration's lead even } \\
\text { in risky situations. }\end{array}$ & 9.5385 & 13.377 & .785 & .874 \\
$\begin{array}{l}\text { I trust the administration to } \\
\text { make the right decisions in } \\
\text { situations that affect me } \\
\text { personally. }\end{array}$ & 9.6429 & 12.728 & .856 & .858 \\
$\begin{array}{l}\text { When it comes to making } \\
\text { decisions that affect me, I } \\
\text { have as much or more faith } \\
\text { in the administration's } \\
\text { judgment as I wou }\end{array}$ & 10.0495 & 13.727 & .808 & .870 \\
$\begin{array}{l}\text { Even if a bad decision } \\
\text { could have very negative } \\
\text { consequences for me, I } \\
\text { would trust the } \\
\text { administration's judgment. } \\
\text { newq20 }\end{array}$ & 10.0989 & 14.178 & & \\
\hline
\end{tabular}

Note: Item 20 was reverse coded

Reliability Coefficients $\quad$ Alpha $=.902$

$\mathrm{N}$ of Cases $=182 \quad \mathrm{~N}$ of Items $=5$ 
PDM Scale

Item-Total Statistics

\begin{tabular}{|c|c|c|c|c|}
\hline & $\begin{array}{c}\text { Scale Mean } \\
\text { if Item } \\
\text { Deleted }\end{array}$ & $\begin{array}{c}\text { Scale } \\
\text { Variance if } \\
\text { Item Deleted }\end{array}$ & $\begin{array}{l}\text { Corrected } \\
\text { Item-Total } \\
\text { Correlation }\end{array}$ & $\begin{array}{l}\text { Cronbach's } \\
\text { Alpha if Item } \\
\text { Deleted }\end{array}$ \\
\hline $\begin{array}{l}\text { I am willing to participate } \\
\text { in change decisions } \\
\text { because I want to have an } \\
\text { input in how the university } \\
\text { is run. } \\
\text { The administration seeks } \\
\text { my input on important } \\
\text { decisions concerning the } \\
\text { change. } \\
\text { I actively participated in } \\
\text { decision-making regarding } \\
\text { this change. } \\
\text { I had many opportunities to } \\
\text { express my opinion about } \\
\text { this change to the decision } \\
\text { makers. } \\
\text { My ideas and opinions are } \\
\text { valued and paid attention to } \\
\text { in making this change. } \\
\text { I have some influence or } \\
\text { say over what goes on } \\
\text { about the change. } \\
\text { It is easy to get my ideas } \\
\text { across to the administration } \\
\text { if I have a suggestion. } \\
\text { newq } 25 \\
\text { newq } 26\end{array}$ & $\begin{array}{l}23.1923 \\
23.2692 \\
22.8681\end{array}$ & $\begin{array}{l}30.911 \\
37.889 \\
36.832 \\
\end{array}$ & $\begin{array}{l}.716 \\
.242 \\
.230\end{array}$ & $\begin{array}{l}.810 \\
.855 \\
.862\end{array}$ \\
\hline
\end{tabular}

Note: Item 25 and 26 were reverse coded.

Reliability Coefficients $\quad$ Alpha $=.844$

$\mathrm{N}$ of Cases $=182 \quad \mathrm{~N}$ of Items $=9$ 
Intention to Resist Change Scale

Item-Total Statistics

\begin{tabular}{|c|c|c|c|c|}
\hline & $\begin{array}{c}\text { Scale Mean } \\
\text { if Item } \\
\text { Deleted }\end{array}$ & $\begin{array}{c}\text { Scale } \\
\text { Variance if } \\
\text { Item Deleted }\end{array}$ & $\begin{array}{l}\text { Corrected } \\
\text { Item-Total } \\
\text { Correlation }\end{array}$ & $\begin{array}{l}\text { Cronbach's } \\
\text { Alpha if Item } \\
\text { Deleted }\end{array}$ \\
\hline $\begin{array}{l}\text { I avoid attending meetings } \\
\text { at which the change is to be } \\
\text { discussed. }\end{array}$ & 16.7088 & 26.771 & .280 & .857 \\
\hline $\begin{array}{l}\text { Either singularly or with } \\
\text { one or more colleagues, I } \\
\text { participate in a public } \\
\text { display/protest against the } \\
\text { change (i.e., le }\end{array}$ & 17.2143 & 24.302 & .650 & .814 \\
\hline $\begin{array}{l}\text { I openly questioned the } \\
\text { rationality of this change in } \\
\text { some public forums. }\end{array}$ & 16.6923 & 23.330 & .542 & .827 \\
\hline $\begin{array}{l}\text { I intend to form coalitions } \\
\text { with others and repress the } \\
\text { change. }\end{array}$ & 17.1044 & 23.177 & .745 & .801 \\
\hline $\begin{array}{l}\text { I refuse to perform the } \\
\text { tasks required of me by the } \\
\text { change. }\end{array}$ & 17.0879 & 23.605 & .724 & .805 \\
\hline $\begin{array}{l}\text { I only do the minimum } \\
\text { required of me by the } \\
\text { change. }\end{array}$ & 16.6374 & 22.553 & .644 & .812 \\
\hline $\begin{array}{l}\text { I deny the needs for the } \\
\text { change in faculty meetings. }\end{array}$ & 16.8352 & 22.636 & .669 & .808 \\
\hline newq36 & 15.7198 & 25.728 & .399 & .842 \\
\hline
\end{tabular}

Note: Item 36 was reverse coded

Reliability Coefficients $\quad$ Alpha $=.840$

$\mathrm{N}$ of Cases $=182 \quad \mathrm{~N}$ of Items $=8$ 
Appendix D: Principle Component Analysis

Change-specific Cynicism Scale

Rotated Component Matrix(a)

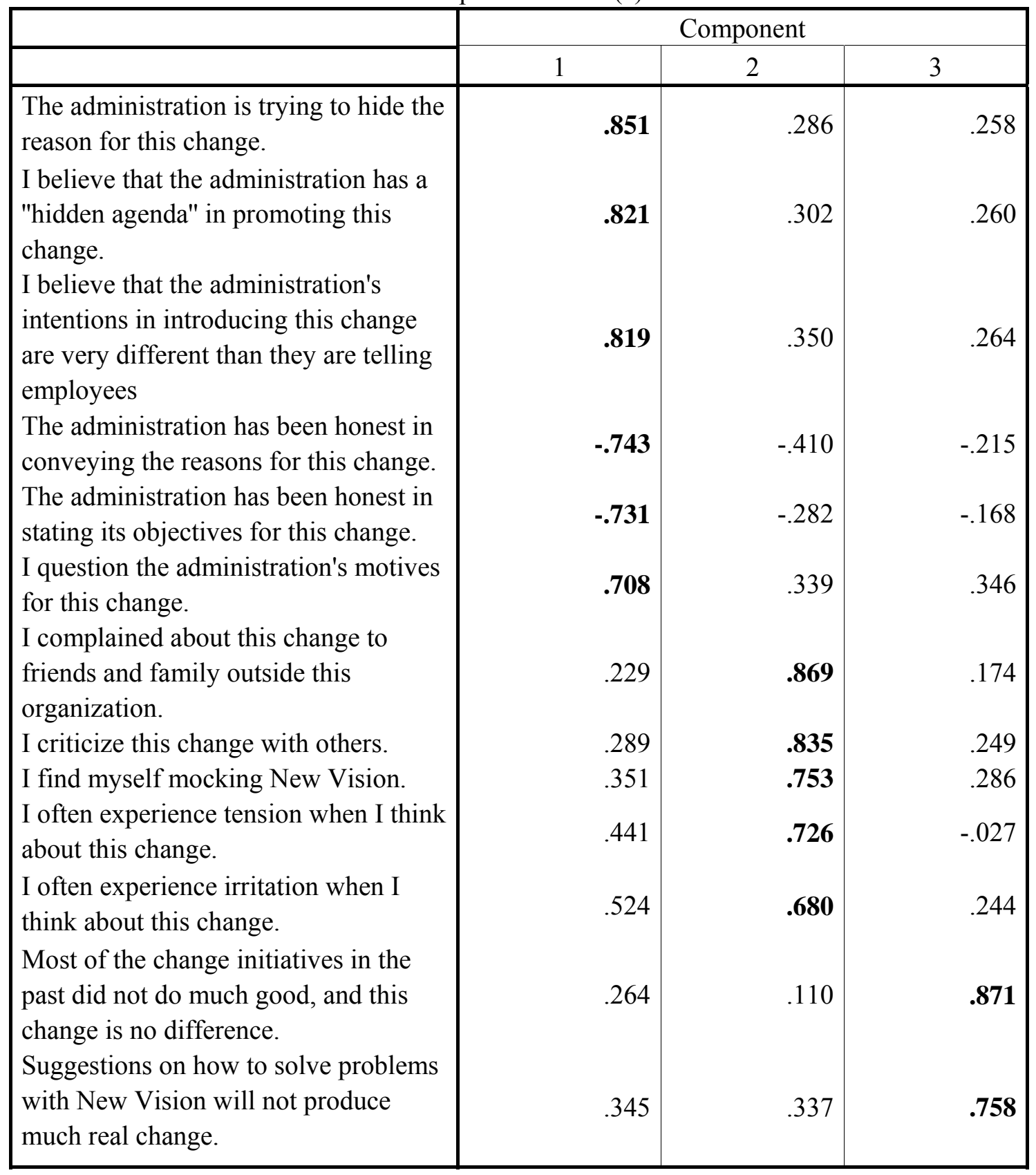


PDM Scale

Rotated Component Matrix(a)

\begin{tabular}{|l|r|r|r|}
\hline & \multicolumn{3}{|c|}{ Component } \\
\hline
\end{tabular}


Intention to Resist Change Scale

Rotated Component Matrix(a)

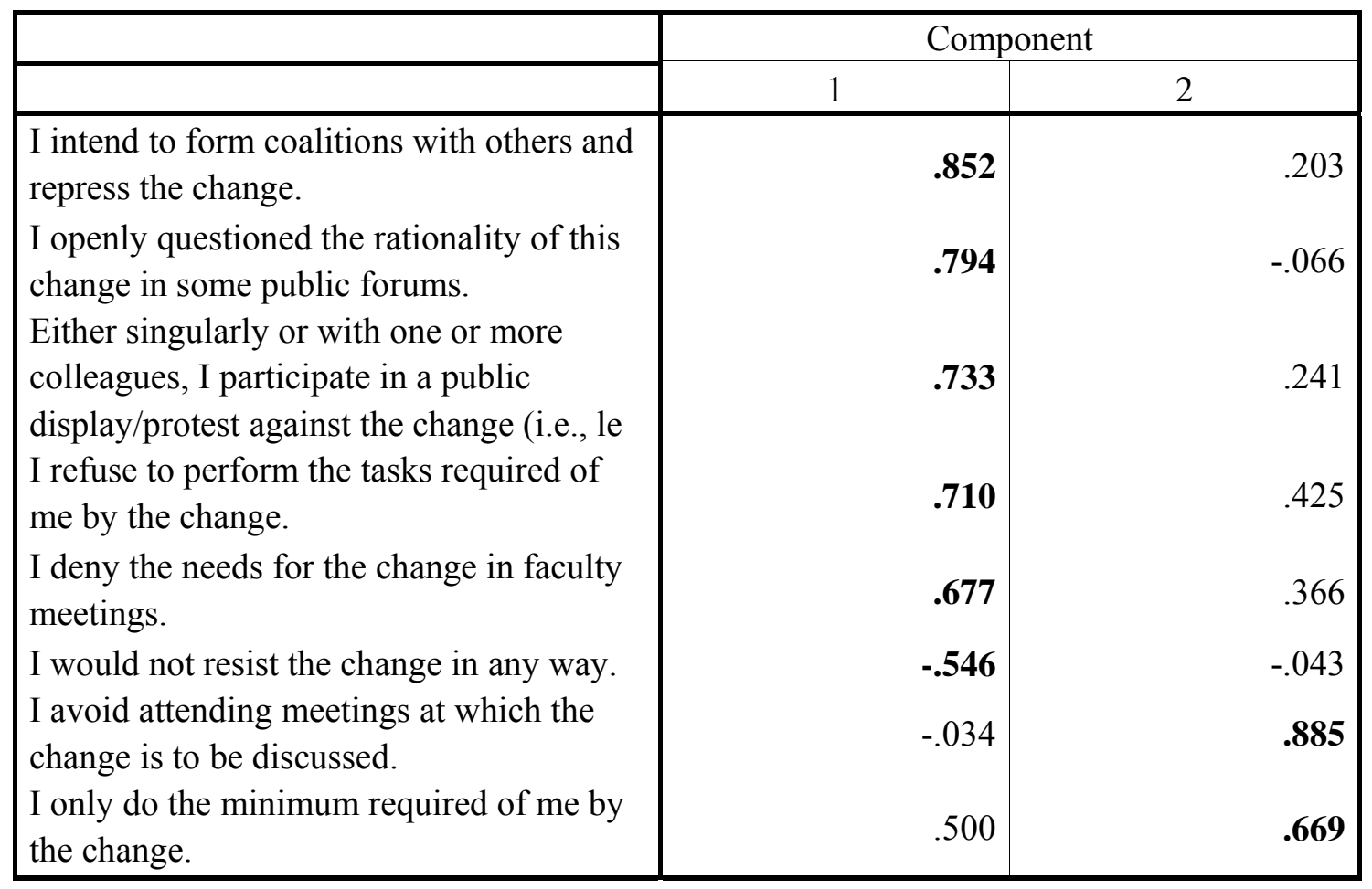


Appendix E: IRB Approval

Ohio University Institutional Review Board Approval of Dissertation Research 
A determination has been made that the following research

Office of Research Compliance Research and Technology Center 117

Athens OH 45701-2979

T: 740.593 .0664

F: 740.593 .9838

www.ohiou.edu/research study is exempt from IRB review because it involves:

Category 2 - research involving the use of educational tests, survey procedures, interview procedures or observation of public behavior Project Title: A Communication Model of Employee Cynicism toward Organizational
Change

Project Director: Yuxia Qian

Department: School of Communication Studies

Advisor: $\quad$ Tom Daniels

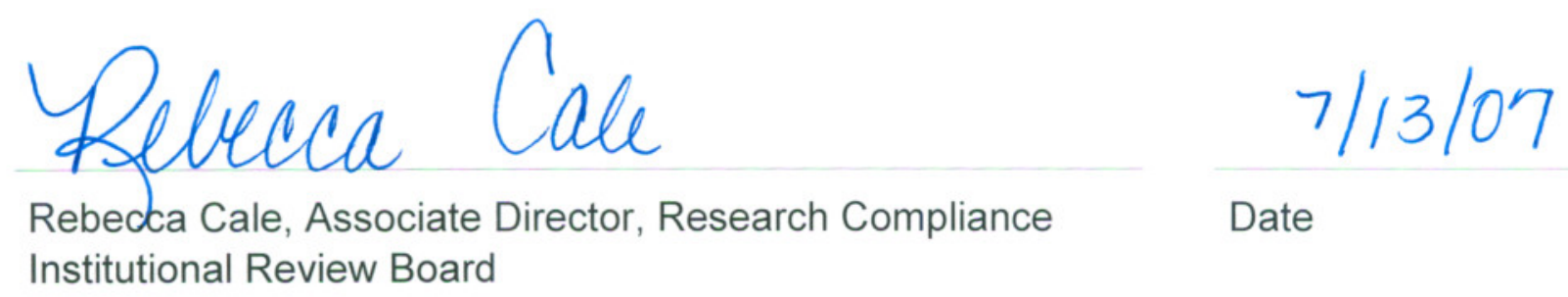

The approval remains in effect provided the study is conducted exactly as described in your application for review. Any additions or modifications to the project must be approved by the IRB (as an amendment) prior to implementation. 